Florida International University FIU Digital Commons

7-15-2011

\title{
An Integrated Multi-Agent Framework for Optimizing Time, Cost and Environmental Impact of Construction Processes
}

\author{
Gulbin Ozcan-Deniz \\ Florida International University, gozca001@fiu.edu
}

DOI: $10.25148 /$ etd.FI1 1080806

Follow this and additional works at: https://digitalcommons.fiu.edu/etd

\section{Recommended Citation}

Ozcan-Deniz, Gulbin, "An Integrated Multi-Agent Framework for Optimizing Time, Cost and Environmental Impact of Construction Processes" (2011). FIU Electronic Theses and Dissertations. 455.

https://digitalcommons.fiu.edu/etd/455 


\section{FLORIDA INTERNATIONAL UNIVERSITY \\ Miami, Florida}

\section{AN INTEGRATED MULTI-AGENT FRAMEWORK \\ FOR OPTIMIZING TIME, COST AND ENVIRONMENTAL IMPACT \\ OF CONSTRUCTION PROCESSES}

A dissertation submitted in partial fulfillment of the

requirements for the degree of

DOCTOR OF PHILOSOPHY

in

CIVIL AND ENVIRONMENTAL ENGINEERING

by

Gulbin Ozcan-Deniz

2011 
To: Dean Amir Mirmiran

College of Engineering and Computing

This dissertation, written by Gulbin Ozcan-Deniz, and entitled An Integrated Multi-Agent Framework for Optimizing Time, Cost and Environmental Impact of Construction Processes, having been approved in respect to style and intellectual content, is referred to you for judgment.

We have read this dissertation and recommend that it be approved.

\section{Girma Bitsuamlak}

Shu-Ching Chen

Nakin Suksawang

Caesar Abi Shdid, Co-major Professor

Yimin Zhu, Major Professor

Date of Defense: July 15, 2011

The dissertation of Gulbin Ozcan-Deniz is approved.

Dean Amir Mirmiran

College of Engineering and Computing

Interim Dean Kevin O'Shea

University Graduate School

Florida International University, 2011 
(C) Copyright 2011 by Gulbin Ozcan-Deniz

All rights reserved. 


\section{DEDICATION}

I dedicate this dissertation to my beloved family, who made this work possible. 


\section{ACKNOWLEDGMENTS}

During my Ph.D journey, I have been guided and supported by a number of people, whom I would like to mention here.

To start with, my grateful thanks are to my dissertation advisor Dr. Yimin Zhu, who has guided me throughout my research process. He has encouraged and challenged me to accumulate my knowledge in achieving both my dissertation and career goals. I also express my gratitude to him for giving me the opportunity to teach courses. His organized mentoring, high expectations, and confidence in me have been motivators for me during my Ph.D study.

Although thanking is not enough, my special thanks are for my parents Nuray Ozcan and Taner Ozcan. Their endless love and guidance made this study, as well as everything I have achieved, possible. I am deeply grateful to them for supporting me unconditionally in all my decisions. I also take this opportunity to thank my brother Alper Ozcan, sister-in-law Burcu Ozcan, and niece Beren Ozcan for their warmth and support. My thanks are also extended to the remaining of my family, such as my grandmother and grandfather, aunts, and all cousins, who have their support and confidence in me.

A special word of gratitude also goes to my husband, Oguz Deniz for his love, caring, and encouragement during this process and the remaining of our lives. His presence and belief in my work has provided me with great strength.

I have been fortunate to have the support of my friends, even though they were miles away. I thank to Dr. Beliz Ozorhon, who has been a great colleague and friend. Her inspiration and valuable ideas are sincerely appreciated. I want to thank to Muge DurusuTanriover for being my responsive journal that I can discuss my studies and more on a 
daily basis. She has been next to me with all her heart, since we were kids. Finally yet importantly, my thanks are to Gulgun Acar-Yesiltepe, who motivated and supported me in all situations. 


\author{
ABSTRACT OF THE DISSERTATION \\ AN INTEGRATED MULTI-AGENT FRAMEWORK \\ FOR OPTIMIZING TIME, COST AND ENVIRONMENTAL IMPACT \\ OF CONSTRUCTION PROCESSES
}

by

Gulbin Ozcan-Deniz

Florida International University, 2011

Miami, Florida

Professor Yimin Zhu, Major Professor

Environmentally conscious construction has received a significant amount of research attention during the last decades. Even though construction literature is rich in studies that emphasize the importance of environmental impact during the construction phase, most of the previous studies failed to combine environmental analysis with other project performance criteria in construction. This is mainly because most of the studies have overlooked the multi-objective nature of construction projects. In order to achieve environmentally conscious construction, multi-objectives and their relationships need to be successfully analyzed in the complex construction environment. The complex construction system is composed of changing project conditions that have an impact on the relationship between time, cost and environmental impact (TCEI) of construction operations. Yet, this impact is still unknown by construction professionals. Studying this impact is vital to fulfill multiple project objectives and achieve environmentally conscious construction. This research proposes an analytical framework to analyze the impact of changing project conditions on the relationship of TCEI. This study includes 
green house gas (GHG) emissions as an environmental impact category. The methodology utilizes multi-agent systems, multi-objective optimization, analytical network process, and system dynamics tools to study the relationships of TCEI and support decision-making under the influence of project conditions. Life cycle assessment (LCA) is applied to the evaluation of environmental impact in terms of GHG. The mixed method approach allowed for the collection and analysis of qualitative and quantitative data. Structured interviews of professionals in the highway construction field were conducted to gain their perspectives in decision-making under the influence of certain project conditions, while the quantitative data were collected from the Florida Department of Transportation (FDOT) for highway resurfacing projects. The data collected were used to test the framework. The framework yielded statistically significant results in simulating project conditions and optimizing TCEI. The results showed that the change in project conditions had a significant impact on the TCEI optimal solutions. The correlation between TCEI suggested that they affected each other positively, but in different strengths. The findings of the study will assist contractors to visualize the impact of their decision on the relationship of TCEI. 


\section{Table of Contents}

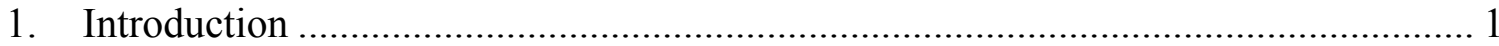

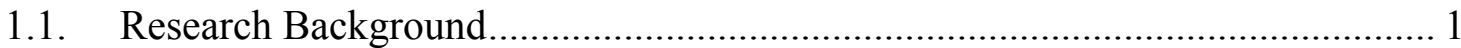

1.2. Research Objectives ............................................................................ 5

1.3. Research Questions and Hypothesis ............................................................. 6

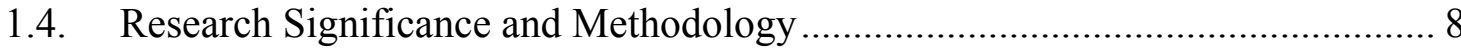

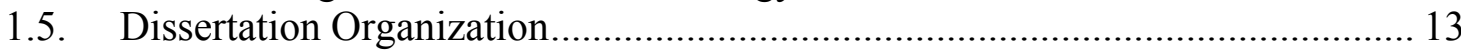

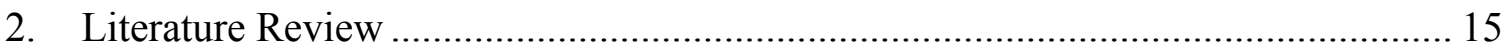

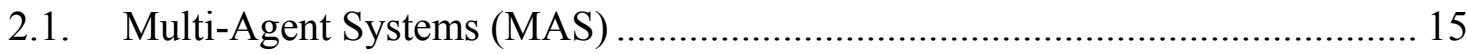

2.1.1. Agents in the Life Cycle of Construction Projects ................................ 15

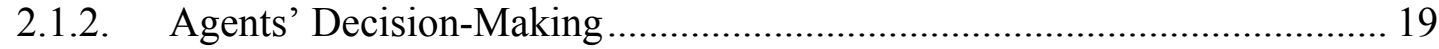

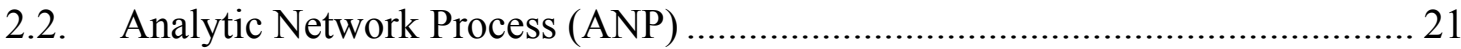

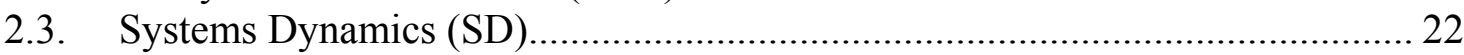

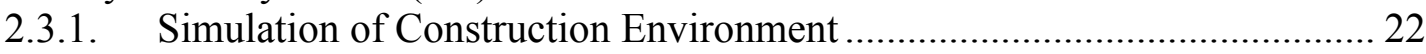

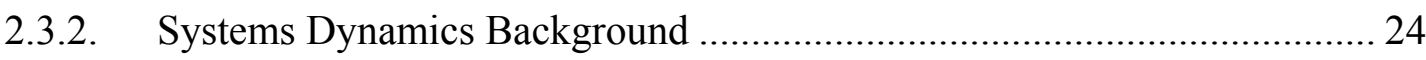

2.4. Multi-Objective Optimization Background ................................................. 32

3. An Integrated Multi-Agent Framework for Optimizing TCEI of Construction

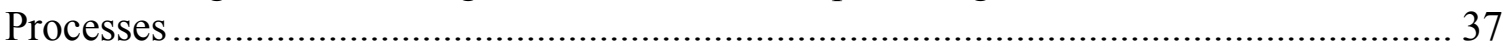

3.1. Decision-Making Model for Construction Projects ....................................... 42

3.1.1. MAS Design..................................................................................... 42

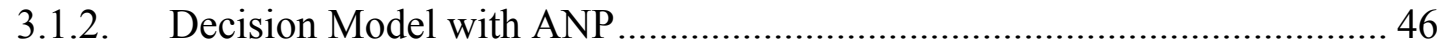

3.2. Systems Dynamics (SD) Model for Construction Projects .............................. 53

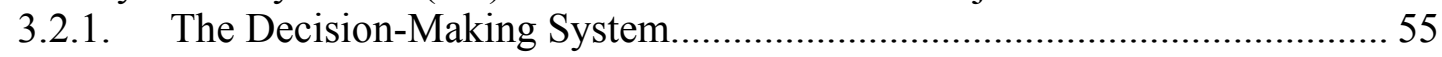

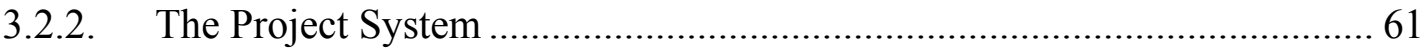

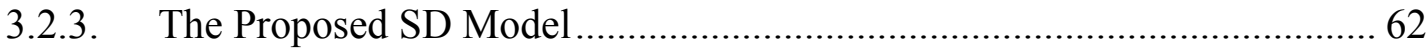

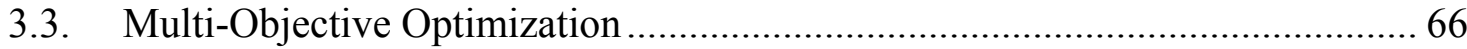

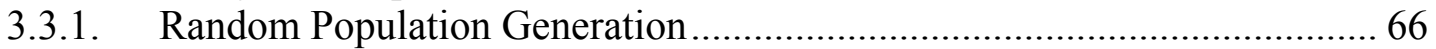

3.3.3. Selection of Solutions ......................................................................... 71

4. Experimentation and Application of the Proposed Framework ............................. 72

4.1. Data Collection and Analysis for Decision-Making ................................... 72

4.1.1. The ANP Decision Model Construction .................................................... 73

4.1.2. Pair Wise Comparison Matrices of Interdependent Components............... 75

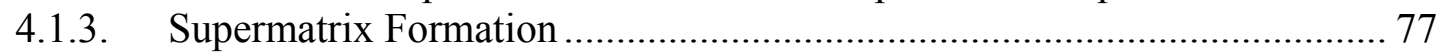

4.1.4. The Relative Importance Weights of Factors .......................................... 77

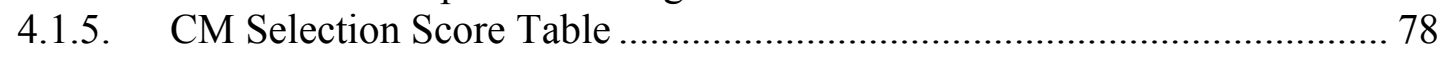

4.2. Data Collection and Analysis for TCEI Calculation ...................................... 82

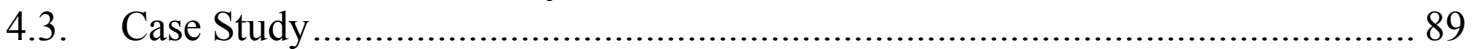

4.3.1. Highway Construction Operations.......................................................... 89

4.3.1.1. Historical Changes in Resurfacing Construction Methods.................. 89

4.3.1.2. Environmental Benefits of New Technologies................................ 91

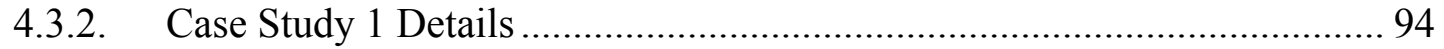




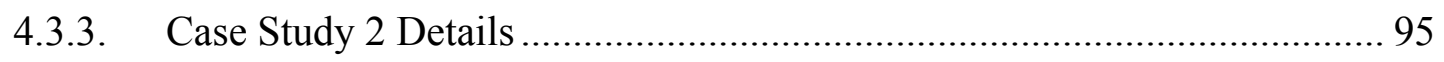

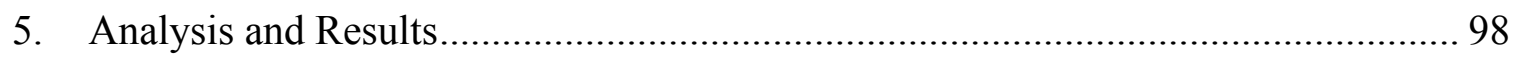

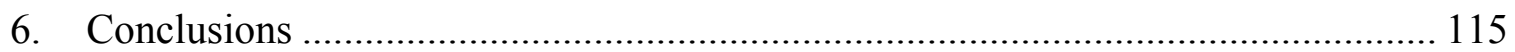

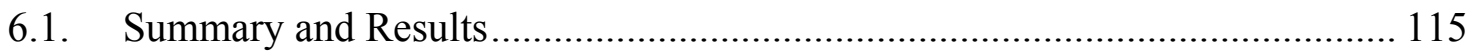

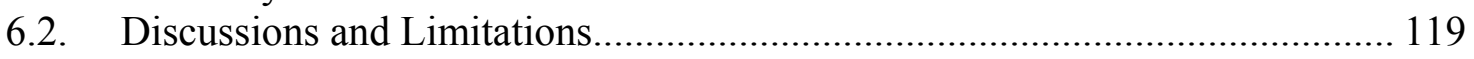

6.3. Conclusions and Future Studies .................................................................. 122

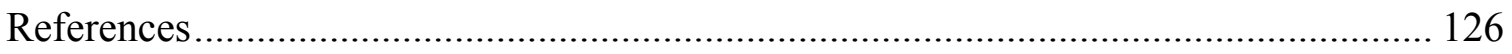

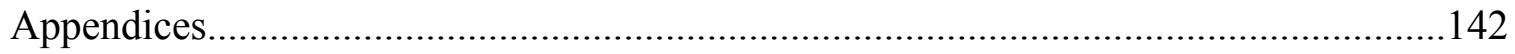

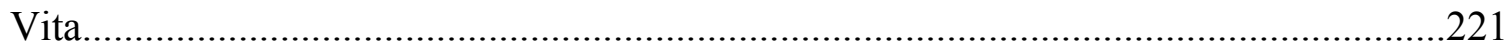




\section{List of Tables}

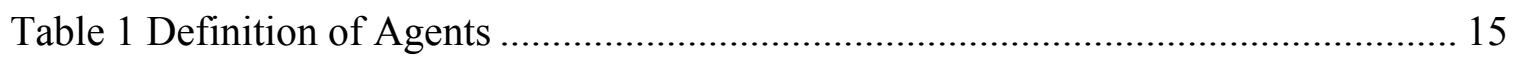

Table 2 System Dynamics Models in Project Management ........................................ 25

Table 3 Project Conditions and Their Corresponding Authors .................................... 43

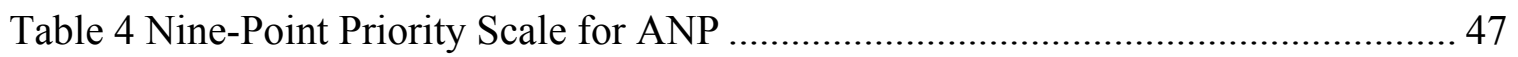

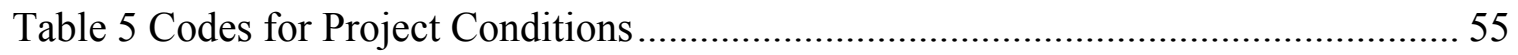

Table 6 Gas Releases for Gasoline Equipments (source: EPA single truck).................. 86

Table 7 Gas Releases for Diesel Equipments (source: EPA single truck)...................... 87

Table 8 Weights of Gases for GHG Content (source: Stern Review, 2006) ................... 88

Table 9 Construction Methods for Resurfacing Project Activities ............................... 93

Table 10 Sample of Resource Results Coded in Numbers ....................................... 101

Table 11 Set of Time, Cost, and GHG Results for the Resources in Table 10............. 101

Table 12 An Example Set of Randomly Formed Probabilities and Their TCEI Results 102

Table 13 Normalized Values for Time, Cost and GHG....................................... 106

Table 14 Fitness Function Values and Normalized TCEI ....................................... 108

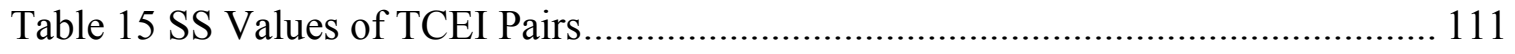

Table 16 Correlation Coefficients of TCEI ............................................................ 111 


\section{List of Figures}

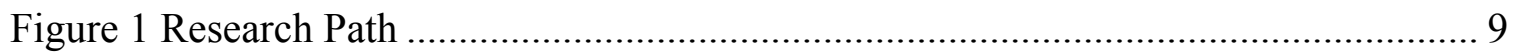

Figure 2 Flow Chart for the Proposed Framework .................................................... 39

Figure 3 An Integrated Multi-Agent Framework for Optimizing TCEI of Construction

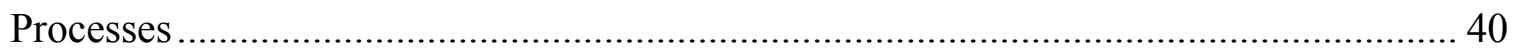

Figure 4 Project Conditions and Decision Paths for Contractor and Owner ................... 45

Figure 5 ANP Decision Model for CM Selection................................................... 50

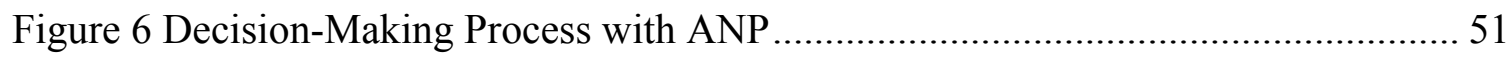

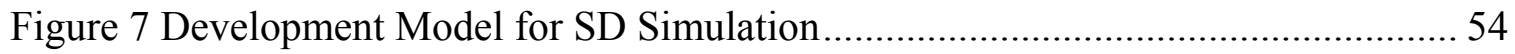

Figure 8 Relations between Project Conditions and Their Indicators .......................... 56

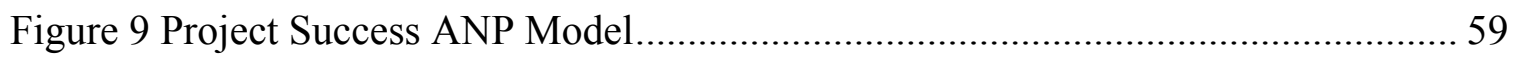

Figure 10 Pair Wise Comparison Matrix for the Project Success ANP Model ................ 60

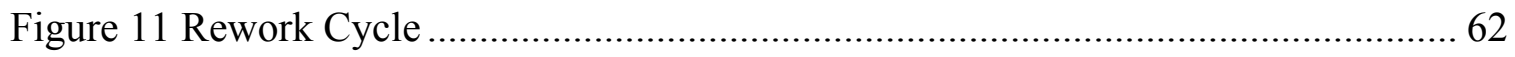

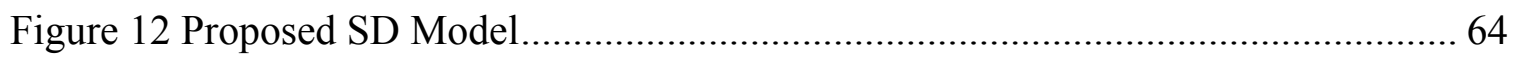

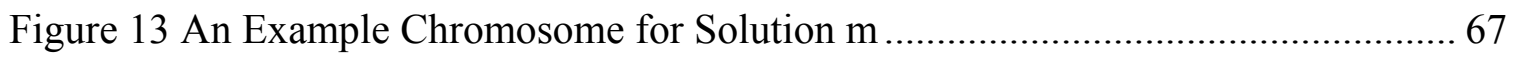

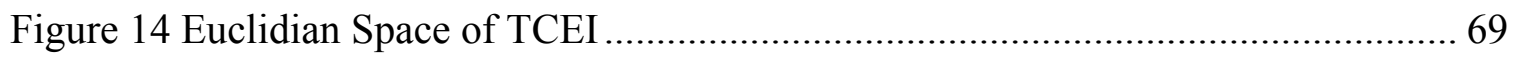

Figure 15 ANP Decision Model Constructed with SuperDecisions ............................. 74

Figure 16 Relative Importance Weights of Nodes............................................... 78

Figure 17 Weighted Matrix for Project Success Determinants .................................. 79

Figure 18 Relative Importance Weights of TCEI ..................................................... 80

Figure 19 Snapshot of Vensim during Simulation.................................................. 100

Figure 20 2-D Figures of Cost vs EI, Cost vs Time................................................ 107 


\section{List of Key Terms}

Term

Explanation

Agent

Anything that can perceive its environment through sensors and can act through effectors (Russell \& Norvig, 2002). Agents in this study refer to parties/professionals in construction (e.g. contractor, owner, etc.).

Analytic Network Process The tool to model complex decision-making problems (ANP) where interactions and dependencies among levels are present (Saaty, 2004).

Construction Processes Construction processes are used as synonyms with construction operations and construction methods $(\mathrm{CM})$ in this study. They explain how the construction work is performed.

Life Cycle Assessment A tool to evaluate the environmental impact of an activity (LCA) or product starting from the extraction of raw material until its end of life (EPA, 1993)

Multi-Objective $\quad$ Refers to the procedure of simultaneously optimizing two Optimization or more conflicting objectives

System Dynamics (SD) A professional field that combines the theory, methods, and philosophy needed to analyze the behavior of complex systems and understanding the change of their behavior over time (Forrester, 1994) 


\section{Introduction}

\subsection{Research Background}

The negative impact of building and building operations on human health and the natural environment has been a subject of research interest in recent years. The influence of building industry on natural resources has shown direct and indirect relations between construction industry and sustainable development (Bourdeau, 1999). The environmental impacts of construction industry, such as resource depletion, biological diversity losses, poor indoor air quality, energy consumption, and emissions causing global warming, acid rain, and smog, are accounted for $40 \%$ and $16 \%$ of annual energy and water consumption worldwide respectively (Lippiatt, 1999). Similarly, the construction sector contributed $30-40 \%$ of natural resource consumption in industrialized countries (Pulselli, Simoncini, \& Marchettini, 2009). Due to the significant amount of energy consumption, the building industry had several environmental concerns, such as harmful emissions. The construction industry is responsible for $30 \%$ of global annual green house gas (GHG) emissions and consumes up to $40 \%$ of all energy (UNEP-SBCI, 2009), while the construction sector in the U.S is accounted for 39\% of primary energy use and $38 \%$ of $\mathrm{CO}_{2}$ emissions (USGBC, 2008). Considering the large number of annual construction projects worldwide, as well as their share in the overall resource consumption, overlooking the environmental impact of construction processes can have seriously adverse effects on the environment.

In addition to this knowledge, although buildings have the highest contribution of environmental impacts, they were also reported to have the largest potential for 
significantly decreasing GHG emissions compared to other major production sectors (IPCC, 2007). Therefore, sustainability literature has focused on defining and assessing environmental performance indicators and environmental scoring systems (e.g., Chen, $\mathrm{Li}$, \& Wong, 2000; Shen, Lu, Yao, \& Wu, 2005a; Tah 2006; Yao, Shen, \& Yam, 2007). Principles of sustainable infrastructure have evolved with the advancement in designs, materials, and construction technologies. Previous studies stated the concern on how to improve construction processes to reduce their negative impact on the natural environment (Cole, 1999). For example, Hendrickson \& Horvath (2000) stated the importance of understanding the environmental impacts of construction operations. Chen, Li, \& Wong (2000) and Gangolells et al. (2009) studied the impact and severity of environmental performance related to construction operations. Even though, the concept of environmental impacts of construction operations is not new, the sustainable movement is still in need to reverse the course of deteriorating natural environment caused by massive amount of construction every year.

Environmentally conscious construction has been studied, and a significant body of knowledge on environmental performance (e.g., Shen, Lu, Yao, \& Wu, 2005a), methods of environmental impact analysis (e.g., Shen, Lu, Yao, \& Wu, 2005a; Sharrard, Matthews, \& Roth, 2007; Li, Zhu, \& Zhang, 2010), and environmentally conscious construction management (e.g., Chen, Li, Kong, \& Xu, 2005) has been demonstrated in literature. Environmentally conscious construction is defined as the encouragement of ecological, economic, and social-cultural sustainability in buildings (Kua \& Lee, 2002). Therefore, the concept includes environmental parameters, as well as other objectives. 
Although previous researchers have clearly summarized the significance of environmental impacts during the construction phase (e.g., Bilec, Ries, Matthews, \& Sharrard, 2006; Sharrard, Matthews, \& Roth, 2007), there are still gaps between the ultimate goal of environmentally conscious construction and contributions of those studies. This is mainly because most of the studies have been directed to understand and analyze solely the relation between environmental impact and construction processes, and overlooked the multi-objective nature of construction projects. Even though there are a couple of exceptions (e.g., Marzouk, Madany, Abou-Zied, \& El-Said, 2008; Wu, Simpson, \& Maier, 2010) reflecting the multi-objectivity to a certain degree, most of the remaining studies have focused on a specific dimension and missed to handle the connection of environmental dimension with other objectives. As construction is a complex system including a number of different parameters and objectives, researchers need to consider the multi-objective nature of construction projects in the planning stage of a construction project, in order to fulfill project objectives and select the most feasible construction methods (CMs).

Studying the multi-objective characteristic of construction projects is needed to understand the impact of different project constraints on decision-making of construction professionals, as well as the building process performance. Building process performance can be expressed in terms of various parameters, which are based on different interests of the involved parties (Cole, 1998). The interests, such as profit and comfort, have received more emphasis than the intricate impact of building processes, materials, and technologies on the natural environment. The existing paradigm focuses on time and cost 
of construction, while the new paradigm suggested in this study is concerned with the life cycle environmental performance, as well as time and cost. Ofori (1992) and Selih (2007) have already mentioned environmental impact as an additional constraint in projects. An innovative approach is to observe the connections of the multiple project objectives with construction operations. This approach brings the idea to add environmental impact (EI) as a new performance parameter to the traditional project criteria, which are time (T) and $\operatorname{cost}(\mathrm{C})$.

The project conditions that are present in the construction system produce an impact on the relationship between time, cost and environmental impact (TCEI) of construction operations. This relationship is still unknown by the construction contractors. In this study, project conditions refer to the external factors that affect the flow of construction projects. These external factors are adverse conditions, such as unavailability of resources or delay of resource delivery. They can also include unexpected conditions, such as poor weather conditions or geotechnical problems. The project conditions affect project parties while making decisions on several items. The project conditions, and likely the simulation of the behavior of parties/agents in construction projects, are dynamic and hard to predict by intuition. Therefore, it is critical to develop an analytic procedure to understand the impact of different project constraints on decision-making of construction professionals. This research proposes a methodology to analyze the decision-making mechanisms of construction agents, as well as their impact on the relationship of TCEI. Being the major project objectives, time and cost has been widely studied and planned by the construction professionals. Even though, other project objectives as quality and safety 
are also important, this study will only include environmental impact. Life cycle assessment (LCA), which is a tool to calculate environmental impact of products starting from extraction to disposal, will be used to evaluate of environmental impact in terms of GHG. Considerations for other objectives, as well as environmental impact categories can be added in the future studies.

\subsection{Research Objectives}

The project conditions (e.g., resource availability) are present in the construction system and produce an impact on the relationship between time, cost and environmental impact (TCEI) of construction operations. It is important to develop a framework to understand the impact of changing project conditions on the relationship of TCEI, while taking into account the multi-objective characteristic of construction projects. The purpose of this study is to develop a better understanding for environmentally conscious construction, by creating An Integrated Multi-Agent Framework for Optimizing TCEI of Construction Processes.

The model will simulate the effect of changing project conditions on the relationship of TCEI, by using a system dynamics perspective. The TCEI output will be feedback to the system to improve its effectiveness. In this manner, the coordination of human and built environments will generate environmentally conscious construction scenarios, which will allow the selection of more feasible and optimal project alternatives. The focus of this research is on the integration of the multi-agents and TCEI parameters, in order to see the impact of decisions on the relationship of TCEI. The interaction between decision- 
making of agents and project processes will be maintained through different resource utilization plans in the system. The TCEI optimal results will be further used to observe the relationship between the three objectives.

\subsection{Research Questions and Hypothesis}

The research objective is to create a framework to simulate and reveal the effect of project conditions on the relationship of TCEI, by using the system dynamics approach in coordination of multi-agent and built systems. Some fundamental questions and hypothesis regarding the research are:

1) How effective is the system dynamics model in simulating multi-agent decisions to reflect the actual solutions? Can the simulation results give an exact fit to the real case solutions? Are there unobserved but possible optimal solutions that are significantly different from the observed states? Do the simulated optimal solutions perform better in achieving environmentally conscious construction than the observed ones?

Project conditions are inherent in every construction system. Multi-agents make decisions and take actions according to the project conditions in their surrounding, as well as the preferences of other parties in the system. Thus, the construction simulation system should define agents, their relationships with each other, and changing system properties to observe the effect of project conditions on the flow of construction processes. The question is whether the multi-agents can be simulated effectively with the proposed system dynamics model to fit the real cases in construction. Considering the simulation gives practical TCEI optimal solutions that are as good as the actual ones, will these 
solutions be significantly different that the currently observed states? Can the simulated solutions that are based on project conditions, result in better resource utilization plans in achieving environmentally conscious construction?

This research hypothesizes that:

1. The system dynamics model will give optimal results that effectively fit to the behaviors of the actual systems.

2. The simulated TCEI optimal solutions will generate resource utilization plans that perform better than the observed solutions in achieving environmentally conscious construction.

2) How can the impact of project conditions on the relationship of TCEI be visible to the contractor? Does this knowledge of TCEI interdependency affect the decisions of construction contractors? Is it possible to quantify the relationship of TCEI according to the change in the contractor's decisions?

The presence of project conditions produce different resource utilization plans that can cause variation in the relationship of multi-objectives. In general, decision-makers do not have a full understanding of the impact of their decisions on TCEI project objectives, as they cannot view the deviations between designed and final versions of the projects caused by their preferences. If the simulation demonstrates the designed and final versions, as well as the interdependency of project objectives, the contractors will be able to visualize the impact of their decisions on the project and change decisions for the sake 
of project success. The question is whether it is possible to quantify the impact of change in contractor's decisions on the relationship of TCEI.

This research hypothesizes that the simulation of different resource utilization plans will demonstrate contractors how significantly their decisions affect the relationship of TCEI. When the contractors are aware of their influence on the project objectives, they will change decisions about construction processes and resources accordingly.

\subsection{Research Significance and Methodology}

The significance of this study is to consider and understand the impact of changing project conditions on the relationship of TCEI. The path followed to model this impact from project conditions to TCEI is shown in Figure 1. The conditions are vital in construction since they are inherent in all projects. Additionally, they affect project parties to change their decisions, such as the type or construction method or resources they would prefer, to deliver the project. As the effect of different conditions will result in different resource utilization plans, ignoring project conditions will cause eliminating not only some of the optimal project alternatives in terms of resources, but also the impact created on the relative importance of multi-objectives. There is a need to model the behavior of complex construction system that includes project conditions, agents' decisions and resource plans. System dynamics is a tool to analyze the behavior of complex systems (Forrester, 1994). Construction being a complex and dynamic system, using system dynamics is a perfect match to create the framework in this study. System dynamics modeling shows a common platform to integrate the agent and project models 
in a single and dynamic unit. The approach is used to simulate the behavior of construction system that is defined by items such as project resources and various parties with different capabilities.

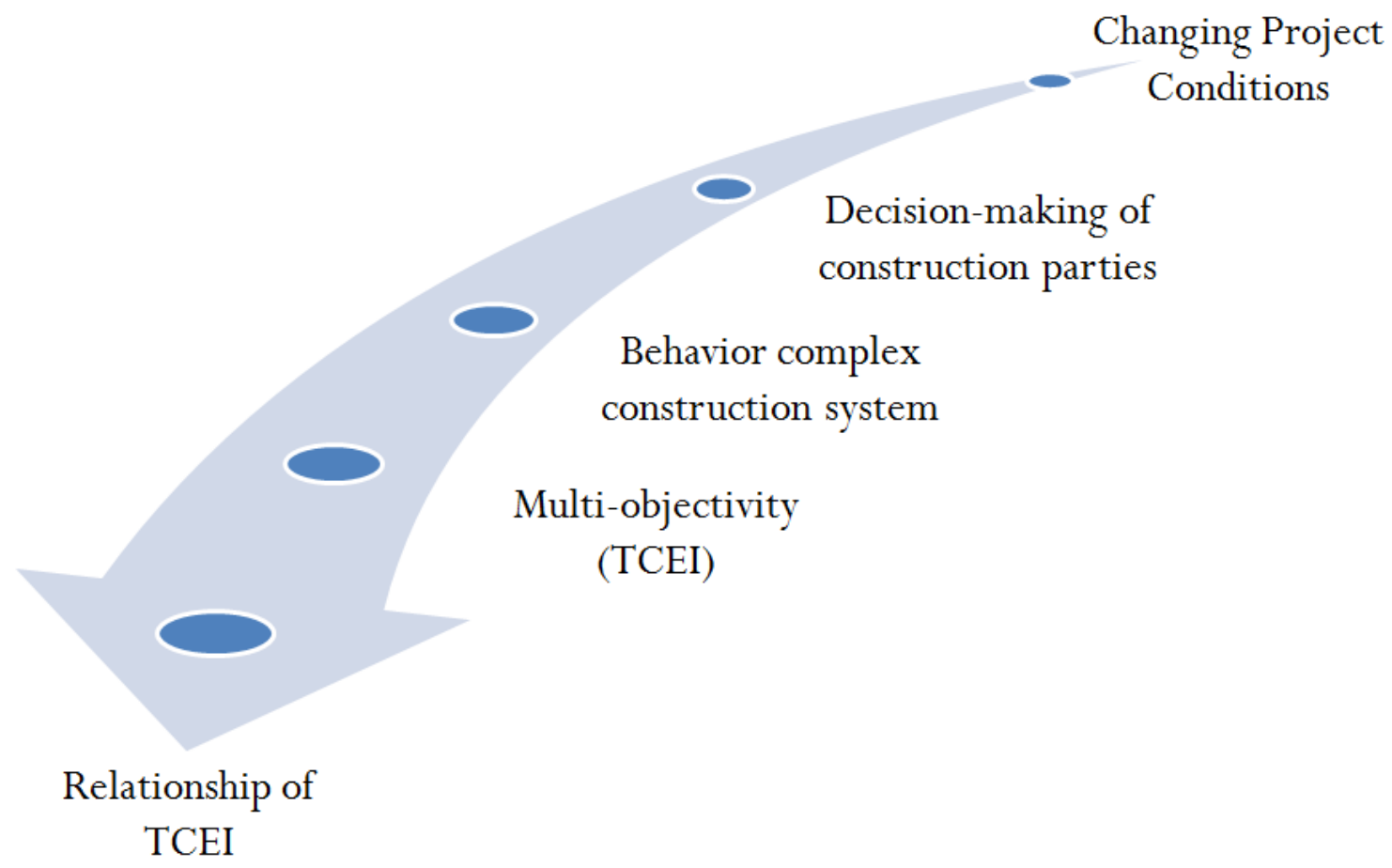

Figure 1 Research Path

The decisions of parties are driven by the changing conditions in their surrounding, as well as the preferences of other agents in the system. For example, the change in resource availability can alter contractor's decision about using the current construction technology. Similarly, owner's financial situation can affect his preferences to change the design, and thus construction methods. By observing the impact of changing project conditions, the agent-based approach will provide the problematic areas before the 
implementation of decisions. Meanwhile, the multi-objectivity of the construction projects will be considered, so that decision-makers will have a full understanding of the impact of their decisions on TCEI, and view the deviations between designed and final version of the projects caused by their preferences. When the agents are integrated to the construction system, the unobserved, hence available and possibly better, environmentally conscious construction scenarios and their corresponding resource alternatives will be visible to the contractor, so that the contractors will have a full understanding of the impact of their decisions on TCEI project objectives.

The analytical framework that will be used to simulate the project conditions and their impact on the relationship of project objectives will be used in the planning stage of construction projects. A multi-disciplinary approach is needed to develop such a structure. The inclusion of multiple areas of work is performed with the following steps:

- The set of sub-systems and the relation between sub-systems are defined for the complex construction system. The sub-systems are classified as decision-making and project systems.

- The decision-making system is generated with the help of multi-agent systems and analytical network process (ANP). The influence of project conditions on the decision of construction agents are modeled in this system. Multi-agents are defined for the life cycle of construction projects. Decision-making rules for multi-agents are created based on the relative importance weights of project conditions obtained from the ANP approach, which is used to model complex decision-making problems (Saaty, 2004). System dynamics is used to simulate 
project conditions and decision-making mechanisms of agents. The output of the system selects the most feasible construction method $(\mathrm{CM})$ under the influence of changing project conditions. $\mathrm{CM}$ includes the type and properties of resources that will be used to deliver the project.

- The selected CM is entered to the project system as input. The project system includes specific project properties, such as resource quantities and unit costs, which can be used to calculate TCEI. When input of project conditions change, a different $\mathrm{CM}$ or resource combination is selected in the decision-making system. This process generates different scenarios each time. The TCEI of the project is calculated for each different scenario.

- Each sub-system of the framework is created based on the published literature and revised by using collected information from highway construction projects. For the decision-making system, the data is collected in the form of a self-prepared survey based on ANP method. ANP results give the relative importance weights of project conditions to be used in decision-making. The qualitative data is analyzed and converted to the quantitative form to be used in connection with the project system. For the project system, project documents such as the contract, schedules, etc. are obtained from the Florida Department of Transportation (FDOT) for finished and ongoing resurfacing projects. The documents are examined to find out the related information, which is further used to calculate TCEI for the multi-objective optimization process.

- The construction method that is planned to be used by the contractor is referred to as the observed or original case. The original construction methods are used to 
form alternative ones. Different resource types and technologies are used to create CM alternatives. For time and cost, conventional estimating and scheduling methods are used in calculation. For cost calculation, the unit costs of the original and alternative cases are obtained and used together with the quantity of resources. Project duration is obtained from project schedules. In order to consider environmental impacts on the complete life cycle of construction projects, environmentally conscious construction, as well as LCA is studied in connection with construction operations. Life cycle assessment boundary and the impact categories are decided considering the scope of this study. Environmental impacts are limited to GHG. For alternative materials, the life cycle inventories are obtained from literature sources. For equipments, fuel consumption data from contracts are converted to GHG emissions. Finally, material and equipment consumptions are summed up to obtain the GHG emissions of the project.

- The decision-making and project systems are related through the construction method selection. A common language and platform is generated to simulate the construction environment. System dynamics approach is used to integrate project conditions, multi-agent systems, ANP process, and TCEI calculation procedure.

- The system dynamics model is tested for usefulness in simulating both decisionmaking and project systems by using three types of tests described in literature: (1) structural similarity to the actual system; (2) reasonable behavior over a wide range of input values; and (3) behavior similarity to actual system behaviors (Sterman, 2000). 
- The synchronization of the system elements is completed and evolved into the proposed framework. The TCEI values estimated for different resource utilization plans are further analyzed by using multi-objective optimization technique to obtain optimal TCEI results.

- The application of the proposed framework is examined by using two case studies from the FDOT projects.

The problem of overlooking the multi-objectivity of construction projects, and the need for simulating the influence of changing project conditions on the relationship of TCEI can be handled by the proposed framework. The decision-making and project subsystems, as well as the multi-objective-optimization technique are combined in the proposed framework to respond to the need in literature. System dynamics model simulates changing project conditions, their influence on agents' decisions, construction method selection process, and the flow of the project, while TCEI objectives are handled by the multi-objective optimization. Each subject will be explained in detail throughout this dissertation to emphasize its contributions to the framework.

\subsection{Dissertation Organization}

This dissertation is divided into six main chapters. Chapter 1 has introduced the issues under investigation, the approaches previously applied to these issues, the statement of the research problem, delimitations in the study's scope, and the significance of the study. Additionally, the conceptual basis of the study was established with research objectives, questions, and hypotheses. Research methodology was also clarified. Chapter 2 reviews 
the multi-disciplinary literature that lays the important empirical and theoretical foundation for this dissertation. The multi agent systems, analytical network process, system dynamics, and multi-objective optimization approaches are presented. In Chapter 3 , an analytical framework is proposed as a combination of the system dynamics and multi-objective optimization models. Besides, models designed in the scope of this research, based on the interpretations of multi agent, analytical network process, system dynamics, and multi-objective optimization approaches, are presented. In Chapter 4, data collection tasks and data analysis procedures are discussed, and analysis results are presented in Chapter 5. The final chapter, Chapter 6, includes a discussion of this study and suggests further research possibilities. 


\section{Literature Review}

\subsection{Multi-Agent Systems (MAS)}

\subsubsection{Agents in the Life Cycle of Construction Projects}

The term "agent" was first proposed at MIT by John McCarthy and Oliver G. Selfridge in the 1950s (Bradshaw, 1997). There exist several definitions for agents in literature as shown in Table 1. In general, an agent can be defined as anything that can perceive its environment through sensors and can act through effectors (Russell \& Norvig, 2002). Nwana (1996) summarized the key concepts of agents from the study of Wooldridge and Jennings (1995) as autonomy, co-operation, and learning. Autonomy refers to being free of human control, co-operation stands for interaction of agents, and learning is the ability of an agent to be intelligent or smart.

Table 1 Definition of Agents

\begin{tabular}{|l|l|}
\hline Author(s) & Definition \\
\hline (Brustoloni, 1991) & "Autonomous agents are systems capable of autonomous, \\
purposeful action in the real world". & "Let us define an agent as a persistent software entity dedicated \\
Spohrer, 1994) & $\begin{array}{l}\text { to a specific purpose. "Persistent" distinguishes agents from } \\
\text { subroutines; agents have their own ideas about how to } \\
\text { accomplish tasks, their own agendas. "Special purpose" } \\
\text { distinguishes them from entire multifunction applications; agents } \\
\text { are typically much smaller". }\end{array}$ \\
\hline
\end{tabular}




\begin{tabular}{|l|l|}
\hline (Maes, 1995) & $\begin{array}{l}\text { "Autonomous agents are computational systems that inhabit some } \\
\text { complex dynamic environment, sense and act autonomously in } \\
\text { this environment, and by doing so realize a set of goals or tasks } \\
\text { for which they are designed". }\end{array}$ \\
\hline $\begin{array}{l}\text { (Wonnings, 1995) } \\
\text { Jentridge }\end{array}$ & $\begin{array}{l}\text { "A computer system, situated in some environment that is } \\
\text { objective". }\end{array}$ \\
\hline
\end{tabular}

With their aforementioned key properties, agents can combine and form multi-agent systems (MAS). MAS are defined as a group of agents, which attempt to maximize their own effectiveness, while cooperating with other agents to achieve the desired objectives (Jennings, Sycara, \& Woodridge, 1999; Xue, Li, Shen, \& Wang, 2005). Ren and Anumba (2004) summarized the key issues in the development of MAS and discussed agent-based approaches in construction. They suggested the usage of MAS in construction to obtain "better quality, increased reliability, and more economic, safer, and more optimal solutions". The literature provides a rich variety of agent-based frameworks in construction. A multi-agent system was developed for construction claims negotiation (MASCOT) to resolve inefficiency problems (Ren, Anumba, \& Ugwu, 2003). The Agent-Based Support for the Collaborative Design of Light Industrial Buildings (ADLIB) project is created to study modeling action and knowledge in a collaborative MAS environment (Anumba, Ren, Thorpe, Ugwu, \& Newnham, 2003). Agents also took place in construction claims negotiation (Ren \& Anumba, 2002) and dynamic rescheduling negotiation (Kim \& Paulson, 2003) studies. Besides, an agent-based framework was 
proposed to solve constructability problems in construction environment (Ugwu, Anumba, \& Thorpe, 2005).

With the development in sustainability, the research attention shifted to investigate the entire supply-chain inputs, together with economic and environmental impacts (Hendrickson \& Horvath, 2000). The establishment and implementation of ISO 14001 standards was suggested to require total commitment and cooperation of all parties involved in the supply chain, including construction contractors, supervisors, designers, manufacturers, and investors (Cysewski, 1995). As mentioned in Gupta, Whitman, \& Agarwal (2001) and Frey, Stockheim, Woelk, \& Zimmermann (2003), MAS offer new means and tools for SCM. The ability of agents to maintain connection between different organizations with dissimilar objectives (Ren \& Anumba, 2004) supports the usage of agent-based models in SCM. For example, Udeja and Tah (2001) have developed a MAS system to improve collaboration in the construction material supply-chain. Xue, Li, Shen, \& Wang (2005) defined the concepts of construction supply-chain and combined it with MAS based on multi-attribute negotiation theory. Additionally, Thabrew, Wiek, \& Ries (2009) considered multi-stakeholder interaction, in order to achieve sustainable decisionmaking.

The structure of agent-based models in SCM has extensive contribution to environmentally conscious construction from a lifecycle perspective. The agents and their connections in SCM studies correspond to the agents in the first stages of LCA in construction. Therefore, agents need to be identified considering SCM elements and 
mechanisms. Agents can behave autonomously, co-operate, and learn (Wooldridge \& Jennings, 1995). Therefore, they are good candidates to simulate not only decisionmaking, but also the dynamic and complex nature of construction from an environmental perspective.

The agents in the life cycle of construction projects include both supply-chain and implementation phase parties. The implementation phase agents were limited to client, contractor, and engineer in the MASCOT system (Ren \& Anumba, 2002), while Ugwu, Anumba, \& Thorpe (2005) defined project agents that included client and design team agents (sub-contractor, construction engineer, manufacturer, etc.). Xue, Li, Shen, \& Wang (2005) listed construction supply-chain agents to be owner, general contractor, and designer, together with sub-agents, such as sub-contractors and suppliers. On the other hand, Thabrew, Wiek, \& Ries (2009) considered agents such as contactor, local authority, housing authority, and manufacturers in LCA to achieve sustainable decision-making. Li, Sheng, \& Liu (2010) summarized players in supply-chains, as raw material supplier, component supplier, a manufacturer, and retailer. The agents in the construction supplychain and LCA literature are adopted and organized to reflect the needs of this research. Considering the scope of highway construction projects, as well as the application of system dynamics modeling, the agents in this study are limited to contractor and owner. This is mainly because the resource selection in the highway construction projects is driven by these agents. Contractor is the agent that selects the construction method, but he/she is bounded to the owner for permissions and approvals. Although other agents are present in the life cycle of a construction projects, contractor and owner are modeled so 
as reflect the influence of other agents, such as manufacturer or vendor. The contractor and owner agents have their own decision-making mechanisms and communication paths with each other to come up with the most feasible resource utilization plans to deliver the project.

\subsubsection{Agents' Decision-Making}

The way agents perceive the conditions in their surrounding and behave in a system can be identified by various decision-making techniques. These theories are used to simulate agent decisions and include the tradeoff between different factors in the agent's system. The tradeoffs or weightings on factors can be obtained by asking people to input directly, or perform pair wise comparison, such as in the analytical hierarchy process (AHP) (Bishop, Stock, \& Williams, 2008). A number of software is available to create decisionmaking models. For example, Logical Decisions is a powerful tool to define alternatives, variables, and model interactions for agent systems. It provides different weighting preference assessment methods ranging from easy-to-use methods to the pair wise tradeoffs (Logical Decisions, 2007).

Survey on MAS literature has revealed a number of tools to form agent simulation platforms and analyze agents' behavior. For instance, TuCSoN (Tuple Centre Spread over the Network) is generated as MAS framework based on a model and a related infrastructure that provides general-purpose and programmable services for supporting agent communication and coordination (Omicini \& Zambonelli, 1999). JADE (Java Agent Development Framework) is a software JAVA-based framework that assists the 
development of distributed multi-agent applications (Bellifemine, Caire, Poggi, \& Rimassa, 2008). ZEUS agent building toolkit also depends on JAVA programming and presents agent functions, such as communication, coordination, planning, scheduling, task execution and monitoring, and exception handling (Tah, 2005). Although not specifically designed for MAS, ExtendSim offers users powerful and easy-to-use simulation software package (Clymer, 2000). The tool allows addition and modification of knowledge libraries. Clymer has formed a graphical simulation library called Operational Evaluation Modeling for Context-Sensitive Systems (OpEMCSS) to integrate agent-network to the simulation system (Clymer, 1999). He has defined complex adaptive system (CAS) as large domains that are composed of communicating sub-systems to achieve the overall system goal.

Each agent can have its decision plan independently and coordinate to generate partialindependent plans with other agents in a centralized or distributed form (Ferber, 1999). The interactions between agents can be defined by a combination of distributed and centralized approaches (Zhang, Hammad, \& Bahnassi, 2009). In the combined approach, a central agent is present to coordinate agents and combine their actions into an overall plan meanwhile agents are free to communicate with each other to come up with their partial-independent decisions. The combined approach is adopted in this study to simulate agents during entire project life. Contractor is the central agent, who collects final decisions of the owner and processes them with the rules defined for its decisions to select the construction method or resource utilization plans. The resource plans are used to calculate their values and view the relationship between TCEI. 


\subsection{Analytic Network Process (ANP)}

As the construction method selection is based on more than one conflicting objectives, it is accounted as a multiple-criteria decision-making (MCDM) problem. MCDM can be classified into two types, as multiple objective and multiple attribute problems. The first one has an infinite number of feasible alternatives, while the second one has a finite set of alternatives (Cheng, Chan, \& Huang, 2002). MCDM methods has been widely used in literature to select the most feasible alternative based on a set of criteria (e.g., Rakas, Teodorovic, \& Kim, 2004) or to rank and assess certain alternatives to achieve the selection process (e.g., Cheng, Chan, \& Huang, 2002).

These theories can be further used to observe the decision-making process of agents and include the tradeoff between different factors affecting decisions into the agent's system. The tradeoffs or weightings of factors can be obtained by asking experts to input directly or perform pair wise comparison, such as in the analytical hierarchy process (AHP) (Bishop, Stock, \& Williams, 2008). AHP was first introduced by Thomas L. Saaty as a decision network, which is composed of clusters, their elements, and links between the elements (Saaty, 1996). It is known as a useful and flexible decision-making tool, which can help people set priorities and make the best decision by handling both qualitative and quantitative aspects of a decision (Chen, Heng, \& Wong, 2005). Even though AHP has been utilized in various areas of construction research and practice since the late 1970s (Zeeger \& Rizenbergs, 1979), as the name implies, it allows users to form only hierarchical relationships between vertical levels of the decision model. Consequently, it 
has no horizontal connections between decision factors in the same level. This shortcoming has been overcome by introducing another analytical technique called analytic network process (ANP). It is more powerful in modeling complex decisionmaking problems than AHP, as interactions and dependencies among levels are present (Saaty, 2004). It is not possible to structure many decision problems hierarchically because of the need for a network that involves cycles between clusters, as well as loops within the same cluster (Saaty \& Vargas, 2006). Therefore, Saaty has recommended to use ANP when the most comprehensive and systematic analysis of influences are needed to be made (Saaty, 1996). The results of ANP are relative importance weights of various parameters. In this study, ANP is used to find the relative importance weights of project conditions. This information is utilized to simulate changing project conditions and decisions of agents.

\subsection{Systems Dynamics (SD)}

\subsubsection{Simulation of Construction Environment}

Construction simulation has its roots in the development of CYCLONE methodology (Halpin, 1977). The CYCLONE has been used to model and analyze various construction operations (Halpin \& Riggs, 1992). The improvement has continued with other simulation tools, such as Simphony (Hajjar \& AbouRizk, 1992) and STROBOSCOPE (Martinez \& Ioannou, 1999) to deal with construction operations in tunneling and earthmoving activities. While the first attempts were to model and analyze various construction operations, the simulation concept moved a step further with the integration of agent-based frameworks. 
Agents beyond their autonomous reasoning and collaboration can create events from interaction with other agents, predict future consequences of current events, and visualize the sensitivity of simulation environment (Rojas \& Mukherjee, 2006). Therefore, various researchers have focused on multi-agents to form the project environment and simulate agent decisions. For example, Dijkstra and Timmermans introduced a multi-agent model to simulate agent behavior related to design decisions (Dijkstra \& Timmermans, 2002). Zayed and Halpin stated the necessity of decision-making as a part of construction operations and created time-cost-quantity charts for deciding production time, production cost and required resources (Zayed \& Halpin, 2000). Soilbelman and Pena-Mora generated a multi-reasoning model (M-RAM), which used agent-like approach to improve the existing design process in time and quality (Soibelman \& Pena-Mora, 2000). Fujii and Tanimoto simulated the interaction between architectural environment and human decisions (Fujii \& Tanimoto, 2004). They considered the changes in the environment and their effect on the next actions.

In the model by Rojas and Mukherjee, a group of autonomous agents made decisions concerning resource allocation, in order to simulate the project within time and cost limits (Rojas \& Mukherjee, 2006). An improved version of this study was to optimize time and cost together with another objective, considering different construction operations. An example is the resource utilization system by Kandil and El-Rayes that optimized time, cost and quality simultaneously (Kandil \& El-Rayes, 2006). They also mentioned fixed relative importance weights for time, cost and quality, as inputs to their model. That is, 
the weights were based on only the user's intuition apart from multi-agents' decisions, which were dependent on changing conditions in the construction environment. Polydoropoulou and Roumboutsos worked on time-cost-quality tradeoff of transport projects and revealed that the perceived utility of time, cost and quality could be different for various project stakeholders (Polydoropoulou \& Roumboutsos, 2009). They addressed the decisions made during construction phase as well and concluded that top management is not always aware of the influence of their decisions on the entire project life.

The presence of multiple and conflicting objectives is one of the major complexities in building projects (Burns, Liu, \& Feng, 1996). They need to be simulated and optimized for the successful completion of the project. These objectives can include time, cost, safety, quality, and sustainability, where their significance among each other can differ from project to project (Kandil, El-Rayes, \& El-Anwar, 2010). The reflections of project conditions and agent preferences on the significance of project objectives need to be considered in simulating dynamic and complex construction systems. System dynamics approach, which will be explained in detail in the next section, offers an extensive method to integrate project conditions and agents' decision-making to simulate construction projects.

\subsubsection{Systems Dynamics Background}

System dynamics (SD) is defined as a methodology for studying and managing complex systems (Sterman, 2000). The concept combines the theory, methods, and philosophy 
needed to analyze the behavior of complex systems and understanding the change of their behavior over time (Forrester, 1994). Jay Forrester is considered as the father of the SD concept, as he developed the methodology's philosophy and described SD as "the investigation of the information-feedback character of industrial systems and the use of models for the design of improved organizational form and guiding policy" (Forrester, 1961). The methodology is further improved by describing the modeling process with examples and several applications (Sterman, 2000).

There is a variety of SD applications in literature. The authors practicing SD in project management and their corresponding topics are summarized in Table 2.

Table 2 System Dynamics Models in Project Management

\begin{tabular}{|l|l|}
\hline Project management topics using SD & Authors \\
\hline Poor schedule performance & (Abdel-Hamid T. K., 1984); (Abdel-Hamid \\
& T. K., 1988); (Abdel-Hamid \& Madnick, \\
& $1991)$ \\
\hline Concealing rework requirements on project & (Ford \& Sterman, 2003a) \\
performance & (Cooper, 1980); (Rodrigues \& Williams, \\
\hline The impacts of changes in project scope & 1997) \\
\hline The effect of rework on project & (Cooper, 1993); (Ford, 1995); (Love, \\
performance & Mandal, \& Li, 1999); (Lee, Pena-Mora, \& \\
\hline
\end{tabular}




\begin{tabular}{|l|l|}
\hline Failures in project fast track & (Ford \& Sterman, 1998); (Ford \& Sterman, \\
implementation & $2003 b)$
\end{tabular}


In general, SD models have three element types: (1) stock elements (state variables); (2) flow elements; and (3) auxiliary variables and constants (Garcia, 2006). These elements allow simulating changes overtime, as well as feedbacks of information (Richardson \& Pugh, 1981). Considering the cause-effect relationships, stocks, flows, and feedback loops are used to model the flow of work and resources through a project (Ogunlana, Li, $\&$ Sukhera, 2003).

The structures of an SD model are described as project features, a rework cycle, project control feedbacks, and ripple and knock-on effects. Firstly, project features represent the development tasks or work packages, as they flow through a project (Lyneis \& Ford, 2007). Secondly, rework cycle shows the iterative flow of work packages with respect to time. Several rework structures has been developed (Cooper, 1980; Richardson \& Pugh, 1981; Abdel-Hamid, 1984; Cooper, 1993; Ford \& Sterman, 1998) and applied to explain different problems (Lyneis, Cooper, \& Els, 2001; Ford \& Sterman, 2003a; Ford \& Sterman, 2003b; Ford, Anderson, de Las Casas, Gokmen, \& Kuennen, 2004; Taylor \& Ford, 2006; Lee, Ford, \& Joglekar, 2007; Ford, Lyneis, \& Taylor, 2007) in literature. Thirdly, controlling feedbacks are used to control a project's performance. For instance, Lyneis and Ford have used "Add People," "Work More," and "Work Faster/Slack Off" feedback loops to meet a project deadline (Lyneis \& Ford, 2007). Finally, ripple and knock-on effects are defined as side effects that take place because of actions taken to close a gap between project performance and targets (Lyneis \& Ford, 2007). 
SD modeling is considered to perform strategically better than traditional operational project management tools, such as work breakdown structures (WBS), critical path modeling (CPM), and component cost estimating (Rodrigues \& Bowers, 1996). The reason, as stated in Rodrigues (1994), is that the traditional methods have their focus on different parts of the project management process, while the SD method considers whole project system. Previous studies have discussed how SD can improve traditional models, how traditional tools can be used to create SD models, and how both methods can be used to inform one another (Williams, 2002). As an example, Park and Pena-Mora integrated SD and CPM to cope with dynamic schedule buffering problems (Park \& Pena-Mora, 2003). In a similar manner, Rodrigues integrated SD with the PMBOK risk management process to present a framework for managing project risk dynamics (Rodrigues, 2001).

Besides the incorporation of SD within the established project management processes, the approach has been extensively used to model development projects. Development projects are defined as systems of diverse components linked by rich interactions (Simon, 1996). The methodology is beneficial in modeling the delayed information feedback, flows and accumulations of work, and the nonlinear relationships that characterize development of construction projects (Cooper, 1993; Ford \& Sterman, 1998). These capabilities of SD not only help to understand the project behavior and performance, but also allow observing how the project performance evolves in response to interactions between managerial decision-making and development processes (Lee, Ford, \& Joglekar, 2007). 
Development process systems have been practiced to create complex products (Browning, Fricke, \& Negele, 2006). Construction projects are good examples for complex products, as they are extremely complex and consist of multiple interdependent components, highly dynamic, and involve multiple feedback processes, nonlinear relationships, and both hard (quantitative) and soft (qualitative) data (Sterman, 1992). SD models have been in use on complex development processes and projects over the last 20 years, and they have contributed significantly to improve project performance (Lyneis, Cooper, \& Els, 2001). The term performance gap has been defined as the difference between actual performance and desired performance to achieve a certain goal. The performance of the process can be determined in different forms, such as the number or rate of products to be processed each day to improve or close the performance gap in terms of time spent (Repenning \& Sterman, 2001).

Several researchers have worked on the effects of resource management on project performance (Cooper, 1993; Graham, 2000; Lee, Ford, \& Joglekar, 2007). For example, Joglekar and Ford benefited from resource productivity improvement and policies for allocating resources among specific development activities to speed up projects (Joglekar \& Ford, 2005). Similarly, Lee et al. focused on development project resource management to improve schedule performance (Lee, Ford, \& Joglekar, 2007). They emphasized the importance of resource management on timely completion of projects and reducing project durations. Additionally, the study has mentioned how the managers' 
ability was constrained by the challenges of managing uncertain project conditions and constraints imposed by cost, product architecture, and project participant relationships.

The constraints that are imposed by external factors, like project conditions or internal factors (e.g., project participant relationships) affect the decision-making structure of systems. Resource-based view (RBV) can serve for this purpose, as it can facilitate all stages of strategy formulation and decision-making processes (Ford \& Mahieu, 1998). Project features in SD models can also be used to model human decision-making, which is typically driven by the perception gaps (differences between perceived progress and real progress), delays in human processes, and nonlinear relationships. The decisionmaking works as a mechanism to minimize the target-performance gap in one or more performance dimensions such as time, cost, quality, and scope (Lyneis \& Ford, 2007).

"Mental models" concept has been an important topic in SD models. They can help to understand how they influence and are influenced by learning and decision-making (Doyle \& Ford, 1998). The concept dates back to 1960s when they were thought to be the mechanism what allow SD computer models to be constructed in the absence of written and numerical data (Forrester, 1961). The characteristics of mental models are defined as fuzzy, incomplete, and imprecisely stated (Forrester, 1971). Although systems of mental models have shortcomings in simulating the dynamic behavior of an informationfeedback system by being able to include only limited number of people or variables, they are used in SD modeling primarily to support dynamic decision-making (Forrester, 1994). Doyle, Ford, Radzicki, \& Trees (2001) have also summarized the characteristics 
and shortcomings of mental models, as well as principles to improve their limitations in SD models. They reported that users might mentally simulate the effects of alternate possible decision rules to predict the future state of the system. The simulation of rules can be integrated to the SD system as mental model based decision-making loops, which can be further used to make simulated state of the system closer to the desired one.

Considering the limitations of mental models, it is obvious that they are not solely enough to simulate SD models. The ideas can be re-used to define certain ways to simulate the decisions of human agents in SD models. Additionally, it is important to overcome the fuzzy nature of mental models (Doyle, Ford, Radzicki, \& Trees, 2001) by combining the concept with other types of information. In this study, the idea of minimizing the difference between simulated and goal states is adopted from mental models and further investigated under the influence of external factors, such as change in project conditions. Park and Pena-Mora (2003) have stated that the previous SD models could not effectively reflect the influence of change on construction performance, especially under certain conditions. Besides, they have emphasized the unpredictability of human responses to work environment and managerial decisions and pointed out the need of flexibility in determining project scope and work dependencies in construction project models.

In order to overcome the aforementioned shortcomings, the proposed SD model uses rework cycle and generates the decision-making mechanisms of agents based on the change in project conditions, as well as the project goals (TCEI). The structure of the 
proposed model is based on previous SD models, while the ideas from mental model studies are considered in simulating the decisions of agents. The properties of project conditions are entered as input to the SD model. Based on the defined decision-making rules, agents select the most feasible $\mathrm{CM}$ under the influence of project conditions. Then, TCEI is calculated for the selected CM. For each different set of inputs, i.e., scenarios CM selection and TCEI calculation are performed by the SD model. The details of the proposed SD model will be explained in the Systems Dynamics (SD) Model for Construction Projects part.

\subsection{Multi-Objective Optimization Background}

Construction literature is rich in studies that concentrate on optimizing time and cost simultaneously. Feng, Liu, \& Burns (1997) viewed time-cost tradeoff problems are as one of the most important aspects of construction decision making and developed a timecost tradeoff curve to show the relationship between project duration and cost. They also investigated the effects of resource selection, such as crew sizes, equipment, method, and technologies on this relation. Feng, Liu, \& Burns (2000) enlarged the time-cost tradeoff by solving the problem under uncertainty. They pointed out the difficulties in time-cost tradeoff problem as arranging the different available resource options for activities. In a similar manner, Leu, Chen, \& Yang (2001) used fuzzy set theory to obtain optimal construction time-cost tradeoff under uncertain activity durations. Marzouk \& Moselhi (2004) presented a framework for optimizing earthmoving operations. They considered the availability and characteristics of earthmoving equipments and their cost components together with time-cost trade-off analysis. El-Rayes \& Kandil (2005) visualized the three- 
dimensional tradeoffs among project time, cost, and quality by evaluating the impact of various resource utilization plans on project performance. In their study, the multiobjective optimization aimed minimizing time and cost, while maximizing quality of a project. They considered construction method, crew formation, and crew overtime policy as decision variables that finally influence single decision variable that was called resource utilization. Azaron, Katagiri, \& Sakawa (2007) created an analytical model to work on the time-cost tradeoff problem. The aim of their study was to minimize time, cost and the variance of project completion time by using the optimal control theory.

The algorithms developed to handle time and cost relationships included heuristic methods (e.g. Fondahl, 1961; Prager, 1963; Moselhi, 1993), mathematical programming (e.g. Henderickson \& Au, 1989; Burns, Liu, \& Feng, 1996; Jiang \& Zhu, 2010), and evolutionary algorithms. Evolutionary algorithms are genetic algorithms (GAs) (e.g. Feng, Liu, \& Burns, 1997; Feng, Liu, \& Burns, 2000) and ant colony optimization algorithms (e.g. Afhsar, Kaveh, \& Shoghli, 2007; Kuang \& Xiong, 2007). Heuristic and mathematical models do not work efficiently, as they can optimize only one objective at a time and cannot guarantee global optimal solutions (Zheng, Ng, \& Kumaraswamy, 2004). Therefore, they are not good for large number of variables and multi-objectives as the case in construction environment. On the other hand, GAs perform better than the conventional optimization methods especially in difficult real world optimization problems (Osyczka, 2002). 
Although the environmental optimization is a developing concept in construction, it is not easy to adopt environmental management in construction, since it does not cause a reduction in the total time or cost of the project, and inversely the environmental regulations can give rise to delay or cost overrun. In a similar manner, any limitation in time or cost can result in an increase or decrease in the environmental impacts of the project (Chen, Li, \& Wong, 2000). There has not been such an optimization tool to handle the interrelations between these three objectives in construction projects. As mentioned before, it is still a new concept to consider a sustainability parameter as one of the objectives among the three dimensional multi-objective optimization researches in construction. The works on multi-objective optimization either, combined time and cost with another project indicator like quality (El-Rayes \& Kandil, 2005), or focused on time-cost tradeoff analysis to optimize the resource of an activity (Marzouk \& Moselhi, 2004). A recent sustainable optimization example is by Wu, Simpson, \& Maier (2010), who performed multi-objective optimization analysis on the design of water distribution systems, considering economic (life cycle cost) and environmental (GHG) objectives. They also used GAs and concluded that significant tradeoffs between the economic and environmental objectives can be observed in the form of a Pareto-optimal front. Another example came from Marzouk, Madany, Abou-Zied, \& El-Said (2008) who tried to optimize total pollution with project duration and cost by using GAs. They analyzed the dynamic nature of construction activities referring to different types of relationships and the change of activities' criticality and proposed a framework to minimize time, cost and pollutants of construction projects. 
Even though Marzouk, Madany, Abou-Zied, \& El-Said (2008) mentioned the need for quantitative assessment during the planning phase, their study emphasized on the importance of revealing and managing excessive pollution during only construction stage. They tried to measure the influence of construction methods and resource utilization decisions on time, cost and emissions, but did not carry this approach to the next level, which is LCA. They minimized a sustainability parameter, such as total pollution and observed its relationship with time and cost, but limited this approach to just one environmental element and one phase of the project life cycle. The dynamic nature of construction environment exists in all phases on the project. Thus, the optimization research is in need of not only integrating TCEI of construction operations, but also handling EI from a life cycle perspective. The multi-objective optimization theory in literature need to be enlarged by adding environmental impact (EI) as a new performance parameter to the traditional project criteria, which are time (T) and cost (C).

Multi-objective optimization has been applied to time and cost tradeoff analysis of construction projects based on different algorithms, e.g., heuristic methods, mathematical programming, and more recently evolutionary algorithms including genetic algorithms and ant colony optimization algorithms. Evolutionary algorithms, such as genetic algorithms, ant colony optimization, and particle swarm optimization are selection-based. The mathematical relationships among variables are not required (Jiang \& Zhu, 2010). This characteristic of evolutionary algorithms make them desirable to time, cost and environmental impact analyses, because the relationships among them are not known, but each of them can be analyzed and calculated independently (Ozcan \& Zhu, 2009). 
Results of analyses by using evolutionary algorithms are typically represented as Pareto front, i.e., a set of optimal solutions. Decision-making methods can be applied to assist users in choosing a right solution, e.g., Mouzon and Yildirim (2008) applied analytical hierarchy process (AHP) to determine the best alternative among a set of solutions on the Pareto front.

Optimization with genetic algorithms has a set of general steps to obtain the Pareto front. The procedure starts with randomly generating a population of solutions. Then, the fitness for each solution on the population is determined by using a fitness function. The convergence of solutions is checked until an adequate level of accuracy is obtained. The adequate level of accuracy works as the stopping criterion for the process. Similar steps are also followed in this study with TCEI solutions. The details of the multi-objective optimization procedure will be explained in the Multi-Objective Optimization part. 


\section{An Integrated Multi-Agent Framework for Optimizing TCEI of Construction \\ Processes}

The analytical framework proposed in this study aims to simulate the project conditions and their impacts on the relationship of project objectives with a long-term goal of achieving environmentally conscious construction. A multi-disciplinary approach is needed to develop such a structure. Therefore, this new perception of simulation integrates both agents' decision-making and project systems to achieve the overall goal of the construction project. This study fulfills the need of such a model by developing a multi-objective optimization framework with TCEI objectives. This chapter will explain the proposed framework that integrates multi-agent systems (MAS), multi-objective optimization, and system dynamics to simulate construction projects in order to visualize the relationship between of the TCEI objectives.

The flow chart for the proposed procedure is shown in Figure 2. The proposed procedure includes multiple areas of work that are as summarized below:

- The set of sub-systems and the relation between sub-systems are defined for the complex construction system. The sub-systems are classified as decision-making and project systems.

- The decision-making system is generated with the help of MAS and ANP. Multiagents are defined for the life cycle of construction projects. Decision-making rules for multi-agents are based on project conditions in the system. Thus, project conditions are input to the decision-making system. ANP is used to calculate the relative importance weights of conditions. Finally, system dynamics approach is 
used to simulate project conditions and observe the CM selected as the output of the system.

- The project system includes project properties, such as resources and calculation of the TCEI objectives. Different resource combination are obtained from the CM selected (i.e., output of the decision-making system) and used in the calculation of TCEI. By this way, the decision-making and project systems are related through construction methods.

- The TCEI values estimated for different resource utilization plans are further analyzed by using multi-objective optimization technique to obtain optimal TCEI results.

- A common language and platform is generated to simulate the construction environment. System dynamics approach is used to integrate project conditions, agent systems, and project objectives (TCEI).

- The synchronization of the system elements is completed and evolved into the proposed framework. 


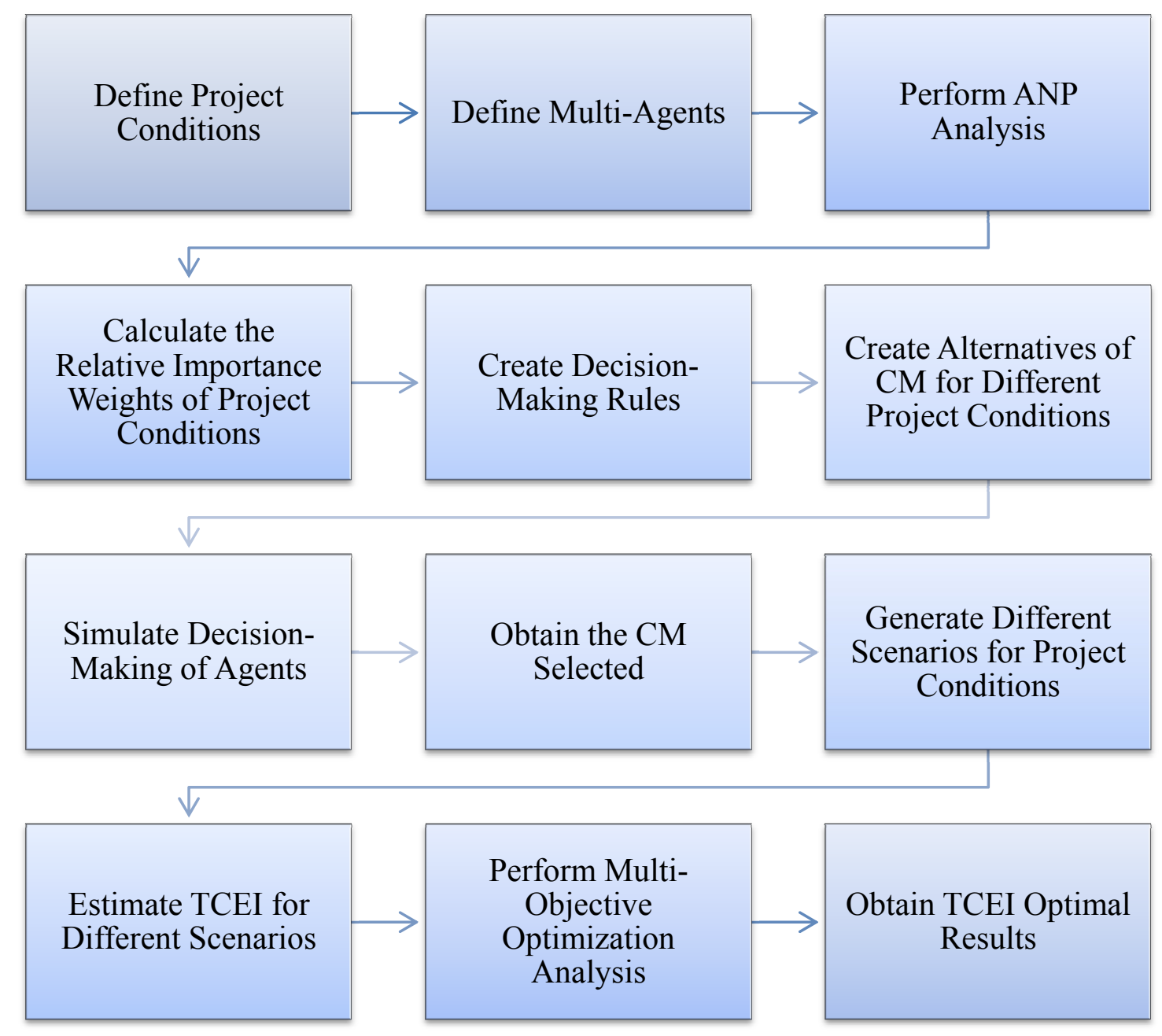

Figure 2 Flow Chart for the Proposed Framework

Considering the multiple areas of work in the previous chapters, this study presents $A n$ Integrated Multi-Agent Framework for Optimizing TCEI of Construction Processes, which is shown in Figure 3. 


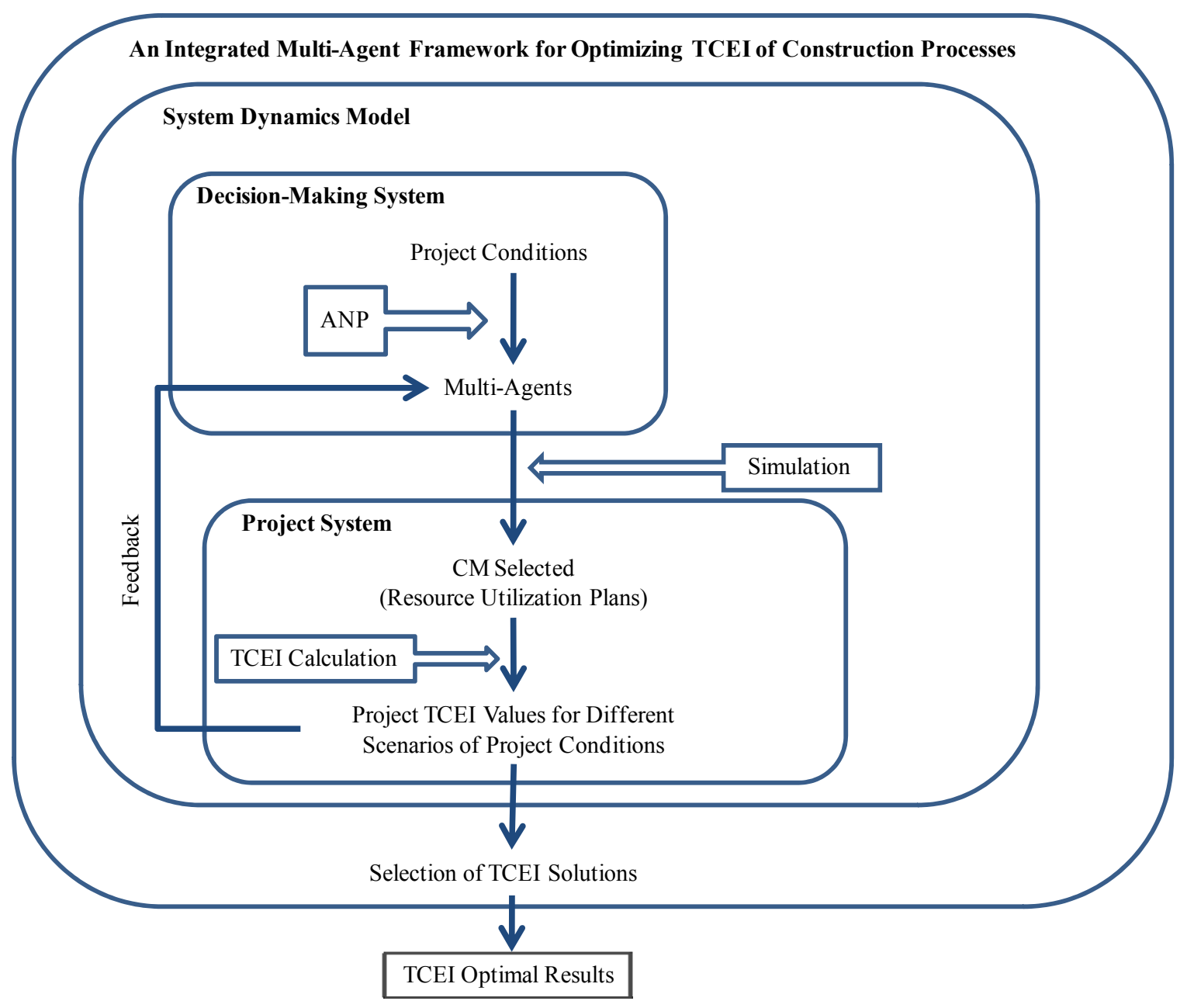

Figure 3 An Integrated Multi-Agent Framework for Optimizing TCEI of Construction Processes

The proposed framework includes the system dynamics model in the core. The SD model is composed of decision-making and project systems. The decision-making system is designed to address the challenge of selecting the most feasible construction method, under the influence of changing project conditions. The changing project conditions are input to multi-agents to start the decision-making process. Although it is a challenge to model agents' decision-making, the current model utilizes the ANP approach and reflects expert opinions into the system. Additionally, IF-THEN rules are simulated by using 
system dynamics. System dynamics, which is a successful tool to simulate complex systems, is a perfect fit for this study, as construction is a complex and dynamic system. When the most feasible CM is selected, the information is input to the project system. The project system is needed to reflect the properties of each project, as well as calculate the TCEI values for different construction methods. The TCEI values are accumulated for different scenarios to be used in the multi-objective optimization part. Multi-objective optimization is used to optimize two or more conflicting objectives at the same time. In this study, there are three conflicting objectives as time, cost and environmental impacts, and the multi-objective optimization process is needed to select the TCEI optimal results. After a random population of TCEI solutions are generated in the system dynamics model, the framework performs optimization and selects the TCEI optimal results based on a certain fitness function. The fitness function has the aim of achieving the minimum time, cost and environmental impacts, which contributes to the overall goal of the framework.

The proposed framework aims to develop a better understanding for environmentally conscious construction, by simulating the effect of changing project conditions on the relationship of TCEI from a system dynamics perspective. The TCEI output of the framework is feedback to the decision-making system to improve its effectiveness. In this manner, the coordination of decision-making and project systems generates scenarios by changing the properties of project conditions. When simulated, the scenarios allow the selection of more feasible and optimal CM alternatives. This framework integrates multiagents and TCEI parameters. Such a framework is needed to simulate the multi-objective 
nature of construction projects and see the impact of decision-making process on the relationship of TCEI.

The multi-agent system created based on pre-defined rules and ANP results create the basis for the decision-making mechanism of agents. Resource utilization plans enable the interaction of decisions to the TCEI calculation and multi-objective optimization. The framework is required to simulate the interaction process, as it cannot be defined by intuition of the contractor. By combining topics from various disciplines, the proposed framework allows the user to observe the impact of project conditions, as well as the decisions on TCEI objectives. The TCEI optimal results are further used to observe the relationship between the three objectives. Numerical examples will be presented to run and analyze the proposed framework. The application of the proposed framework and its results will be discussed in Chapters 4 and 5. Before the application and results, the multiple areas of work that contribute to the proposed framework will be discussed in detail in the following parts.

\subsection{Decision-Making Model for Construction Projects}

\subsubsection{MAS Design}

In order to achieve the overall system goal, the decisions of agents are determined by predefined rules that reflect several project conditions in the surrounding. Construction project environment can experience conditions, such as permission requirements of the project, cases regarding resource issues, or unexpected environmental problems. These conditions cause agents to act in different manners. Conditions and actions can form IF- 
THEN rules that characterize agents' decisions in the system. Only the conditions that can have an influence on the construction method selection and likewise on the resource utilization plans are employed in this study.

The conditions that affect the decision-making of agents are defined based on previous studies about highway construction, change causes, and change effects. Examples for possible project conditions and their corresponding authors mentioning them are shown in Table 3.

Table 3 Project Conditions and Their Corresponding Authors

\begin{tabular}{|c|c|}
\hline Project Conditions & Corresponding Authors \\
\hline Unavailability of resources & $\begin{array}{l}\text { (Chan \& Kumaraswamy, 1996); (Rojas \& } \\
\text { Mukherjee, 2003); (Mukherjee, Winn, \& } \\
\text { Rojas, 2005); (Assaf \& Al-Hejji, 2006); } \\
\text { (Sun \& Meng, 2009) }\end{array}$ \\
\hline Delay in resource delivery & $\begin{array}{l}\text { (Chan \& Kumaraswamy, 1996); (Al- } \\
\text { Momani, 2000); (Rojas \& Mukherjee, } \\
\text { 2003); (Mukherjee, Rojas, \& Winn, 2004); } \\
\text { (Wu, Hsieh, Lu, \& Cheng, 2004); (Rojas \& } \\
\text { Mukherjee, 2006); (Assaf \& Al-Hejji, } \\
\text { 2006); (Arun \& Rao, 2007) }\end{array}$ \\
\hline Increase in unit cost of resources & (Frimpong, Oluwoye, \& Crawford, 2003); \\
\hline
\end{tabular}




\begin{tabular}{|c|c|}
\hline & $\begin{array}{l}\text { (Mukherjee, Rojas, \& Winn, 2004); (Arain } \\
\text { \& Pheng, 2005); (Rojas \& Mukherjee, } \\
\text { 2006); (Arun \& Rao, 2007) }\end{array}$ \\
\hline $\begin{array}{l}\text { Unexpected conditions (e.g., bad weather, } \\
\text { labor strike, unforeseen ground conditions) }\end{array}$ & $\begin{array}{l}\text { (Chan \& Kumaraswamy, 1996); (Al- } \\
\text { Momani, 2000); (El-Rayes \& Moselhi, } \\
\text { 2001); (Mukherjee \& Rojas, 2003); } \\
\text { (Mukherjee, Rojas, \& Winn, 2004); (Wu, } \\
\text { Hsieh, Lu, \& Cheng, 2004); (Assaf \& Al- } \\
\text { Hejji, 2006); (Rojas \& Mukherjee, 2006) }\end{array}$ \\
\hline $\begin{array}{l}\text { Change in design (e.g., client initiated } \\
\text { variations, change orders by owner) }\end{array}$ & $\begin{array}{l}\text { (Chan \& Kumaraswamy, 1996); (Williams } \\
\text { T. M., 2000); (Wu, Hsieh, Lu, \& Cheng, } \\
\text { 2004); (Assaf \& Al-Hejji, 2006); (Sun \& } \\
\text { Meng, 2009) }\end{array}$ \\
\hline $\begin{array}{l}\text { Adverse financial issues of owner (e.g., } \\
\text { changes in cash flow) }\end{array}$ & $\begin{array}{l}\text { (Hanna, Russell, \& Vandenberg, 1999); } \\
\text { (Assaf \& Al-Hejji, 2006); (Sun \& Meng, } \\
\text { 2009) }\end{array}$ \\
\hline $\begin{array}{llll}\text { Adverse market conditions } & \text { (affecting } \\
\text { owner) } & & & \\
\end{array}$ & $\begin{array}{l}\text { (Williams T. M., 2000); (Arain \& Pheng, } \\
\text { 2005); (Sun \& Meng, 2009) }\end{array}$ \\
\hline
\end{tabular}

As stated in Table 3, adverse financial issues and adverse market conditions have an influence on the owner's decision, while the remaining ones determine contractor's decision on construction method selection. Owner has the authority to initiate change in design as a condition to contractor. Figure 4 shows the project conditions and decision 
paths for contractor and owner. As mentioned before, these agents and their decision paths are modeled considering the influence of other agents that are present in the life cycle of the project. Even though the decision paths for owner and contractor are comprehensive and fulfill the needs of this study, they are flexible to be further detailed by adding other agents in the agent system.

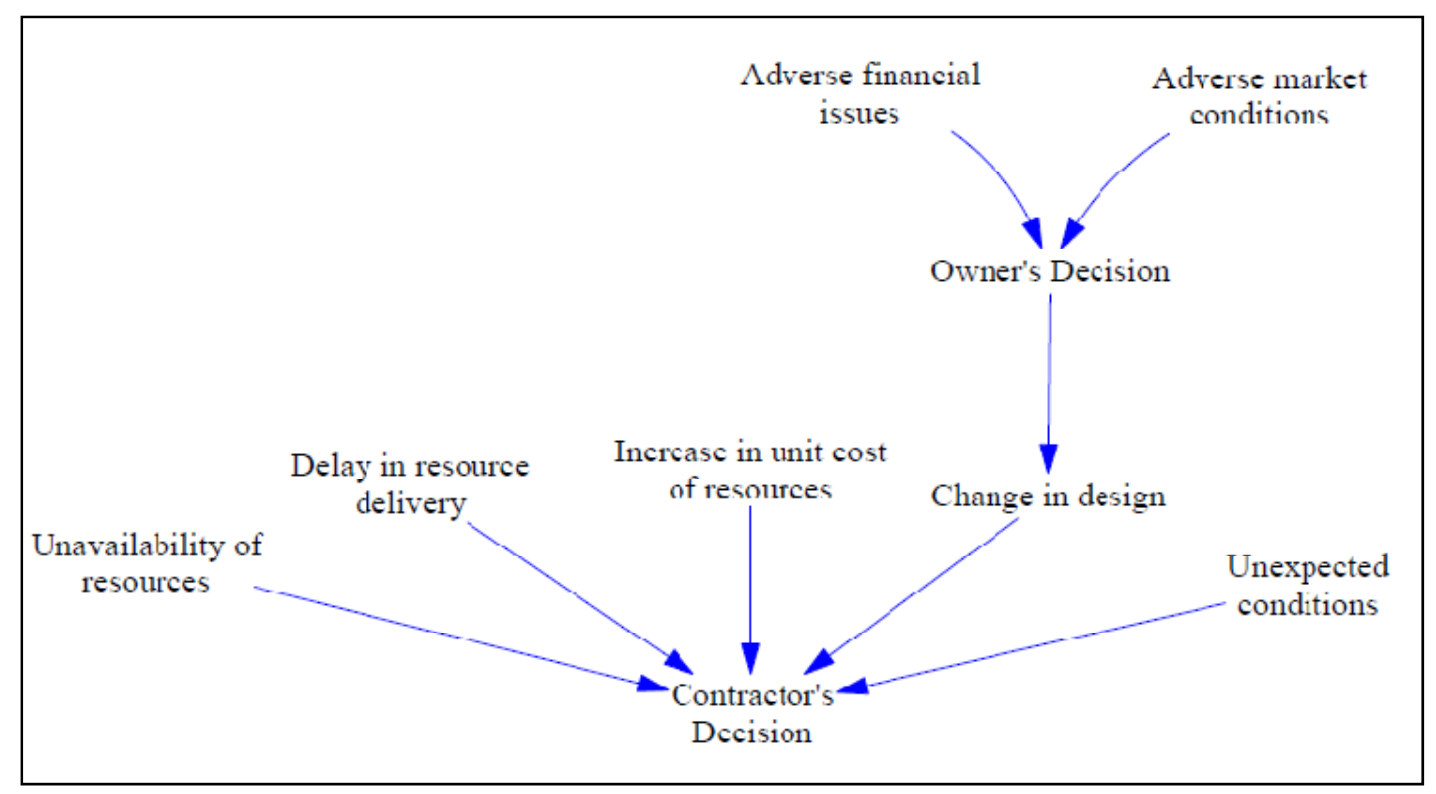

Figure 4 Project Conditions and Decision Paths for Contractor and Owner

The decision paths for contractor and owner form the decision-making sub-system of the analytical framework. The decision-making mechanisms have the following properties:

- Each agent has its specific conditions and decides on corresponding actions.

- The condition-action combination generates rules for the agent's decisions.

- Conditions are IF part of the rules, while actions are THEN part of the rules. 
- The owner states whether there is a change in design. In this case, change in design is the action of the owner. Then, it influences the contractor and becomes one of the contractor's conditions.

- Actions of the contractor identify the construction method selection or the resource utilization such as material, crew, and equipment.

Project conditions given in Figure 4 are defined by two indicators as importance weight and probability. Importance weight stands for the relative importance among conditions depending on different types of construction methods. Probability denotes the chance of occurrence for each condition. The combination of importance weights and probabilities of conditions affecting each agent is used to explain how the person decides under certain constraints. When the decision-making system is simulated, the contractor agent ends up in selecting the most feasible construction method under the influence of the conditions present in the complex construction system. Further information on how to generate the decision-making mechanisms for owner and contractor will be explained in the Decision Model with ANP and System Dynamics Model Design sections.

\subsubsection{Decision Model with ANP}

The ANP decision problem can be constructed by using four main steps, which are problem structuring and model construction, preparation of pair wise comparison matrices of interdependent component levels, supermatrix formation, and determination of the relative importance weight of each factor. The decision problem should be identified and decomposed into a set of manageable and measurable levels. The top-most 
level is the decision problem, while the lowest level is usually the scenario or alternative level (Saaty, 1980). The decision problem is decomposed into clusters, and clusters are further decomposed into attributes (nodes). ANP allows dependencies both within a cluster (inner dependence) and between clusters (outer dependence) (Saaty, 2001). Thus, important components of the problem are defined in the form of clusters and nodes, as well as the relationships between them.

Similar to AHP, ANP utilizes expert judgments to obtain relative importance of one of two components over the other in a pair wise comparison process on a third component in the system, with respect to the underlying control criterion. A control criterion is an important way to focus thinking, while answering the question of dominance (Saaty, 2005). In order to learn the strength of dominance between two components, one should ask, "What is the relative importance of the first component compared with the second one with respect to influencing a certain criterion?” A fundamental scale was suggested by Saaty to collect data and perform pair wise comparison (Saaty, 1980). The nine-point priority scale to represent the intensities of judgments in ANP is shown in Table 4.

Table 4 Nine-Point Priority Scale for ANP

\begin{tabular}{|l|l|l|}
\hline $\begin{array}{l}\text { Intensity of } \\
\text { importance }\end{array}$ & Definition & Explanation \\
\hline 1 & Equal importance & $\begin{array}{l}\text { Two activities (row and column components) } \\
\text { contribute equally to the objective }\end{array}$ \\
\hline
\end{tabular}




\begin{tabular}{|l|l|l|}
\hline 3 & $\begin{array}{l}\text { Moderate } \\
\text { importance }\end{array}$ & $\begin{array}{l}\text { Experience and judgment slightly favor one (row } \\
\text { component) over another (column component) }\end{array}$ \\
\hline 5 & Strong importance & $\begin{array}{l}\text { Experience and judgment strongly favor one (row } \\
\text { component) over another (column component) }\end{array}$ \\
\hline 7 & $\begin{array}{l}\text { Very strong } \\
\text { importance }\end{array}$ & $\begin{array}{l}\text { An activity (row component) is strongly favored } \\
\text { over another (column component), and its } \\
\text { dominance is demonstrated in practice }\end{array}$ \\
\hline 9 & $\begin{array}{l}\text { Extreme } \\
\text { importance }\end{array}$ & $\begin{array}{l}\text { The evidence favoring one activity over another is } \\
\text { of the highest possible order of affirmation, i.e. } \\
\text { overwhelming dominance of an activity (row } \\
\text { component) is over another (column component) }\end{array}$ \\
\hline $2,4,6,8$ & Intermediate & $\begin{array}{l}\text { Used to represent compromise between the } \\
\text { priorities listed above }\end{array}$ \\
\hline
\end{tabular}

The pair wise comparison is usually handled in a matrix format, where the diagonal is rated as 1 (equal importance). Then, the top triangle is used to enter the scores for each row-column component pair, and their reciprocal values are automatically assigned to the reverse triangle within the matrix. When the pair wise comparisons are completed, the relative importance values are used to calculate the eigenvector of each of the constructed matrices. The consistencies of judgments need to be computed, as it can be a problem during the ANP process. Saaty set three acceptable levels for consistency as 0.05 for 3 by 3 matrix, 0.08 for 4 by 4 matrix, and 0.1 for other matrices (Saaty, 1994). 
After the consistency levels are satisfied for each matrix, they are combined to form the supermatrix (Saaty, 1996). The supermatrix represents the influence priority of an element on the left of the matrix on an element at the top of the matrix (Saaty, 2005). There is a three-step procedure in supermatrix calculation (Saaty, 2001). The first step is composed of calculating the unweighted supermatrix directly from pair wise comparisons among components affecting each other. Second step includes generating the weighted supermatrix by considering the interactions between the clusters of components and then, normalizing the weighted supermatrix by making it column stochastic, i.e., sum of the column values add up to 1 . Third step is generating the limit supermatrix by raising the weighted supermatrix to powers, until it converges and remains stable. All of the columns in the supermatrix that stand for any nodes need to have the same value to complete stabilization. For the purpose of mathematical computation of supermatrix, commercially available software, such as SuperDecisions can be used. SuperDecisions, which was developed by William J. Adams of Embry Riddle Aeronautical University and Rozann W. Saaty, is an appropriate tool to solve decision problems with a network model (Saaty R. W., 2003). The supermatrix generated by the software gives the relative importance weights of clusters and nodes, so that the magnitudes of influence of each node on the decision problem are obtained.

ANP has been widely used in literature for project evaluation and selection (e.g., Meade \& Presley, 2002; Cheng \& Li, 2005), project location selection (e.g., Partovi, 2006; Tuzkaya, Onut, Tuzkaya, \& Gulsun, 2008), and performance measurement (e.g., Yurdakul, 2003; Cheng \& Li, 2006; Ozorhon, Dikmen, \& Birgonul, 2007). In this study, 
ANP is selected to perform construction method selection based on project conditions. The ANP decision model for CM selection is shown in Figure 5. The CM selection problem is composed of two clusters as project conditions and CM indicators. Project conditions are further decomposed into seven nodes, while $\mathrm{CM}$ indicators are decomposed into three nodes. As it can be observed from the arrows, there is an inner dependence in the project conditions and an outer dependence between two clusters.

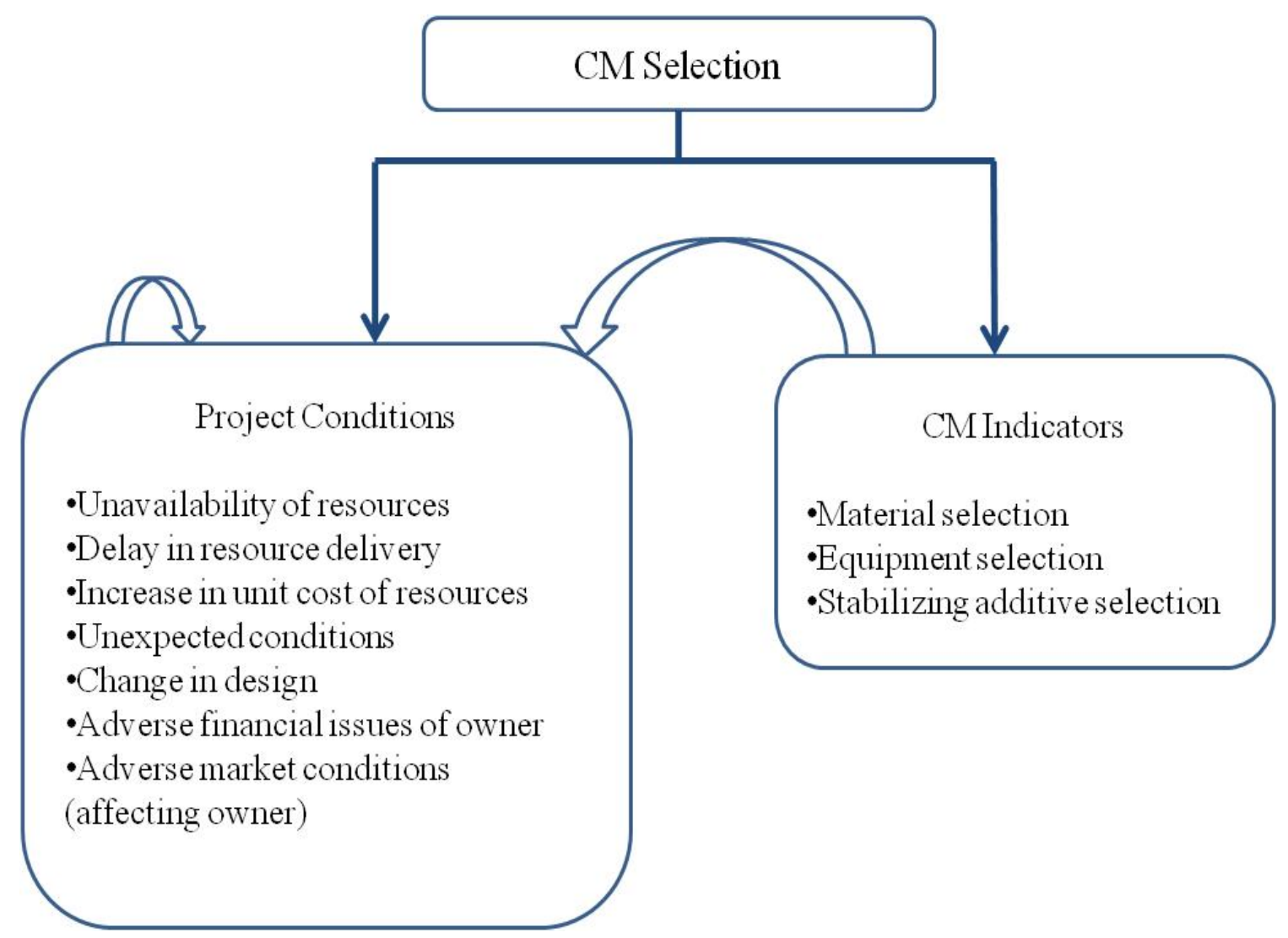

Figure 5 ANP Decision Model for CM Selection 
The decision problem is constructed based on the main steps of ANP and the utilization of ANP results to select the best construction method. The essential steps of the decisionmaking process with ANP are shown in Figure 6.

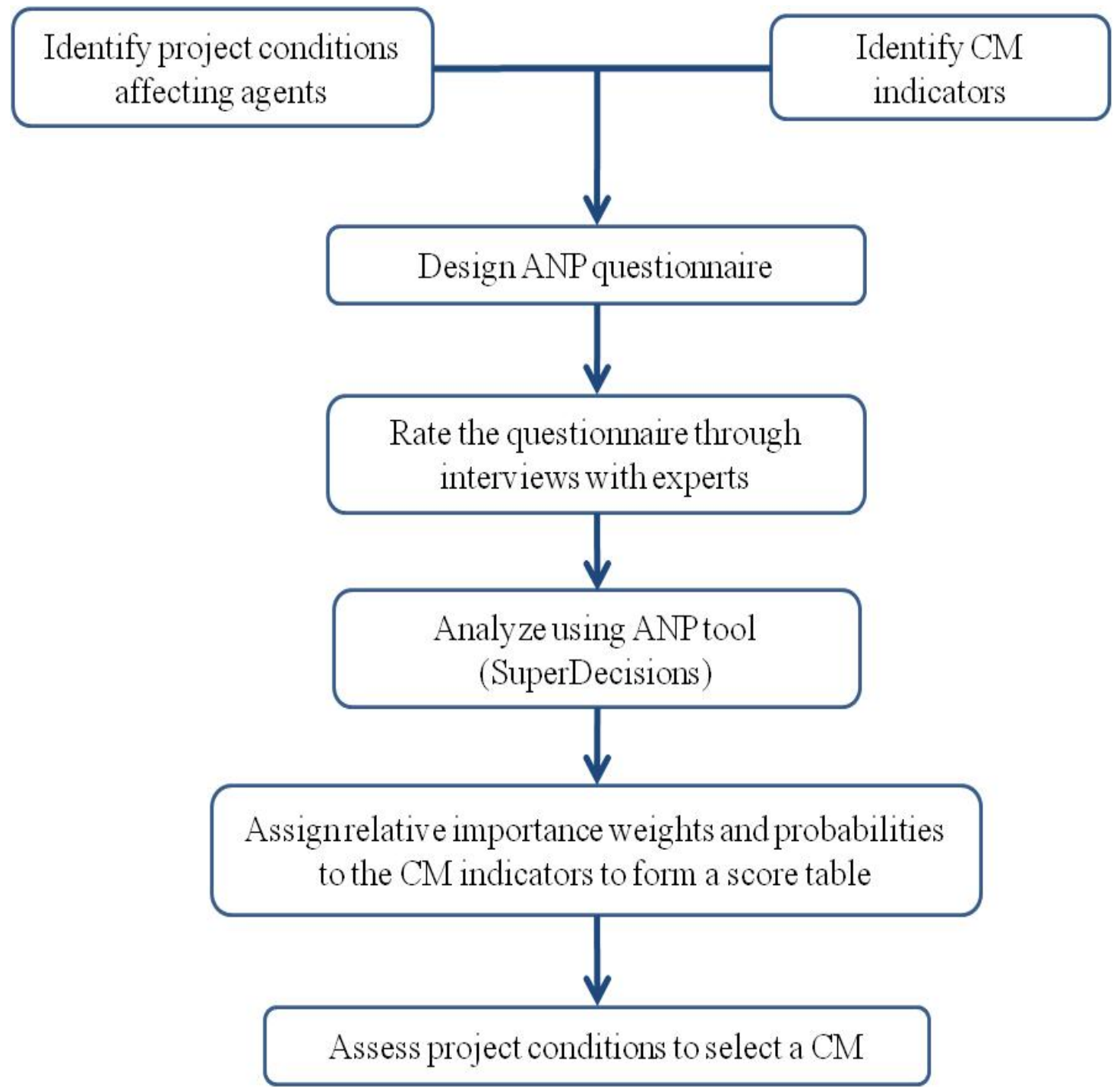

Figure 6 Decision-Making Process with ANP

The first two steps involved the identification of project conditions affecting agents and $\mathrm{CM}$ indicators. The indicators are defined based on common properties of construction 
operations. Material selection, equipment selection, and stabilization performance of the highway are selected to reflect CM properties. The process of defining project conditions affecting contractor and owner has already been mentioned in the Multi-Agent Systems (MAS) part. As given in Figure 4, adverse financial issues and adverse market conditions of owner cause change in design. This is regarded as interdependence in the project conditions cluster, which should be considered in designing ANP questionnaire. The questionnaire needs to be designed in a matrix format to compare components between and within clusters. It is rated through interviews with professionals, who are best to assign weights to the criteria. The ratings are entered based on pair wise comparison between row and column components and by using the nine-point priority scale. The individual ratings for each matrix are analyzed by using the ANP tool SuperDecisions. After the analysis, the $\mathrm{CM}$ indicators are assigned relative importance weights based on project conditions. The questionnaire further includes sections to ask for the probability of occurrence of each condition. The probabilities are used with the relative importance weights to form a score table for each $\mathrm{CM}$ indicator. The multiplication of probability and relative importance weight of each condition defines the influence of the condition on the $\mathrm{CM}$ indicators. For example, unavailability of resources has its probability and impact from user opinions and ANP results. When the two values are multiplied, this condition is represented by a numerical value. This process is repeated for three CM indicators. Thus, each condition has three numerical values for material, equipment, and stabilizing additive selection. When the numerical values for seven conditions are calculated for all $\mathrm{CM}$ indicators, the relative importance weights of $\mathrm{CM}$ indicators are used to combine results and select the most feasible resources for the project. In order to 
achieve the selection, the ranges in the score tables are matched with the corresponding CMs. As an example, when material score falls in a certain range material type-1 is selected to be used in the project. The same logic applies to equipment and stabilizing additive selection. The ranges or boundaries to select resources are generated by analyzing opinions of professionals. The highway construction professionals were asked questions to give importance to different project conditions, resource types, and project objectives. As one of the aims of this study is to observe the impact of changing project conditions on the relationship of TCEI, the professional opinions and decision-making tools are used to analyze $\mathrm{CM}$ selection process, under the influence of different conditions. By this way, the project conditions are further assessed with the project goals (TCEI) to select the most feasible CM. Details about data collection and processing for the $\mathrm{CM}$ selection will be given in the Experimentation and Validation section.

\subsection{Systems Dynamics (SD) Model for Construction Projects}

In order to overcome the aforementioned shortcomings, the proposed SD model uses rework cycle and generates the decision-making mechanisms of agents based on the change in project conditions, as well as the project goals (TCEI). Project conditions help to define decision rules by using qualitative information, while the calculation procedure for TCEI that is integrated in the SD model enhances the simulation by providing quantitative information. These two processes need to be integrated in the complex construction system. For this purpose, the set of sub-systems and the relation between sub-systems are defined for construction projects. The sub-systems are classified as decision-making system and project system. SD is used to integrate project objectives 
(TCEI), decision-making and project sub-systems. The development model that is used for SD simulation is shown in Figure 7.

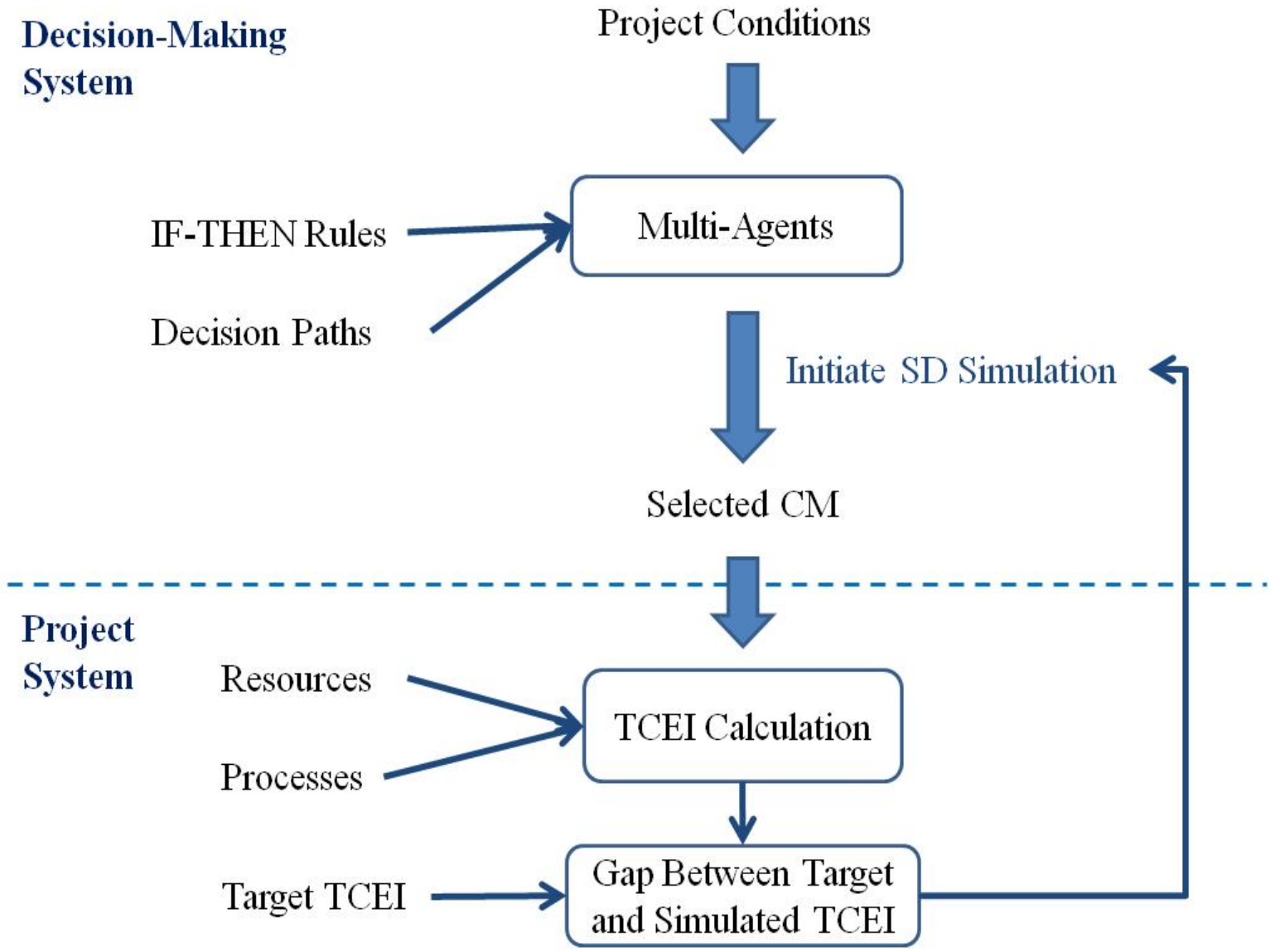

Figure 7 Development Model for SD Simulation

The decision-making system is composed of agents and their decision paths. The properties of these topics have already been summarized in the Multi-Agent Systems (MAS) part. As a reminder, the decision paths of owner and contractor agents are influenced by seven conditions. The most feasible construction method is selected by the contractor under the influence of project conditions. Selected construction method is 
entered into the project system. The project system includes project processes and resources to calculate the project goals, TCEI. By this way, the decision-making and project systems are related through construction methods.

The first step to develop a model is to define a language that represents conditions, actions and activities in the system domain (Rojas \& Mukherjee, 2006). A common language allows not only reusing, but also combining the information of input variables. By this ways, system produces various scenarios to optimize. This ability makes the framework generic enough to be used in the simulation of different types of projects with multiple objectives. Therefore, a common language and platform is generated to simulate the construction environment by SD modeling.

\subsubsection{The Decision-Making System}

First, decision-making system is handled in detail. In order to present a mathematical formulation of the flow, input and output parameters of the SD model are given unique codes. For example, the input parameters for the decision-making system are project conditions to generate decision rules of agents. In this case, conditions should be defined in a consistent format. The project conditions are numbered from 1 to 7 , and their codes are shown in Table 5.

Table 5 Codes for Project Conditions

\begin{tabular}{|l|l|}
\hline Code & Project Conditions \\
\hline
\end{tabular}




\begin{tabular}{|l|l|}
\hline C1 & Adverse financial issues of owner \\
\hline C2 & Adverse market conditions (affecting owner) \\
\hline C3 & Change in design \\
\hline C4 & Unavailability of resources \\
\hline C5 & Delay in resource delivery \\
\hline C6 & Increase in unit cost of resources \\
\hline C7 & Unexpected conditions \\
\hline
\end{tabular}

As mentioned before, each condition is described by its importance weight (IW) and probability of occurrence (P). IWs and Ps are presented by the numbers of their project conditions. The relations between project conditions and their indicators (IWs and Ps) are shown in Figure 8.

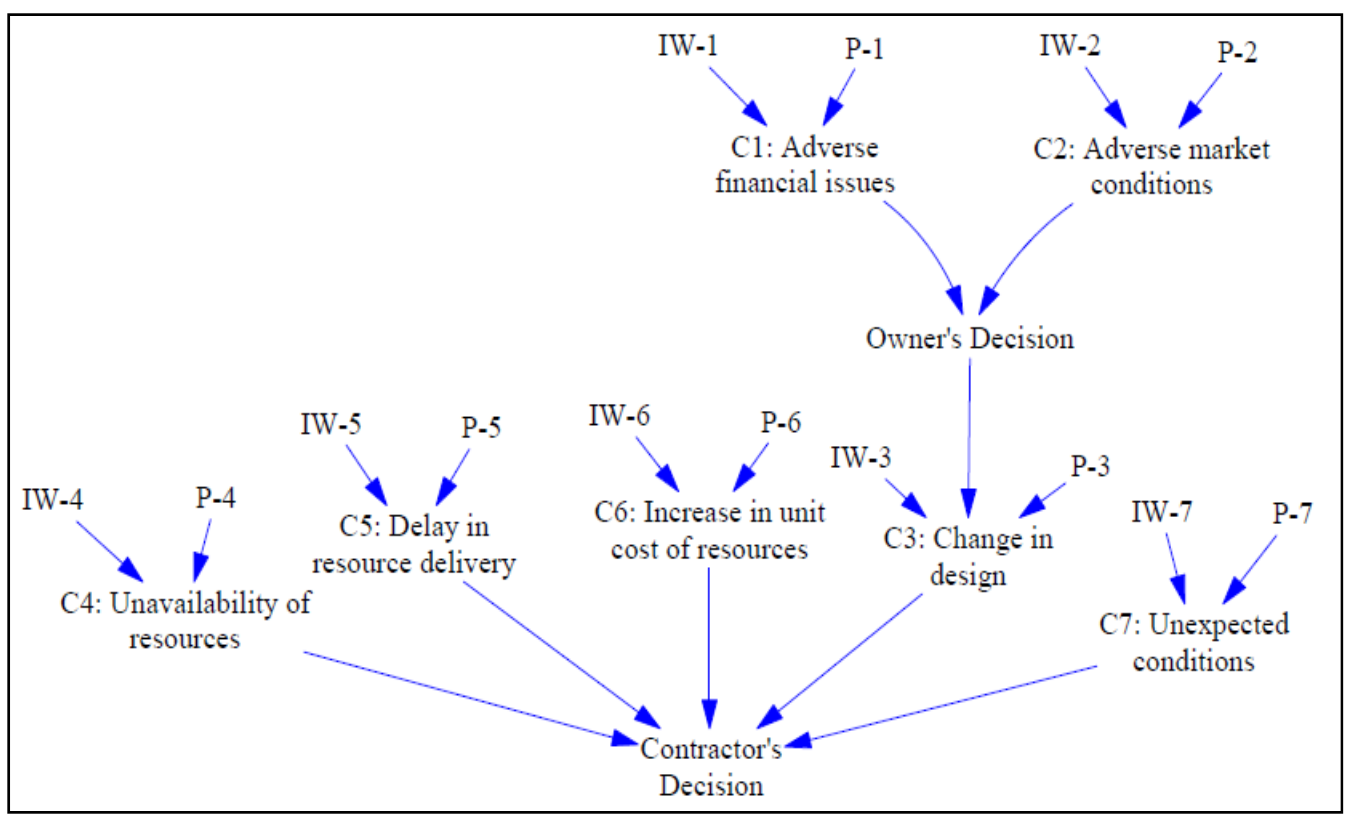

Figure 8 Relations between Project Conditions and Their Indicators 
IW values are obtained from the ANP model results, while P values are directly input by the user. The decision-making mechanisms of agents are distributed among the CM indicators. As the three $\mathrm{CM}$ indicators (material selection, equipment selection, and stabilizing additive selection) will have different IW results from the ANP analysis, the IW coding is further detailed to have a prefix that stands for the $\mathrm{CM}$ indicator. For example, for material selection, the importance weight of the first condition is coded as MAT-IW-1. For equipment selection, the code for the same condition is EQUI-IW-1, while for stabilizing additive selection; it is STAB-IW-1. As the probabilities are the same for different $\mathrm{CM}$ indicators, they are only symbolized with the conditions number, i.e., P-1 for the first condition.

The mathematical formulation for each project conditions is created based on the language of the SD software Vensim. Vensim PLE software was developed by Ventana Simulation Environment (Vensim, 2007). Being a user-friendly tool that is capable of presenting and analyzing flows and controls in a SD model (Bousquet \& Le Page, 2004), Vensim is selected to perform the SD simulation in this study. The Vensim CM selection model and the functions of the decision-making system that are generated in Vensim are shown in Appendix A.

The selection of CM is performed to find out the most feasible resource plans to satisfy TCEI under the impact of project conditions. Therefore, the questionnaire asks the performance of the material types with respect to decreasing time, cost and 
environmental impact, as well as the relative importance weights of TCEI. The performance of the material types is used to define boundaries where the contractor selects a certain construction method for the project. Thus, they are reflected in the functions of the CM Selection control unit in the Vensim model. The decision-making is performed by using IF-THEN rules, where IF part is the CM indicators and THEN part is the selected construction method.

The relative importance weights of TCEI with respect to the project success criterion can be estimated in two ways. The first way is to the eigenvector of the TCEI pair wise comparison matrix manually. The algorithms to calculate the eigenvector is present in literature (Cheng \& Li, 2001). Alternatively, the second way is to form a small ANP model and use SuperDecisions for the eigenvector that presents the relative importance weights of TCEI. Using the software is preferred in this study to prevent computation mistakes that can arise from the manual calculation procedure.

The project success ANP model constructed with SuperDecisions is shown in Figure 9. Project success is defined as the goal of the model. The determinants of the project success are defined in a separate cluster including nodes time, cost and environmental impact. The nodes of the Determinants cluster are compared with respect to the Goal cluster. Therefore, the arrow for the interaction is drawn from project success (parent component) to time, cost and environmental impact (child components). The pair wise comparison matrix for the project success ANP model is shown in Figure 10. It should be noted that this is the neutral matrix given in SuperDecisions, i.e., no pair wise comparison 
has been entered and thus, all pairs have the value 1 (equal importance). The weighted matrix and the relative importance weights of TCEI will be presented in the Data Collection and Analysis for Decision-Making part.

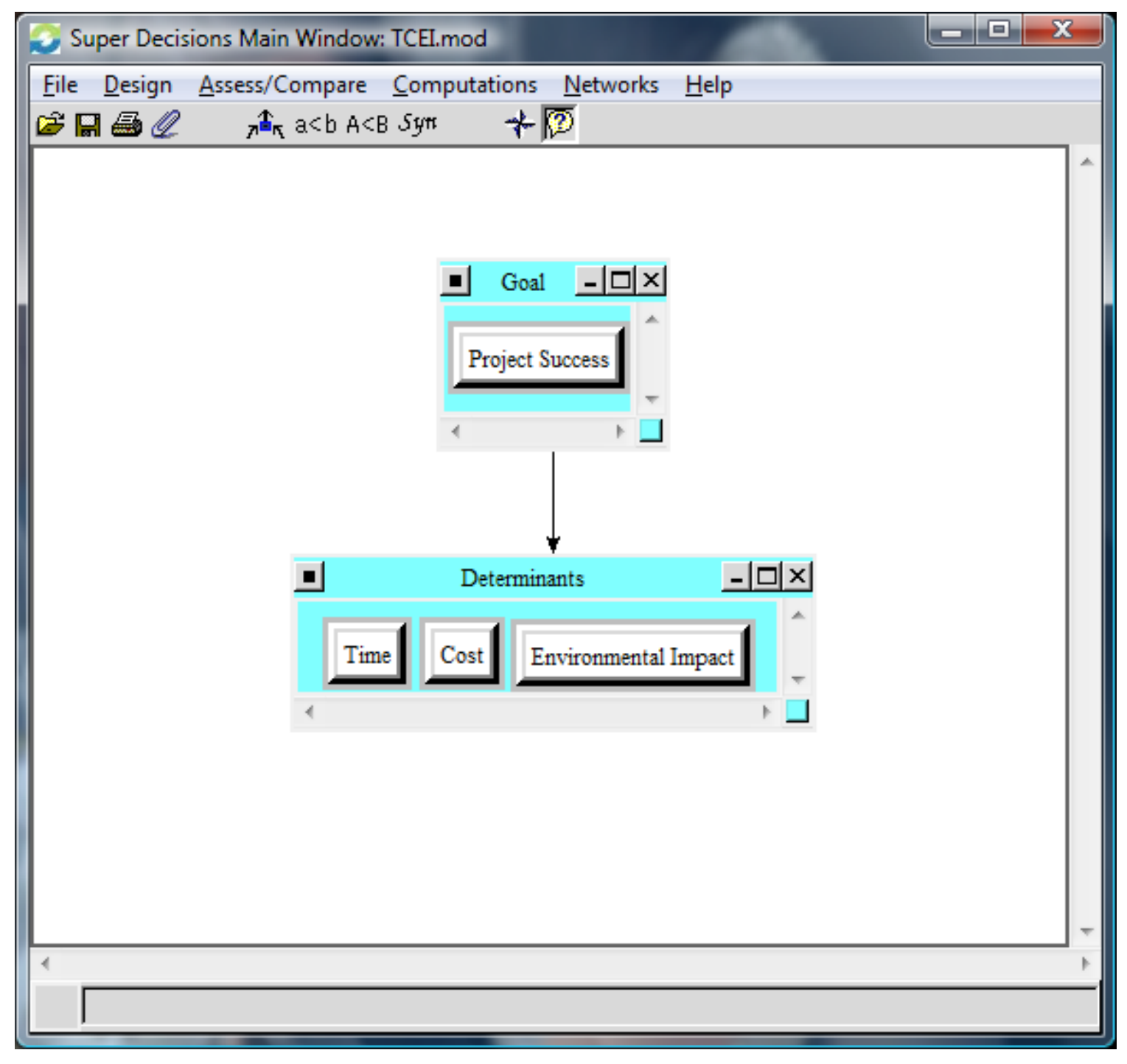

Figure 9 Project Success ANP Model 


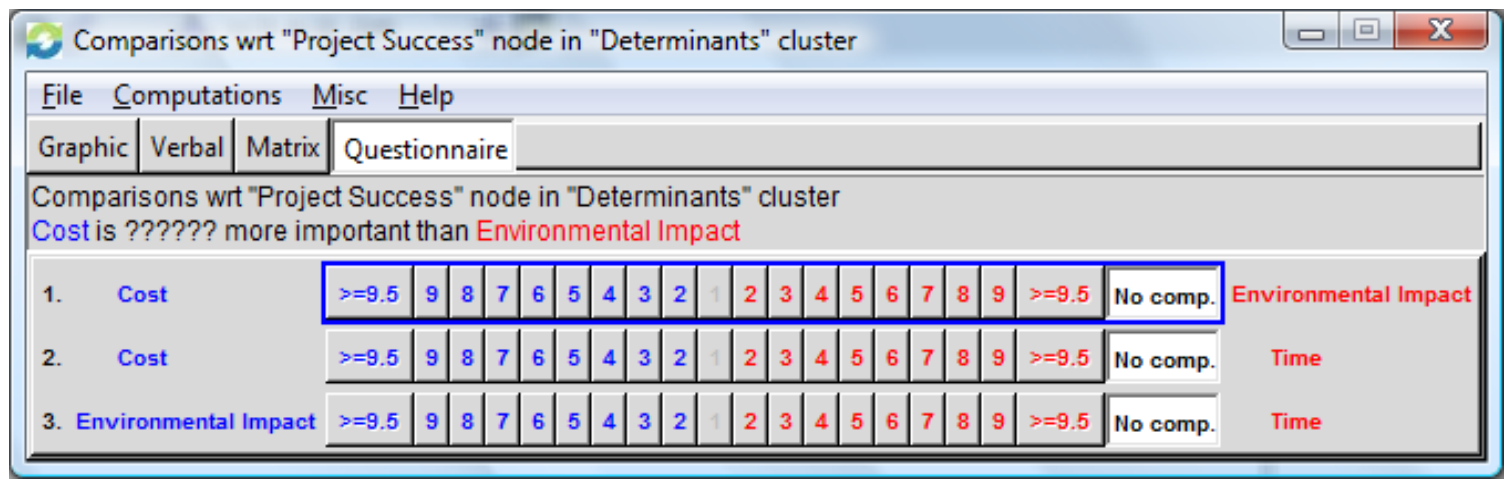

Figure 10 Pair Wise Comparison Matrix for the Project Success ANP Model

A set of construction methods is defined with its $\mathrm{CM}$ indicators (material selection, equipment selection, and stabilizing additive selection). First, the relative importance weights of project conditions with respect to material selection are multiplied by their probabilities to obtain the overall material score. Then, the relative importance weights of TCEI are used to calculate the weighted total score for each material type. When the material types are ranked according to project success, they are matched with the overall material score. The material matching the overall material score is selected for the project. The selection procedures for equipment and stabilizing additive are performed in the same manner. The CM selection is represented by IF-THEN rules. The CM selection function and the IF-THEN rules are shown in Equation 1, Equation 2, Equation 3, and Equation 4. The values for the constants (e.g. Y, Z, and K) for different i values will be derived from the ANP analysis in the Data Collection and Analysis for Decision-Making part.

$\mathrm{CMi}=\{\mathrm{Mi}, \mathrm{Ei}, \mathrm{Si}\}$

Equation 1 
IF Material Score $=Y$, THEN select Mi, where i $\in[0,5]$.

Equation 2

IF Mx = Mi \& Equipment Score $=$ Z, THEN select Ei, where i $\in[0,2]$.

Equation 3

IF Mx $=$ Mi \& Ex = Ei \& Stabilizing Additive Score $=$ K, THEN select

Equation 4 Si, where $i \in[0,2]$.

\subsubsection{The Project System}

The project system is composed of resources and processes related to the project, as well as TCEI calculation. When the construction method is selected by the contractor under the influence of project conditions, it is entered into the project system. The construction method is presented with the three $\mathrm{CM}$ indicators, as mentioned before. By using the $\mathrm{CM}$ indicators, the resource types for each activity are input to the simulation. Additionally, information, such as the resource quantities, unit costs, activity durations, and fuel consumptions of equipments are available in an MS Excel database to calculate project time, cost and GHG for each activity. The details of this calculation process will be given in the Data Collection and Analysis for TCEI Calculation part. After TCEI is calculated by using the MS Excel database, the output is further input to the control units in the project SD model. The Vensim project model is shown in $\underline{\text { Appendix B. }}$.

The TCEI calculated under the influence of project conditions are represented in the Project Time, Project Cost and Project GHG items in the project model. Then, this information is compared to the target time, cost and GHG entered by the user. The gap between project TCEI and target TCEI are calculated to find the suitability of the CM selected. The suitability of the $\mathrm{CM}$ selected is further used with the rework cycle to 
maintain the flow of the SD system. The details of the rework cycle will be explained in the next part.

\subsubsection{The Proposed SD Model}

This part integrates the decision-making and project SD models to generate the proposed SD model that will simulate the complex construction system. As in all SD models, the simulation in this study is also controlled by a rework cycle. The rework cycle is shown in Figure 11.

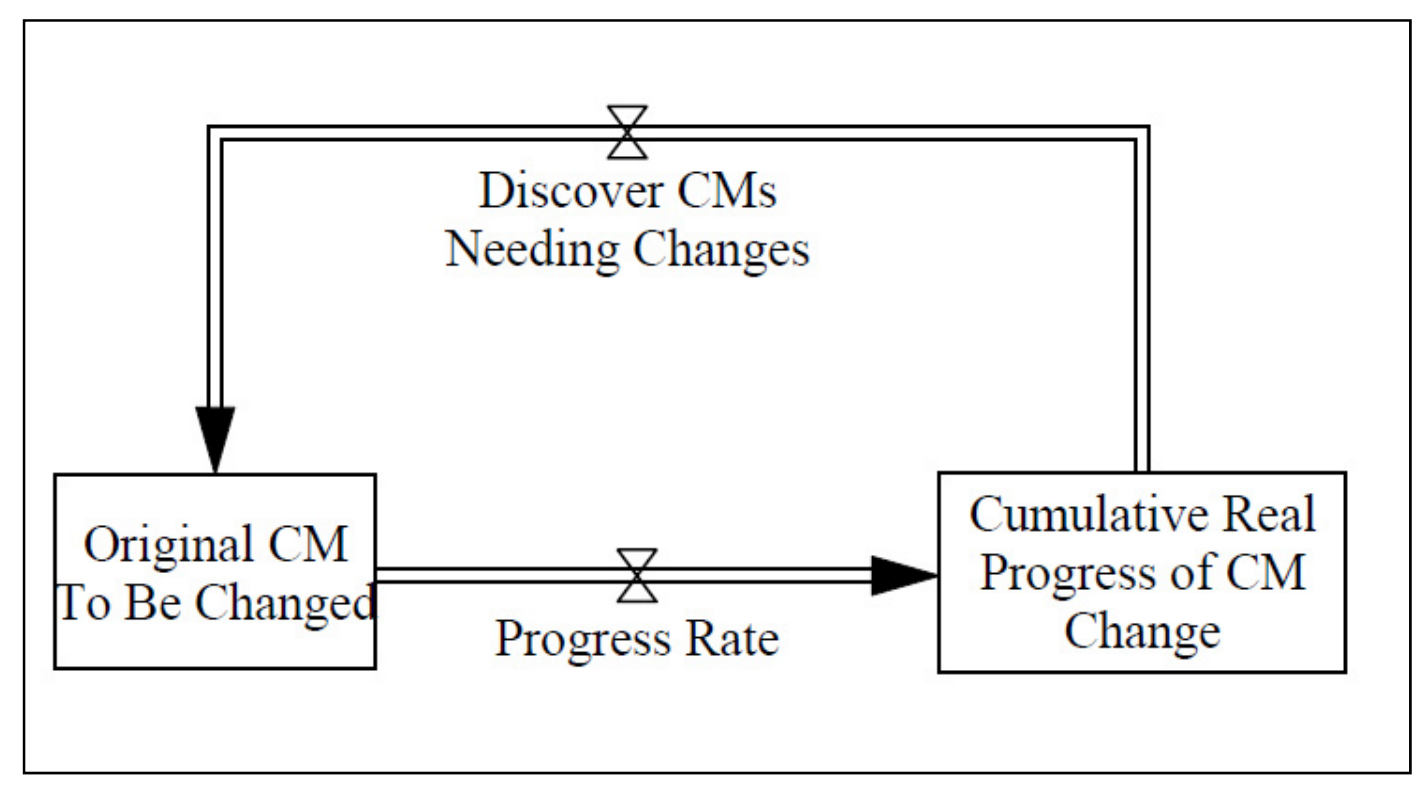

Figure 11 Rework Cycle

The rework cycle decides if the current construction method need to be changed, or it is the selected one to be used in the project. The flows Progress Rate and Discover CMs Needing Changes get inputs from the project system, and the stock Cumulative Real 
Progress of CM Change sends outputs to the decision-making system. By this way, the feedback loop is achieved in the proposed SD model.

The proposed SD model is shown in Figure 12. The complex system includes project conditions, agents' decision-making mechanisms, selected construction method and its resources, TCEI calculation, and the target TCEI for the project. The CM selection is decomposed into resources, which represents the outputs of the decision-making procedure of agents. Resources are selected based on the status of CM indicators and reflects the logic of the IF-THEN rules to perform decision-making. 


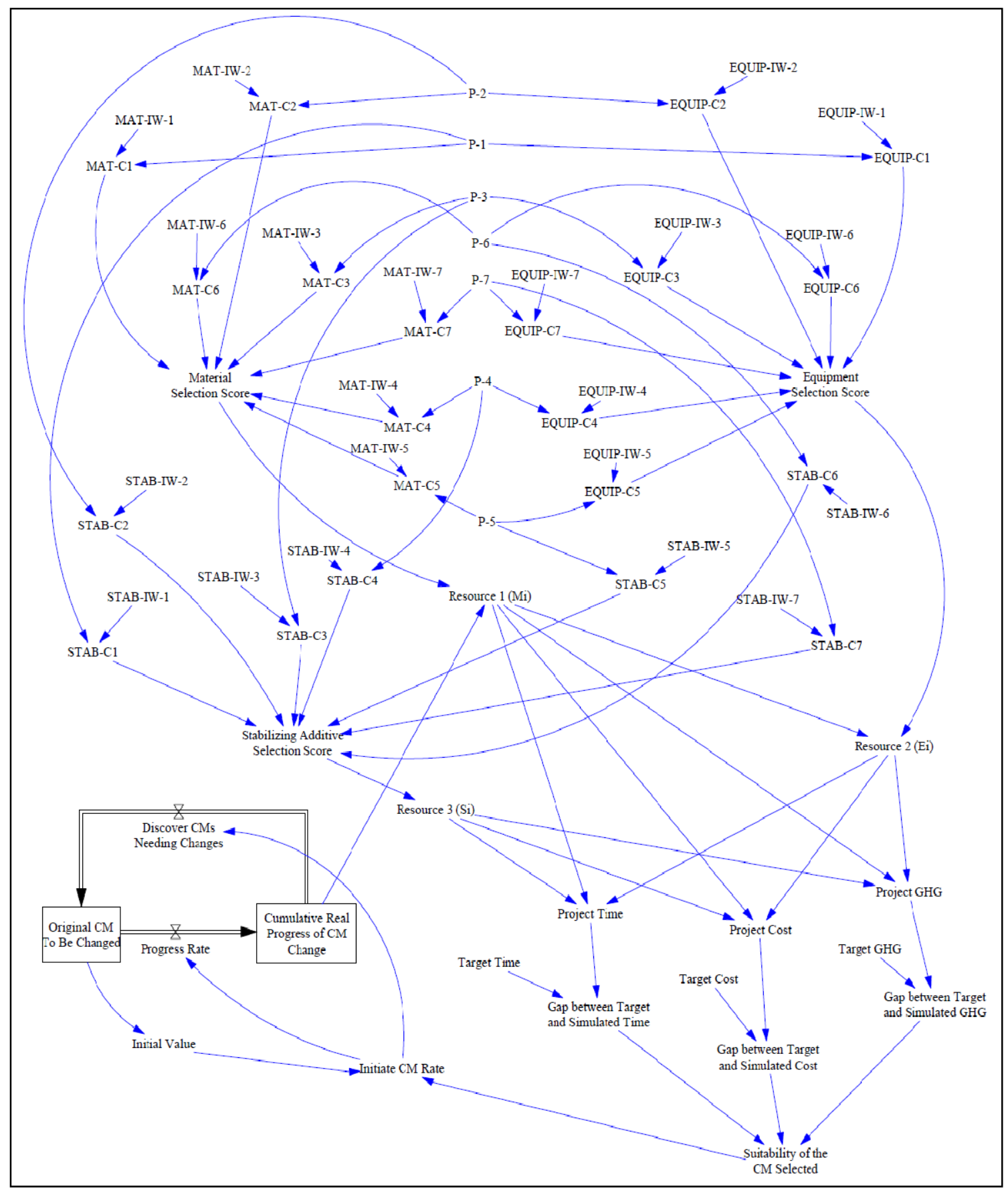

Figure 12 Proposed SD Model

The feedback loop takes place to simulate the $\mathrm{CM}$ selection process. As the interconnection between decision-making and project models are sustained through the 
CM selection items, i.e., resources, Resource 1 (Mi) receives Cumulative Real Progress of CM Change and controls the simulation. When the Cumulative Real Progress of CM Change command is received, the most feasible construction method is selected under the influence of project conditions. As mentioned in the Decision-Making System part, a set of construction method is defined with its $\mathrm{CM}$ indicators (material selection, equipment selection, and stabilizing additive selection). The $\mathrm{CM}$ indicators state which resources will be used in each activity. Then, the project time, cost and GHG are calculated and compared with the target time, cost and GHG for the project. The feedback from Suitability of the CM Selected is used to set Initial CM Rate, which is further entered into the rework cycle through flows. The simulation stops if the selected CM is suitable for the user. If it is not, the simulation continues to reach the desired suitability of the CM selected value or the minimum possible value set by the user. The functions for the Vensim proposed model are shown in Appendix C. 


\subsection{Multi-Objective Optimization}

The multi-objective optimization procedure is designed based on genetic algorithm literature and the outcomes of the proposed SD model, to look for the relationship between TCEI. The proposed system dynamics model is used to simulate the decisions of agents, as well as to reflect their influence on the construction processes. When the simulation is complete, the most feasible resource utilization plans are selected by the model for each set of input, and project TCEI values can be obtained as outcomes of the system. As the project conditions, agent systems, construction processes, and TCEI are linked through the system, the change in project conditions are reflected to the TCEI values in each simulation. The optimization analysis procedure is as follows:

1. Generate a population of solutions randomly.

2. Determine the fitness for each solution on the population.

3. Perform crossover and mutation.

4. Generate a new generation.

5. Check for convergence of solutions, if level of accuracy is adequate, then stop.

6. Repeat from step 2 as necessary.

\subsubsection{Random Population Generation}

In this study, a construction project is defined as a set of changing project conditions and their associated construction methods. The change in project conditions are defined as a set of probability of occurrences of $N$ conditions. " $i$ " denotes the $i^{\text {th }}$ condition, which will have a number of different probability values $\mathrm{L}_{\mathrm{i}}$. There are up to $U=\prod_{j=1}^{n} L i$ different inputs of project conditions, where $U$ is the universe of possible solutions. Thus, the size 
of the solution universe $U$ is equal to $L_{1} x L_{2} x \ldots x L_{n}$. This shows that the number of different inputs of probabilities is the array of all conditions of the project.

An example of population includes $S$ solutions. Each solution, represented by a chromosome, such as solution $m\left(\mathrm{~S}_{\mathrm{m}}\right)$, contains all conditions of a project, so the length of a chromosome is $n$. An example chromosome for a solution $m$ is shown in Figure 13. Each condition, as well as its probabilities $\left(\mathrm{P}_{\mathrm{i}}\right)$, are analyzed separately and have an associated value of time, cost and environmental impact.

Solution $m$

\begin{tabular}{|l|l|l|l|l|}
\hline $\mathrm{P}_{1}$ & $\mathrm{P}_{2}$ & $\mathrm{P}_{3}$ & $\cdots$ & $\mathrm{P}_{\mathrm{n}}$ \\
\hline
\end{tabular}

Figure 13 An Example Chromosome for Solution m

In order to find the different alternatives of construction methods, the proposed SD model is simulated with different inputs, such as the different probabilities of project conditions. The various combinations of probabilities for the seven project conditions resulted in selecting different construction methods. Each activity, as well as its alternatives, are analyzed separately based on the input probabilities, and have an associated value of time, cost and environmental impact. After the construction method is selected, a solution, $\mathrm{S}_{\mathrm{m}}$, is thus associated with three objectives, time, cost and environmental impact, defined as $\left(\mathrm{T}_{\mathrm{m}}, \mathrm{C}_{\mathrm{m}}, \mathrm{EI}_{\mathrm{m}}\right)$. Time $\mathrm{T}_{\mathrm{m}}$ is calculated as the project duration. Cost $\mathrm{C}_{\mathrm{m}}$ is the total cost of all activities of the solution. Environmental impact $\mathrm{EI}_{\mathrm{m}}$ is the total environmental impact, which refers to the total GHG emissions of all activities of the solution. The estimated time, cost and GHG values for different probability inputs form 
different population of solutions, which are used for the multi-objective optimization. Once the universe of possible solutions is obtained, random populations of solutions are generated by using different probability inputs and their associated TCEI values. The random population for the case study is discussed in detail in the Analysis and Results part.

\subsubsection{Objective Function and Fitness Evaluation}

The multi-objective optimization process searches for optimal/near optimal tradeoffs among minimizing project duration, project cost and project GHG. The objective functions (OFs) for time, cost and EI are expressed as in Equation 5, Equation 6, and Equation 7.

$\mathrm{OF}_{\mathrm{T}}=\operatorname{MIN}\left(\mathrm{T}_{\mathrm{m}}\right)$, where $\mathrm{m}=[1, \mathrm{U}]$

Equation 5

$\mathrm{OF}_{\mathrm{C}}=\operatorname{MIN}\left(\mathrm{C}_{\mathrm{m}}\right)$, where $\mathrm{m}=[1, \mathrm{U}]$

Equation 6

$\mathrm{OF}_{\mathrm{EI}}=\operatorname{MIN}\left(\mathrm{EI}_{\mathrm{m}}\right)$, where $\mathrm{m}=[1, \mathrm{U}]$

Equation 7

To understand the multivariable approach, an Euclidian space is defined having the variables T, C and EI, as shown in Figure 14. Each solution of project objectives can be plotted in the three-dimensional space, the origin of which has $(0,0,0)$ values for TCEI. In mathematical terms, it is correct to assume that an absolute dominant solution would be the origin of the space. However, it is clear that this is not possible in real terms, as there would not be any project with no cost, no duration and no environmental impact. The solutions are expected to lie in a certain boundary called the possibility frontier. For 
establishing the parameters of optimal solutions, the possibility frontier in the space created will have a set of limits. The lowest boundary would happen in the corner of the box created by the boundaries that is closer to the origin. This point will be calculated by selecting the minimum time, cost and environmental impact achievable in each activity and adding them accordingly to obtain the total minimum achievable.

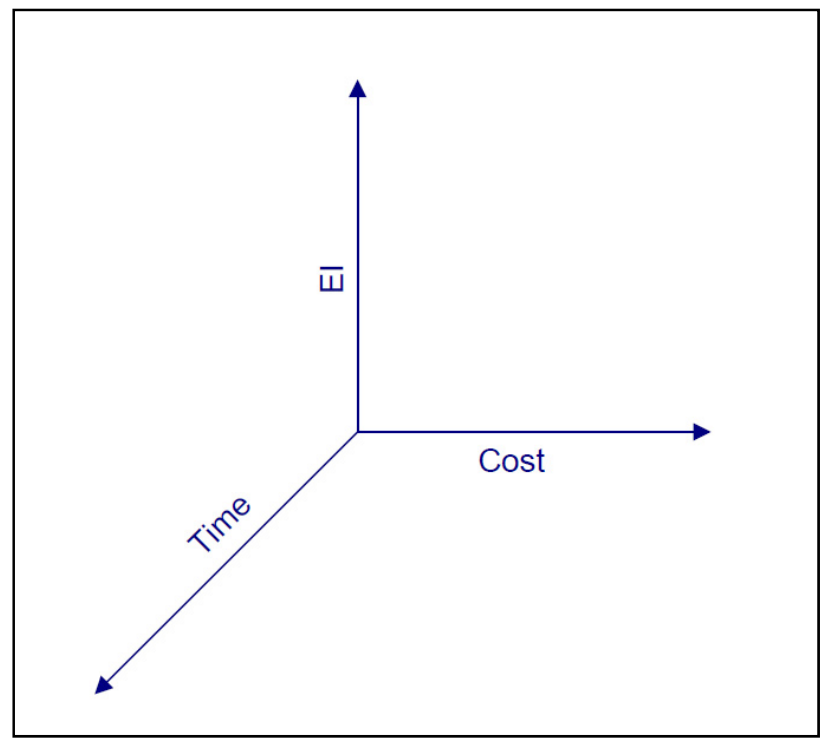

\section{Figure 14 Euclidian Space of TCEI}

This point will be considered as the origin of a new subspace containing all possible existing solutions only. An important point is that the dimensions of project objectives are different from each other. The estimated time, cost, and EI (i.e., GHG) are days, dollars (\$), $\mathrm{kg} \mathrm{CO} 2$ eq, respectively, and thus, they need to be normalized before the optimization. The new space of possible solutions is normalized using as an upper limit of the corresponding maximums of time, cost and environmental impact. The total difference between the maximum and the minimum on each dimension will have then a 
total dimension of one. The normalized values for time, cost and environmental impact for a solution $\mathrm{K}$ are calculated by using Equation 8, Equation 9, and Equation 10. The objective function utilizes the normalized values of the project objectives to find the optimal TCEI and its corresponding construction methods.

$$
\begin{aligned}
& \text { Normal } T_{K}=\frac{T_{K}-T_{\min }}{T_{\max }-T_{\min }} \\
& \text { Normal } C_{K}=\frac{C_{K}-C_{\min }}{C_{\max }-C_{\min }} \\
& \text { Normal } E I_{K}=\frac{E I_{K}-E I_{\min }}{E I_{\max }-E I_{\min }}
\end{aligned}
$$

Equation 9

Equation 10

The fitness function in Equation 11 is used to evaluate the performance of each solution. The performance is determined by a fitness function, which is defined as the total distance between the solution obtained and the origin in the new normalized subspace. A lower fitness value means a better solution as the solution is closer to the origin.

$$
f\left(T_{K}, C_{K}, E I_{K}\right)=\sqrt{\text { Normal }_{K}^{2}+\text { Normal }_{K}^{2}+\text { Normal EI }_{K}^{2}}
$$

Equation 11

Repetitive construction projects such as highway construction are restricted to certain activities and resources that are used repeatedly for different sections of the project. For this reason, the number of activities, as well as the number of alternative construction methods is limited in this case. Therefore, it is possible to create formulas and the objective function in the spreadsheet format to conduct multi-objective optimization. A 
population of solutions is generated randomly, and the normalized TCEI values are calculated. Then, the one or ones having the minimum fitness value, i.e., being closer to the origin of a new subspace, is selected to be in the optimal solution set.

\subsubsection{Selection of Solutions}

After the random population generation, fitness of chromosomes in the population tends to converge to a single solution. This is where a stopping criterion should be implemented to set the desirable convergence rate. The best possible answer is obtained by selecting the chromosomes considering the sorted fitness values of the population. The fitness values are sorted from the lowest to the highest. When the chromosomes in the resulting population comply with the criteria set in size and proximity, the most feasible solution is achieved, and the optimization process is finalized.

An application example will be analyzed in the following part to illustrate the use of the procedure in optimizing project duration, project cost and project GHG, while complying with the project conditions, such as the resource constraints. The results will be further used to observe the relationship between TCEI. 


\section{Experimentation and Application of the Proposed Framework}

This chapter provides a complete description of the research instruments that are used to collect and process data. This study has the mixed method approach, as qualitative data collection for decision-making and quantitative data collection for TCEI calculation. The details of both phases are provided together with their analysis methods. Then, the application of the proposed framework is presented by using two case studies from highway construction projects.

\subsection{Data Collection and Analysis for Decision-Making}

ANP is used together with the staticized groups method in this study to calculate the relative importance weights of decision components, i.e., project conditions. Then, the relative importance weights are used with the probability of occurrence of conditions. When the probabilities are multiplied with the relative importance weights for seven conditions, scores for the CM indicators are obtained separately. IF-THEN rules are designed to define the boundaries of CM scores in the decision-making SD model. The boundaries are utilized to form levels of scores. When the $\mathrm{CM}$ indicator falls in a certain level, the system selects a certain type of material. As an example, when the material selection score is 15 (out of 100), the system selects the material type that falls in the level $[0,20]$. The boundary values ( 0 and 20 in this case) are obtained from professional opinions. Professionals are asked to state their ideas about the performance of materials, so that the best performing material is identified. Then, the best performing material is assigned to the cases that experience the majority of change in project conditions. The 
same logic applies for equipment and stabilizing additive selection. IF-THEN rules were given in the generic equation format in the System Dynamics Model Design part.

As mentioned before, ANP and the staticized groups method allow performing decisionmaking based on project conditions in the complex construction system. In this section, the ANP decision model will be discussed in detail.

The ANP decision problem is constructed by using four main steps as problem structuring and model construction, preparation of pair wise comparison matrices of interdependent component levels, supermatrix formation, and determination of the relative importance weight of each factor. The decision problem is identified and decomposed into a set of manageable and measurable levels by using SuperDecisions software developed by William J. Adams and Rozann W. Saaty (Saaty, 2003).

\subsubsection{The ANP Decision Model Construction}

The first step is to construct the ANP decision model. The ANP model is composed of two parts, as a control hierarchy that control the interactions (interdependencies and feedback) and a network of influences among the components in different levels of the system. The top-most level components are called clusters, and they are further decomposed into nodes. For the goal of CM selection, favorability of project conditions and resource performance are defined as major determinants. These determinants are further decomposed into nodes in the next level of the system. The ANP decision model constructed with SuperDecisions is shown in Figure 15. 


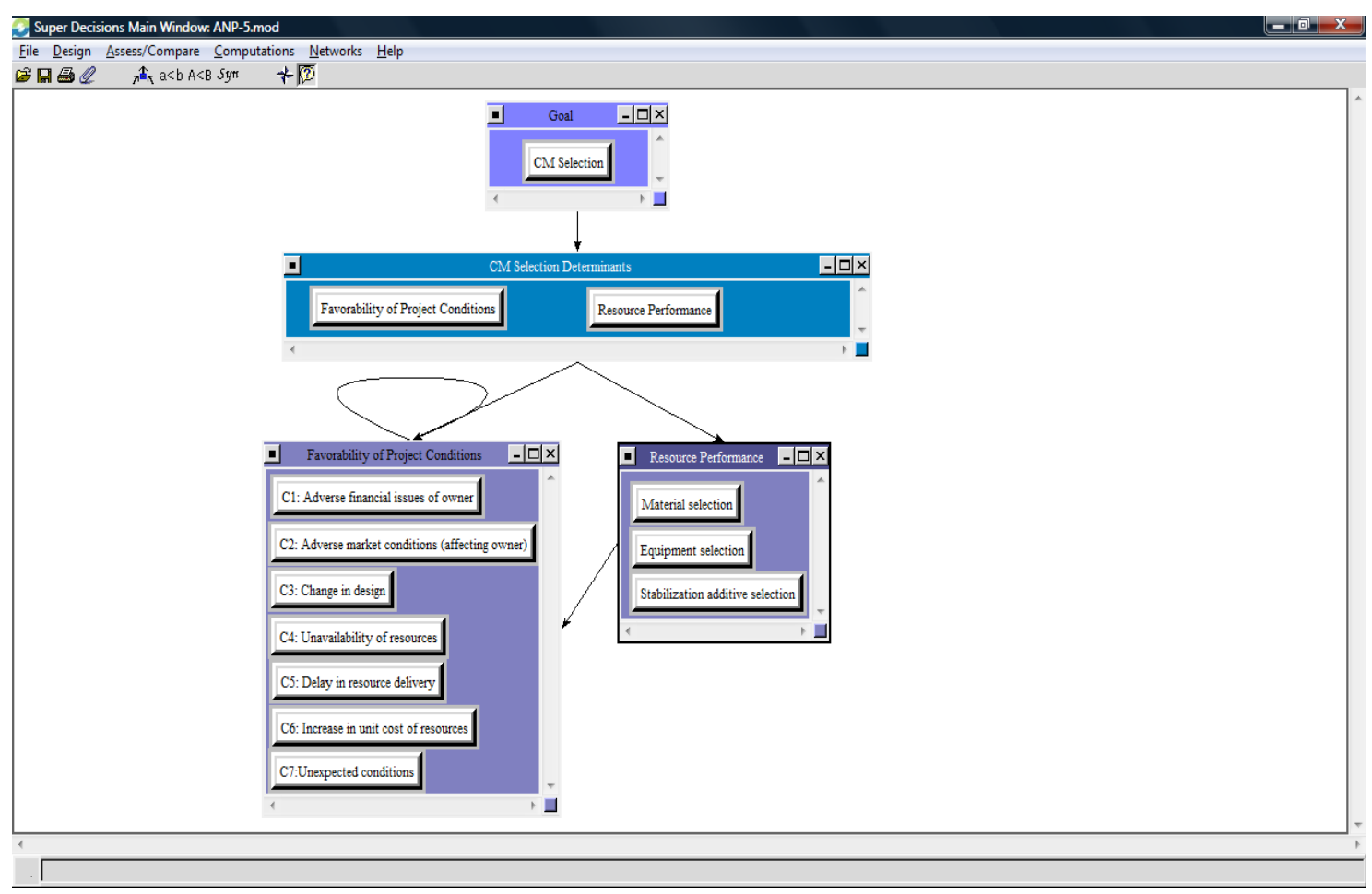

Figure 15 ANP Decision Model Constructed with SuperDecisions

Project conditions from $\mathrm{C} 1$ to $\mathrm{C} 7$ are nodes for the favorability of project conditions cluster, while material selection, equipment selection, and stability additive selection are nodes for the resource performance cluster. The arrows in Figure 15 indicate the interactions (i.e., interdependencies and feedback) within the clusters, as well as between the clusters and nodes. The arrows are drawn from the parent component to the child components. The parent component stands as the control criterion to compare two or more child components. For example, CM selection is the parent component for favorability of project conditions and resource performance. Then, favorability of project conditions and resource performance are compared with respect to $\mathrm{CM}$ selection. This type of straight arrows shows outer dependencies among clusters and among nodes. On 
the other hand, loop arrows that start from and finish on the same cluster stands for inner dependencies within a cluster. For instance, the loop arrow for the favorability of project conditions shows that some of the project conditions affect the others that are in the same cluster.

\subsubsection{Pair Wise Comparison Matrices of Interdependent Components}

The second step is to prepare pair wise comparison matrices based in the ANP decision model. As mentioned in the Decision Model with ANP part, ANP uses professional judgments in the form of pair wise comparisons to obtain relative importance of components, with respect to the underlying control criterion. The components and their underlying control criterion are observed from the inner and outer dependencies in the model. When the dependencies are set, pair wise comparisons can be generated.

The relative importance weights of components are calculated through interviews and discussions with professionals. Structured interviews of professionals in the highway construction field were conducted to gain their perspectives in decision-making under the influence of certain project conditions. Four interviews were conducted with professionals. Although there is no minimum number of interviews set for ANP in literature, it can be stated that the consistency of interviews were satisfactory to have observations and fulfill the principles of this research. Pavement Design Survey that is created to collect professional judgments is shown in the Appendix D. Questions 1-7 in the survey intend to collect data for ANP analysis. The pair wise comparison matrices are formed for each interaction within and between clusters in the ANP decision model. The 
experts were asked to fill the pair wise comparison matrices by using the nine-point priority scale. The staticized groups method is used to aggregate the judgments of individuals.

The staticized groups technique is described as the Delphi method with one round of estimates (Dayananda, Irons, Harrison, Herbohn, \& Rowland, 2002). Hallowell and Gambatese define staticized groups as an alternative to the Delphi method without feedback or iteration (Hallowell \& Gambatese, 2010). There are several studies in literature to compare staticized and interacting groups methods (e.g., the Delphi method). Some studies concluded that staticized groups perform better (Hackman \& Morris, 1975; Boje \& Murnighan, 1982), while some others stated that there is "little or no difference" in their performances (Fischer, 1981; Sniezek, 1990). Erffmeyer and Lane converted individual judgments to group scores and found that there are significantly higher correlations between these measures in the results of staticized groups than in the outcomes of interacting groups (Erffmeyer \& Lane, 1984). The Delphi method requires individuals to interact with the group and alter their opinions to conform to a group decision, which may cause the individual to imply conformity without actually changing his/her opinion (Rohrbaugh, 1979). Considering the performance of staticized groups over interacting groups method, in addition to the availability and schedules of professionals, staticized groups technique is used in this study. The method aims to find out the statistical average of the individuals' judgments, while increasing the reliability of ANP. The ANP pair wise comparison matrices that are formed by the results of the structured interviews are shown in Appendix E. 


\subsubsection{Supermatrix Formation}

The third step is to synthesize pair wise comparison matrices to form the supermatrix. There is a three-step procedure in supermatrix calculation, as mentioned before in the Decision Model with Analytic Network Process (ANP) part. The unweighted supermatrix (derived directly from pair wise comparisons), the weighted supermatrix (normalized by making it column stochastic, i.e., sum of the column values add up to 1), and the limit supermatrix (stabilized the weighted supermatrix until all of the columns have the same value) are generated with SuperDecisions software. The unweighted, weighted, and limit supermatrices are shown in Appendix F.

\subsubsection{The Relative Importance Weights of Factors}

The last step is to compute the relative importance weight of each node on construction method selection. The limit supermatrix created by SuperDecisions presents the relative importance weights as priorities for all nodes in the model that sum up to 1 . The priorities are also available as normalized by cluster, i.e., priorities sum up to 1 in each cluster. The relative importance weights of nodes are shown in Figure 16, as normalized by cluster and as given in the limit supermatrix. Consistency ratios were found to be less than 0.10 . 


\begin{tabular}{|c|c|c|c|c|}
\hline \multicolumn{3}{|c|}{20 Super Decisions Main Window: ANP-5-with weights.mod: .... } & $\square \square$ & Х) \\
\hline \multicolumn{5}{|c|}{ Here are the priorities. } \\
\hline Icon & Name & Normalized by Cluster & Limiting & 인 \\
\hline No Icon & $\begin{array}{l}\text { Favorability of Project } \\
\text { Conditions }\end{array}$ & 0.24998 & 0.089305 & \\
\hline No Icon & Resource Performance & 0.75002 & 0.267943 & \\
\hline No Icon & $\begin{array}{l}\text { C1: Adverse financial } \\
\text { issues of owner }\end{array}$ & 0.22169 & 0.083091 & \\
\hline No Icon & $\begin{array}{c}\text { C2: Adverse market } \\
\text { conditions (affecting ow }\end{array}$ & 0.16524 & 0.061932 & \\
\hline No Icon & C3: Change in design & 0.04685 & 0.017561 & \\
\hline No Icon & $\begin{array}{l}\text { C4: Unavailability of } \\
\text { resources }\end{array}$ & 0.23607 & 0.088482 & \\
\hline No Icon & $\begin{array}{l}\text { C5: Delay in resource } \\
\text { delivery }\end{array}$ & 0.26938 & 0.100966 & \\
\hline No Icon & $\begin{array}{l}\text { C6: Increase in unit cost } \\
\text { of resources }\end{array}$ & 0.03753 & 0.014068 & \\
\hline No Icon & c7:Unexpected conditions & 0.02323 & 0.008708 & \\
\hline No Icon & CM Selection & 0.00000 & 0.000000 & \\
\hline No Icon & Equipment selection & 0.18181 & 0.048714 & \\
\hline No Icon & Material selection & 0.27272 & 0.073073 & \\
\hline No Icon & $\begin{array}{l}\text { Stabilization additive } \\
\text { selection }\end{array}$ & 0.54547 & 0.146155 & $\vee$ \\
\hline Okay Co & opy Values & & & \\
\hline
\end{tabular}

\section{Figure 16 Relative Importance Weights of Nodes}

\subsubsection{Selection Score Table}

The CM selection table was formed in two parts. In the first part, the relative importance weights of the project success ANP model were calculated to define the boundary conditions. In the second part, the relative importance weights of the ANP decision model were used with the probabilities of occurrences and TCEI ratings to find out the material, equipment, and stabilizing additive scores. 
As mentioned in the Decision-Making System part, the project success ANP model need to be analyzed to generate IF-THEN rules for the CM selection score table. The weighted matrix for project success determinants is shown in Figure 17. In order to obtain scores in this matrix, the professionals were asked pair wise comparison questions between cost \& environmental impact, cost $\&$ time, and environmental impact $\&$ time. The question was in the format "What is the relative importance of Cost compared with Environmental Impact with respect to achieving project success?" The answer was "Cost is strongly more important than Environmental Impact with respect to achieving project success." This answer was converted to a numerical value (5 in this case) based on Nine-Point Priority Scale for ANP given in Decision Model with Analytic Network Process (ANP) part. Similarly, for cost \& time, the experts rated as "Cost is equally important as Time with respect to achieving project success." and for environmental impact \& time, "Time is moderately more important than Environmental Impact with respect to achieving project success." The numerical values for cost \& time and environmental impact \& time were entered as 1 and 3 respectively.

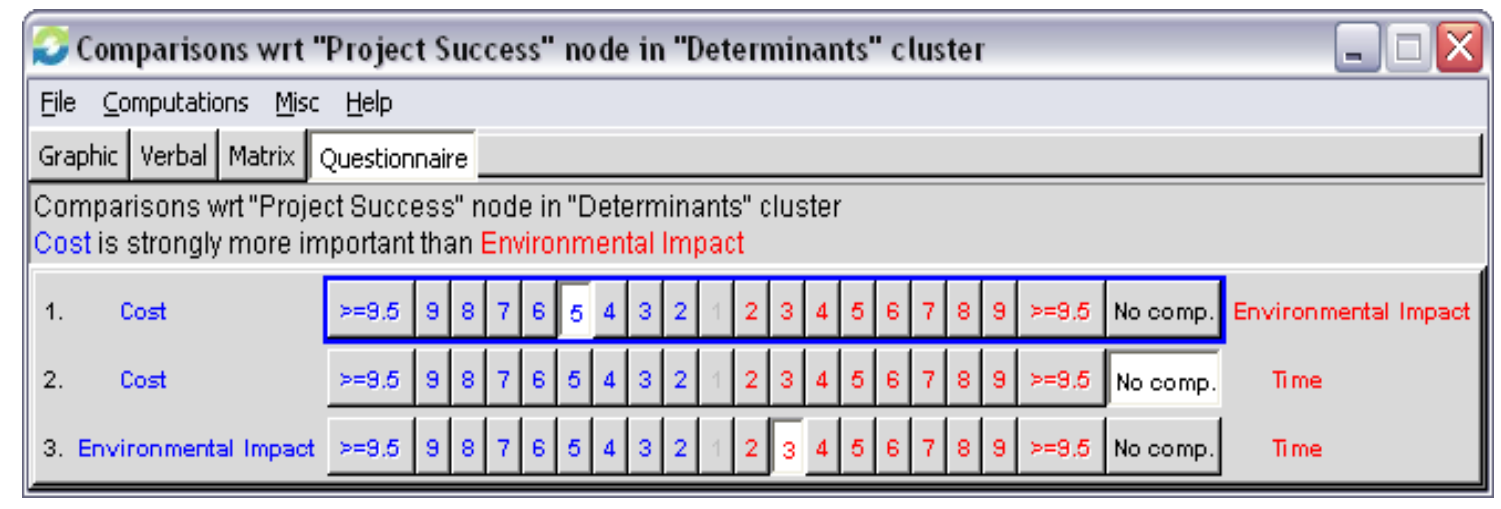

Figure 17 Weighted Matrix for Project Success Determinants 
The weighted matrix was used to run the model in SuperDecisions and calculate the relative importance weights of TCEI. In the project success ANP model, there are no nodes for TCEI clusters. Therefore, the unweighted, weighted, and limit supermatrices had the same results. Similarly, the priorities obtained as normalized by cluster and as given in the limit supermatrix were equal. The relative importance weights of TCEI calculated in SuperDecisions are shown in Figure 18.

\begin{tabular}{|c|c|c|c|c|}
\hline 3 Sup & er Decisions Main & th weights.mod:... & $=\square$ & X \\
\hline & $\mathrm{He}$ & orities. & & \\
\hline Icon & Name & $\longdiv { \text { Normalized by Cluster } }$ & $\longdiv { \text { Limiting } }$ & 슨 \\
\hline No Icon & Cost & 0.55534 & $\longdiv { 0 . 5 5 5 3 4 4 }$ & \\
\hline No Icon & Environmental Impact & 0.11112 & 0.111118 & \\
\hline No Icon & Time & 0.33354 & 0.333538 & \\
\hline No Icon & Project Success & 0.00000 & $\longdiv { 0 . 0 0 0 0 0 0 }$ & \\
\hline Okay $\mathrm{Co}$ & opy Values & & & \\
\hline
\end{tabular}

\section{Figure 18 Relative Importance Weights of TCEI}

The relative importance weights were multiplied with the performance of materials that was collected from the interview. By this way, the weighted TCEI was calculated and summed up to calculate the weighted total for each material type. The material types were ranked according to their weighted performance on project success. The materials from best performing to least performing were obtained as Hot In-Place (HIP) mix, 
Superpave, recycled Hot Mix Asphalt (HMA), virgin HMA, and virgin Warm Mix Asphalt (WMA). The boundary conditions were set as $\min 0$, $\max 100$ with increments of 20. The increment [0-20] is assigned to the least performing material, while the increment [80-100] is assigned to the best performing one. The top boundary is set to 100 , as the overall material score is estimated based on this denominator.

The overall material score for each project is calculated by using the importance weights of project conditions and the probabilities entered by the user. The importance weights are multiplied with the probabilities and summed up to the overall material score. Then, this score is matched with one of the material increments. The material matching the overall material score is selected for the project. The definition of boundary conditions and selection procedures for equipment and stabilizing additive are performed in the same manner. The CM score table is created in the form of the IF-THEN rules (as given in Equation 2, Equation 3, and Equation 4) for each project. The rules are entered into the decision-making system to select the most feasible construction method. For example, assuming Superpave asphalt falls between boundaries [40,60], IF the material score is 50, THEN the system selects Superpave asphalt for the paving activity. Similar IF-THEN rules and boundary conditions are also followed for the equipment and stabilizing additive selection. The details of the IF-THEN rules will be presented for the case studies. Before the case studies, next step will summarize the methods to calculate TCEI for the implemented and alternative construction methods. 


\subsection{Data Collection and Analysis for TCEI Calculation}

Three types of data such as project duration, project cost and environmental impact were collected and processed before they are used for optimization and analysis. Data in the form of plans, contract (which includes resource types and amount, as well as fuel consumptions of equipments), schedule, and daily progress report were collected from the Florida Department of Transportation (FDOT). Then, the required information was identified through these sources and time, cost and environmental impact values were calculated for alternate construction operations (including the original construction method). Project duration and cost data was derived using conventional scheduling and estimating methods. For the implemented construction operation, the schedules from the FDOT were examined to find out the duration of the three resurfacing activities, which were milling, paving, and friction course. For the alternatives, the duration was estimated by the schedules available or by using reports from the FL State Material Office (e.g., Sholar, Page, Musselman, \& Moseley, 2004).

The contract obtained from the FDOT included unit costs and quantities of resources. The unit costs and quantities of work done for three activities were identified for the cost calculation. The unit costs in the contract were used for calculating the cost of the original construction operation. For the alternative construction methods, the unit costs of different materials were obtained from literature sources. Another way to estimate the unit cost was to find the proportion between the unit costs of the alternative and the original material. The costs for all alternatives were estimated by using both ways. 
Environmental impacts were limited to GHG emissions, which were calculated based on the fuel consumptions of equipments given in the contract and the life cycle inventory (LCI) data from literature. Environmental impact data of observed or alternate construction operations could only be derived by using life cycle assessment (LCA) due to the lack of data support in practice.

LCA is a tool to evaluate the environmental impact of an activity or product starting from the extraction of raw material until its end of life (EPA, 1993). It is an important tool for evaluating the environmental impacts of products and services from a "cradle to grave" perspective (Bengtsson, 2001). LCA is described as the most sophisticated tool to consider and quantify the consumption of resources and the environmental impacts associated with a product or process (Curran, 1996).

A number of researchers described the life cycle phases in different manners. While some included raw materials extraction, material production, transport, construction, use, and end of life (Keoleian, Blanchard, \& Reppe, 2001), some others divided the life cycle of building into five as material exploitation, material production, construction \& installation, operation \& maintenance, and demolition (Zhang, Hammad, \& Bahnassi, 2009). As an example, Bilec, Ries, Matthews, \& Sharrard (2006) summarized LCA steps as raw material extraction, manufacturing, use, and end-of-life. The number of phases can change among researchers, but the idea remains constant to give the lifetime journey of building and its material components starting from the derivation of material to ending in the waste. By this way, LCA includes not only the construction, but also the remaining 
phases of building elements, and considers the effects on environment caused by different operations in all stages of a construction project.

Environmental impacts can be calculated in different categories such as green house gas (GHG) emissions, energy consumption, acidification, pollutants to air and water, etc. through the life cycle phases. Construction literature is rich in LCA studies that focus on energy consumptions and GHG emissions of buildings. For example, Sartori \& Hestnes (2007) used LCA to compare the energy utilization of conventional and low-energy buildings through their lives. In a similar manner, Xing, Xu, \& Jun (2008) applied a lifecycle inventory model to compare two construction materials: steel and concrete, in terms of energy consumptions and emissions. In the scope of this research, the calculation of environmental impacts is focused on evaluating GHG emissions by using the LCA approach.

LCA has been widely applied to the evaluation of building products, systems, and construction processes, and considered as a sophisticated tool to quantify the consumption of resources and environmental impact associated with a product or process (Curran, 1996). Three types of LCA-based assessment methods are available, including process-based, input-output analysis, and hybrid. The advantages and disadvantages of each approach have been discussed in literature (Bilec, Ries, \& Matthews, 2007).

Environmental impact data may need significant amount of preparation according to the scope of analysis. In this study, LCA data are applied to the analysis of the environmental 
impact of identified materials, energy, water, and other resources associated with a construction operation. There are three types of sources for environmental impact data. The first choice is the database associated with a LCA software tool. For example, the ATHENA $^{\circledR}$ Impact Estimator/EcoCalculator has a built-in life cycle inventory for environmental impact assessment. This source is not applicable to this study, as ATHENA does not have the required database for highway construction projects. The second source is the LCI databases, e.g., the one developed by the National Renewable Energy Laboratory (NREL, 2004). The first and the second choice are closely related, because ATHENA tools use the NREL LCI database. However, the second source provides some flexibility for customization when needed. The third source is literature. The second and third sources are also related, as the previous studies have included LCI data for different construction materials and equipments. For example, EPA eGRID (EPA, 2008) provides data of the national average emissions by electricity consumption. Construction equipment and tools used by contractors typically consume fuel. EPA provides data regarding the environmental impacts of different types of fuel (EPA, 2009). In addition, the EPA MOBILE 6.1/6.2 provides a tool to estimate several types of pollutants, such as carbon dioxide $\left(\mathrm{CO}_{2}\right)$, hydrocarbons $(\mathrm{HC})$; carbon monoxide $(\mathrm{CO})$; and oxides of nitrogen (NOx), generated by gas, diesel, or natural-gas-fueled cars, trucks, buses, or motorcycles (EPA, 2003). In terms of highway construction, Chappat \& Bilal (2003) conducted an analysis on GHG emissions and energy usage of more than 20 different paving product types. Dorchies (2008) has also worked on a variety of pavement structures and quantified their GHG emissions and energy consumption. 
In this study, literature source is used to determine GHG emissions of different alternatives of construction activities. The LCI information from literature was used to calculate the GHG emissions caused by materials and equipments in highway projects. The quantity takeoff data was analyzed with process, transportation, and landfilling inventory values to calculate the GHG ( $\mathrm{kg} \mathrm{CO} 2 \mathrm{eq}$ ) of different materials. On the other hand, the fuel consumption data for both the original and alternative construction methods was utilized to find out the environmental impacts caused by equipments. The fuel consumption was in gallons for gasoline and diesel equipments. This information needed to be converted to $\mathrm{kg} \mathrm{CO} 2$ eq to obtain the total $\mathrm{GHG}$ emissions for materials and equipments of the project. The first step was to find out the types and quantities of gases released to air by the consumption of gasoline and diesel fuel sources. EPA has developed an LCI that includes the gas releases for different energy sources. The types of gas releases for gasoline and diesel equipments are shown in Table 6 and Table 7 respectively. By converting the fuel consumption of equipments from gallons to liters and using the gas release information from EPA in $\mathrm{kg} / \mathrm{L}$, the quantity of gases released were calculated in $\mathrm{kg}$.

Table 6 Gas Releases for Gasoline Equipments (source: EPA single truck)

\begin{tabular}{|l|l|}
\hline Type of Gas & Release Amount (kg/L) \\
\hline Carbon dioxide (CO2) & $2.27 \mathrm{E}+00$ \\
\hline Carbon monoxide (CO) & $4.07 \mathrm{E}-02$ \\
\hline Methane (CH4) & $4.89 \mathrm{E}-04$ \\
\hline
\end{tabular}




\begin{tabular}{|l|l|} 
Nitrogen oxides (NOx) & $1.33 \mathrm{E}-02$ \\
\hline Nitrous oxide (N2O) & $9.56 \mathrm{E}-05$ \\
\hline Particulates, $>2.5$ um, and $<10 \mathrm{um}$ & $6.50 \mathrm{E}-05$ \\
\hline Sulfur oxides (SOx) & $5.42 \mathrm{E}-04$ \\
\hline VOC, volatile organic compounds & $3.03 \mathrm{E}-03$ \\
\hline
\end{tabular}

Table 7 Gas Releases for Diesel Equipments (source: EPA single truck)

\begin{tabular}{|l|l|}
\hline Type of Gas & Release Amount (kg/L) \\
\hline Carbon dioxide (CO2) & $2.93 \mathrm{E}+00$ \\
\hline Carbon monoxide (CO) & $4.21 \mathrm{E}-03$ \\
\hline Methane (CH4) & $7.07 \mathrm{E}-05$ \\
\hline Nitrogen oxides (NOx) & $2.09 \mathrm{E}-02$ \\
\hline Nitrous oxide (N2O) & $1.06 \mathrm{E}-04$ \\
\hline Particulates, $>2.5$ um, and $<10 \mathrm{um}$ & $4.03 \mathrm{E}-04$ \\
\hline Sulfur oxides (SOx) & $6.46 \mathrm{E}-04$ \\
\hline VOC, volatile organic compounds & $1.44 \mathrm{E}-03$ \\
\hline
\end{tabular}

The second step was to convert the gas releases to the equivalent $\mathrm{kg} \mathrm{CO} 2$. The content of GHG is composed of certain gases, some of which result from diesel and gasoline usage. The gases that contribute GHG emissions and their percentage weights are shown in Table 8, as given in the Stern Review (2006). It can be observed from that some of the gases released by fuel consumption do not contribute to GHG, such as nitrogen oxides 
(NOx) and sulfur oxides (SOx). Therefore, only the gases that are in the GHG content were used in the calculation.

Table 8 Weights of Gases for GHG Content (source: Stern Review, 2006)

\begin{tabular}{|l|l|}
\hline Burden & $\%$ (CO2 eq) \\
\hline Carbon dioxide (CO2) & 0.770 \\
\hline Methane (CH4) & 0.140 \\
\hline Nitrous oxide (N2O) & 0.800 \\
\hline Chlorinated hydrocarbons (HFCs) & 0.005 \\
\hline Chlorofluorocarbons (PFCs) & 0.002 \\
\hline Sulfur hexaflouride (SF6) & 0.010 \\
\hline
\end{tabular}

Finally, the GHG emissions for materials and equipments were summed up to obtain the total GHG (kg CO2 eq) emissions of the construction method alternatives. It should also be noted that the environmental impact in this research was limited to GHG because of the availability of data. However, the proposed framework can be applied to include other impact categories, as well as GHG, to examine the effect of construction operations from a life cycle point of view.

It was observed that data collection and processing was one of the major challenges for environmental impact data. The findings of the qualitative data collected from interviews aided in understanding the quantitative data collected from the projects, and they were 
synchronized to test the framework with the case studies. The application of the proposed framework will be demonstrated in the Case Study part.

\subsection{Case Study}

The purpose of the case studies is to experiment the proposed framework and determine optimized construction alternatives in terms of time, cost and environmental impacts. As mentioned before, environmental impact is limited to GHG in this study. Therefore, major steps in examining the case studies include defining highway construction operations, calculating time, cost and GHG, simulating the SD model, and performing optimization analysis. Before explaining the case studies in detail, the next part will summarize the historical changes and new technologies for highway construction operations.

\subsubsection{Highway Construction Operations}

\subsubsection{Historical Changes in Resurfacing Construction Methods}

Highway resurfacing projects consist of core activities, such as milling the existing asphalt, placing asphaltic concrete, and putting the concrete friction course. The resurfacing operation is performed lane by lane. In the conventional method, the existing asphalt is milled and hauled by dump trucks to be recycled. The new asphaltic concrete to be placed can be a virgin or recycled mix. An asphalt composition shows differences not only in terms of recycled concrete amount, but also at its temperature of mixing. 
Among the many mix design methods, Marshall and Hveem are the two widely accepted Hot Mix Asphalt (HMA) design methods (Bahia, 1993). Although Marshall mix design method has been widely used by the DOTs in the U.S., it showed downsides in the performance, and thus, the Strategic Highway Research Program (SHRP) has developed a performance-based asphalt binder and asphalt mix specifications (Roberts, Mohammad, \& Wang, 2002). The development of new laboratory testing equipment, as well as the development of performance graded (PG) binder specifications and tests were resulted in Superpave, an acronym for superior performing asphalt pavements (Larsen, 2003). While Superpave is an innovation in the HMA, Warm Mix Asphalt (WMA) technology, which handles the mixing process in a lower temperature than HMA, has been developed in Europe and practiced in the U.S. (Chowdhury \& Button, 2008).

In addition to the progress in asphalt mix design, the equipment technology has evolved for better milling and placing asphalt performance. Hot In-Place (HIP) recycling technology is proposed to combine milling the existing asphalt and placing asphaltic concrete activities in resurfacing projects. The new technology has a single unit for recycling the existing pavement and mixing the milled pavement with new paving materials. By this way, HIP eliminates hauling and handling of the recycled HMA from milling (Russell, Uhlmeyer, DeVol, \& Johnson, 2010).

Regarding equipments, the evolvement is based on not only the technology, but also fuel type and use. Low-carbon or biofuels, which are mostly derived by soybeans, are promising strategies to reduce life cycle GHG emissions (EPA, 2009). 


\subsubsection{Environmental Benefits of New Technologies}

The LEED system has been used as a rating mechanism in design and construction of buildings. Similarly, the Greenroads system has been developed as a performance metric for quantifying sustainability of roadway design and construction. Greenroads system works as "a sustainability accounting tool" for roadways and presents best practices to achieve sustainability. The required practices are called "Project Requirements," and they are mandatory to have a Greenroad. There are 11 project requirements including pavement maintenance, life cycle cost analysis, and life cycle inventory. The voluntary practices are optional and called "Voluntary Credits." Voluntary credits are divided into 5 groups as Environment \& Water (EW), Access \& Equity (AE), Construction Activities (CA), Materials \& Resources (MR), and Pavement Technologies (PT). Among these groups, Construction Activities (CA) includes Fossil Fuel Use Reduction and Equipment Emission Reduction, while Materials \& Resources (MR) considers Full Life Cycle Assessment (LCA) and Energy Efficiency. Additionally, Pavement Technologies (PT) has the content of innovative technologies, such as WMA (Muench \& Anderson, 2009).

Construction contractors are reported to influence the GHG emissions by activities, such as fuel selection, equipment idling, electricity use, equipment maintenance, equipment selection, and materials recycling (EPA, 2009). In terms of materials, different asphalt mixing methods have different outcomes in environmental impacts. For example, using a recycled mix in paving or performing Reclaimed Asphalt Pavement "RAP" reduces demand for new materials, saves energy, and reduces carbon output (Huddleston, 2008). 
In a similar manner, WMA technology causes less fuel/energy consumption, decreased emissions, and dust production (Chowdhury \& Button, 2008). Quantitatively, WMA has been found to reduce the air pollution, the fossil fuel consumption, and the smog formation of HMA by $24 \%, 18 \%$, and $10 \%$, respectively. On the overall, WMA has provided $15 \%$ reduction on the environment impacts of HMA (Hassan, 2009). As an emerging technology, HIP recycling is reported to produce a reduction of $15 \%$ in overall energy use per tonne laid down, and lead to significant amount of savings in resources (CCE, 2005). When HMA and HIP technologies are compared, HIP consumes 110-250 MJ less energy per tonne than HMA pavement preservation and rehabilitation methods (Terrel \& Hicks, 2008).

Regarding fuel selection, replacing petroleum gasoline or diesel with biodiesel is stated to reduce GHG emissions by approximately $25 \%-65 \%$. Switching from petroleum diesel to biodiesel can be in different amounts as $100 \%$ (B100) or $20 \%$ (B20). The life cycle GHG emissions are proportional to the blending amount of petroleum (EPA, 2009). For instance, B100 is estimated to have $78 \%$ of reduction, while the reduction for B20 is approximately 16\% (U.S.-DOE, 2007).

In the scope of this study, existing methods and new technologies for highway construction are used to generate several construction alternatives for the resurfacing projects. Possible construction methods are defined for the core activities, which are milling, resurfacing, and placing friction course. Various construction methods in terms 
of material, equipment, and technology selection formed 16 combinations for the three activities. Construction methods for resurfacing project activities are shown in Table 9.

Table 9 Construction Methods for Resurfacing Project Activities

\begin{tabular}{|l|l|l|l|}
\hline \multicolumn{5}{|c}{ Construction Methods } \\
\hline No & Resurfacing & Milling & Friction Course \\
\hline CM1 & Virgin-Conventional HMA & Conventional equipment & FC-5 \\
\hline CM2 & Virgin-Conventional HMA & Biodiesel equipment & FC-5 \\
\hline CM3 & Recycled-Conventional HMA & Conventional equipment & FC-5 \\
\hline CM4 & Recycled-Conventional HMA & Biodiesel equipment & FC-5 \\
\hline CM5 & Virgin-WMA & Conventional equipment & FC-5 \\
\hline CM6 & Superpave & Conventional equipment & FC-5 \\
\hline CM7 & HIP Mix (Marshall+milled) & H.I.P.'s equipment & FC-5 \\
\hline CM8 & HIP Mix (Marshall+milled) & HIP Biodiesel & FC-5 \\
\hline CM9 & Virgin-Conventional HMA & Conventional equipment & FC-9,5 \\
\hline CM10 & Virgin-Conventional HMA & Biodiesel equipment & FC-9,5 \\
\hline CM11 & Recycled-Conventional HMA & Conventional equipment & FC-9,5 \\
\hline CM12 & Recycled-Conventional HMA & Biodiesel equipment & FC-9,5 \\
\hline CM13 & Virgin-WMA & Conventional equipment & FC-9,5 \\
\hline CM14 & Superpave & Conventional equipment & FC-9,5 \\
\hline CM15 & HIP Mix (Marshall+milled) & H.I.P.'s equipment & FC-9,5 \\
\hline CM16 & HIP Mix (Marshall+milled) & HIP Biodiesel & FC-9,5 \\
\hline
\end{tabular}




\subsubsection{Case Study 1 Details}

The Case Study 1 is a resurfacing project from FDOT District 6 . The project includes milling the existing asphalt, placing asphaltic concrete, and putting the concrete friction course activities. Originally, milling is performed with conventional equipment, and the milled asphalt is hauled by dump trucks to be recycled. Superpave asphalt is used in paving, while FC-5 is used for the friction course layer. Based on the original construction method, existing methods and new technologies for highway construction are used to generate several construction alternatives for the same project. 16 combinations shown in Table 9 are applied to the project to define the alternatives for the different activities.

In the case study, the differences among alternatives were reflected by different types of material, equipment, and stabilizing additive content of materials. Time, cost and GHG were calculated for different types of construction methods by using the procedures explained in the Data Collection and Analysis for TCEI Calculation part. The original project duration was obtained by the bar chart received in the data package. The duration for alternative construction methods, except the HIP, was estimated based on the original duration. For HIP mix and equipment, the duration was estimated by using published sources from the FDOT. The original cost information was available in the contract with details, such as quantities and unit costs of resources. The unit costs for the alternative resources were found through literature and used together with the quantities of resources to calculate the project cost for alternative construction methods. 
The calculations for time and cost were straightforward, as the conventional estimating methods were used. However, for the calculation of GHG the data provided by FDOT required further preparation. The LCI information from literature was used together with the quantities of materials to calculate GHG emissions of different alternatives. The quantity takeoff data was analyzed with process, transportation, and landfilling inventory values to calculate the GHG ( $\mathrm{kg} \mathrm{CO} 2 \mathrm{eq}$ ) of different materials, while the fuel consumption data was utilized to find out the GHG caused by equipments. The gasoline and diesel consumption of equipments were available in the contract. First, the types and quantities of gases released to air were calculated. Then, these values were converted to $\mathrm{kg} \mathrm{CO} 2$ eq and summed up with the GHG obtained from materials. The functions in $\underline{\text { Appendix G }}$ were used to simulate Case Study 1 in the proposed SD model. Because of different properties of the project conditions, the model selected different resource combinations. The selected resource combination resulted in outcomes as the estimated time, cost and GHG. A list of possible resource combinations and estimated time, cost and GHG values are also shown in Appendix G. The estimated time, cost and GHG values will be further analyzed in the Analysis and Results for multi-objective optimization.

\subsubsection{Case Study 2 Details}

The Case Study 2 is a resurfacing project from FDOT District 4 . The project includes the same activities with Case Study 1, which are milling the existing asphalt, placing asphaltic concrete, and putting the concrete friction course. In the original set of 
construction method, Superpave asphalt is used in paving. Before the pavement of the new asphalt, the old asphalt is milled by using conventional equipment. The milled asphalt is hauled by dump trucks to be recycled. For the friction course layer, FC-9,5 is used as the basic material. The original construction method is referred to as existing method in this study. As mentioned befire, the existing method shows one way of delivering the project. The same project can be performed by using different resource utilization plans, as well as different construction methods. As the activities and alternatives of Case Study 2 are consistent with Case Study 1, 16 combinations shown in Table 9 are also applied to this project.

The same steps of calculation in Case Study 1 were also used in Case Study 2. The differences among alternatives were reflected by different types of material, equipment, and stabilizing additive content of materials, and time, cost and GHG were calculated for different types of construction methods by using the procedures explained in the Data Collection and Analysis for TCEI Calculation part. The calculations for time and cost were straightforward as the conventional estimating methods are used, while the calculation of GHG is performed with the help of data provided by FDOT and LCI information from literature. The functions in Appendix $\mathrm{H}$ were used to simulate Case Study 2 in the proposed SD model. The model was simulated with different properties of the project conditions, and the model selected different resource combinations for various probabilities. The selected resource combination has output the estimated time, cost and GHG. A list of possible resource combinations and estimated time, cost and GHG values 
are also shown in Appendix H. The estimated time, cost and GHG values will be further analyzed in the Analysis and Results for multi-objective optimization. 


\section{Analysis and Results}

The proposed framework was analyzed by using data from the case studies. The analysis was performed in three steps. In the first step, the systems dynamics model was analyzed to observe its effectiveness in simulating both decision-making and project systems. In the second step, the TCEI output of the system dynamics model was explored by multiobjective optimization technique. In the third step, the optimization results were examined to observe whether it was possible to set the relationship of TCEI according to the change in the contractor's decision.

For the first step, the proposed SD model was simulated by using various inputs, such as different probabilities of project objectives. The probabilities were formed randomly by using a function in MS Excel. The snapshot of Vensim during simulating the proposed SD model with a random set of probabilities is shown in Figure 19. For each condition, the score was calculated by multiplying its relative importance weight and probability. An example material score for project condition-1 is shown in Equation 12. This procedure was repeated for seven conditions to calculate the score of project conditions for material, equipment, and stabilizing additive selection. Then, the scores of project conditions were combined for each $\mathrm{CM}$ indicator. The equations for the $\mathrm{CM}$ indicators that are composed of the scores of seven conditions are given in, Equation 13, Equation 14, and Equation 15. The remaining equations for the case studies can be found in $\underline{\text { Appendix G and Appendix H. }}$ 
"MAT-C1"= "MAT-IW-1"*"P-1"

Material Selection $\quad$ Score $=$ "MAT-C1"+"MAT-C2"+"MATC3"+"MAT-C4"+"MAT-C5"+"MAT-C6"+"MAT-C7"

Equipment Selection Score= "EQUIP-C1"+"EQUIP-C2"+"EQUIPC3"+"EQUIP-C4"+"EQUIP-C5"+"EQUIP-C6"+"EQUIP-C7"

Stabilizing Additive Selection Score="STAB-C1"+"STAB-

C2"+"STAB-C3"+"STAB-C4"+"STAB-C5"+"STAB-C6"+"STAB-

C7"
Equation 12

Equation 13

Equation 14

Equation 15 


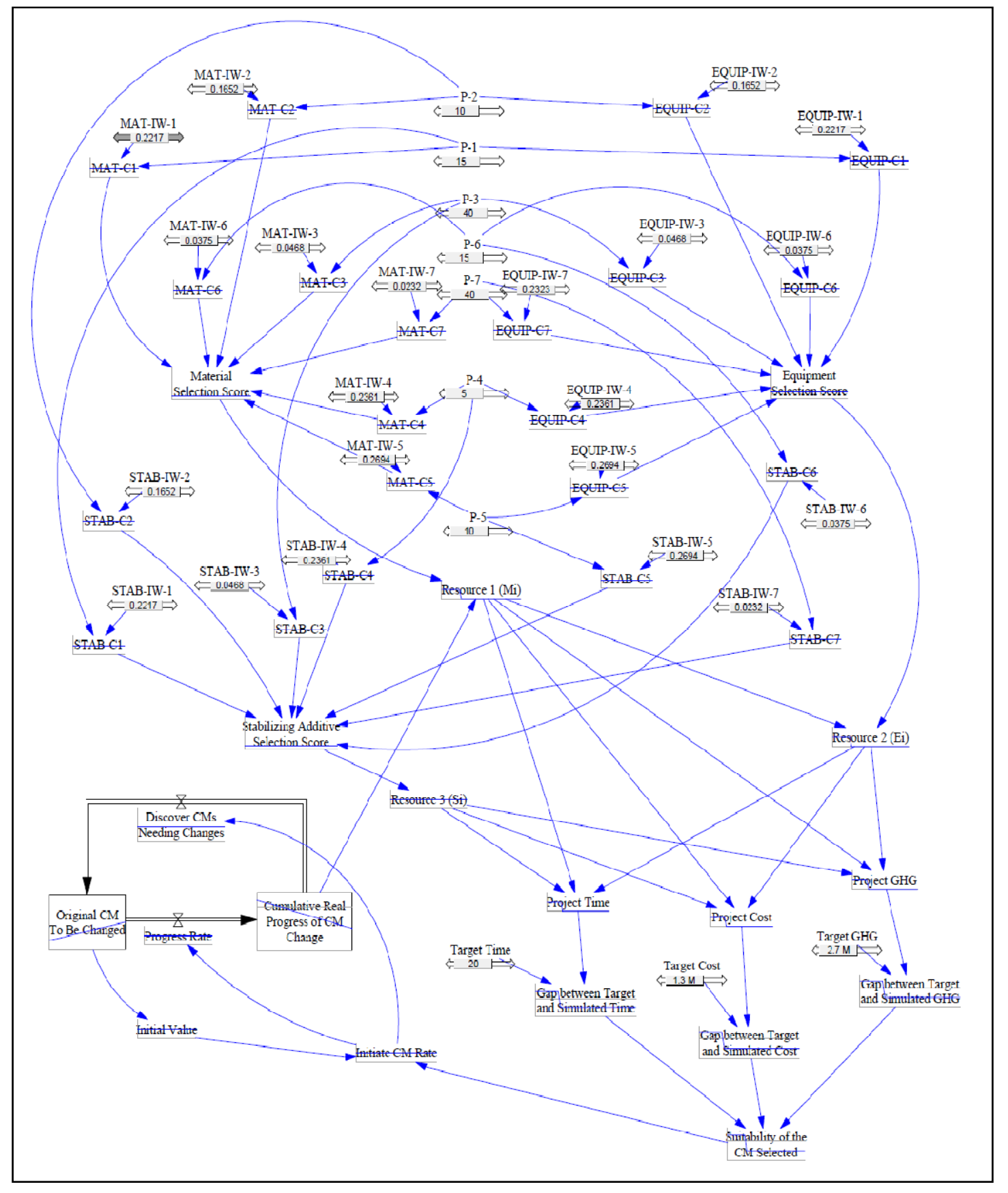

Figure 19 Snapshot of Vensim during Simulation

The CM selection was decomposed into $\mathrm{M}_{\mathrm{i}}, \mathrm{E}_{\mathrm{i}}$, and $\mathrm{S}_{\mathrm{i}}$ in the model. The results of the simulation gave "i" numbers that described the type of resources. A sample of resource results coded in numbers is shown in Table 10 for Case Study 1. The output of Vensim 
can be saved as a text document. Then, the document in .txt format is entered to MS Excel to obtain results in the tabular form. The results in the form of $\mathrm{CM}\left(\mathrm{M}_{\mathrm{i}}, \mathrm{E}_{\mathrm{i}}, \mathrm{S}_{\mathrm{i}}\right)$ are further decoded into the construction methods and their corresponding resource types. For example, $\mathrm{CM}\left(\mathrm{M}_{3}, \mathrm{E}_{1}, \mathrm{~S}_{2}\right)$ stands for the selection of virgin-WMA for the resurfacing activity, diesel equipment for the milling activity, and FC-9,5 layer for the friction course activity. For each set of different probabilities, such resource results were obtained.

Table 10 Sample of Resource Results Coded in Numbers

\begin{tabular}{|l|r|}
\hline Resource 1 (Mi) Runs: & Resource 1 (Mi) \\
\hline Base14 & 3 \\
\hline Resource 2 (Ei) Runs: & Resource 2 (Ei) \\
\hline Base14 & 2 \\
\hline Resource 3 (Si) Runs: & Resource 3 (Si) \\
\hline Base14 & 2 \\
\hline
\end{tabular}

Additionally, the simulation gave TCEI output based on the resource types selected for the project. The set of time, cost, and GHG results for the resources in Table 10 is shown in Table 11. The dimensions of the objectives are days for time, dollars for cost and $\mathrm{kg}$ $\mathrm{CO} 2$ eq for GHG emissions.

Table 11 Set of Time, Cost, and GHG Results for the Resources in Table 10

\begin{tabular}{|l|c|}
\hline Project Time Runs: & Project Time \\
\hline Base14 & 36 \\
\hline Project Cost Runs: & Project Cost \\
\hline Base14 & $2,03 E+11$ \\
\hline Project GHG Runs: & Project GHG \\
\hline Base14 & $4,47 E+11$ \\
\hline
\end{tabular}


Different probabilities resulted in different resource utilization plans, as well as different project TCEI in the form of Table 11. An example set of randomly formed probabilities and their TCEI results are shown in Table 12. An infinite number of similar set of probabilities can be entered into the proposed SD model. The last two trials of this set stand for the extreme cases. Extreme cases in simulation were recommended by Sterman (Sterman, 2000). Therefore, simulations using extreme parameter values (e.g., with minimum and maximum possible probabilities) were performed, in addition to the inspection of model equations with a wide range of probabilities. In the $19^{\text {th }}$ case, all probabilities are 0 (out of 1), which meant there was no negative change regarding the project conditions. This case can be referred as the best-case scenario. In the $20^{\text {th }}$ case, all probabilities were 1 (out of 1), which meant all negative changes regarding the project conditions took place. This case can be referred as the worst-case scenario.

Table 12 An Example Set of Randomly Formed Probabilities and Their TCEI Results

\begin{tabular}{|r|r|r|r|r|r|r|r|r|r|r|}
\hline \multicolumn{1}{l|}{ Trial \# } & P-2 & P-1 & P-3 & P-6 & P-7 & P-4 & P-5 & C (\$) & T (days) & GHG (kg CO2 eq) \\
\hline 1 & 0.61 & 0.63 & 0.35 & 0.10 & 0.27 & 0.51 & 0.99 & $1,945,751.89$ & 36 & $3,857,983.11$ \\
\hline 2 & 0.44 & 0.63 & 0.98 & 0.88 & 0.17 & 0.62 & 0.67 & $1,945,751.89$ & 36 & $3,857,983.11$ \\
\hline 3 & 0.00 & 0.17 & 0.49 & 0.80 & 0.80 & 0.38 & 0.63 & $1,998,046.87$ & 36 & $4,130,521.55$ \\
\hline 4 & 0.27 & 0.74 & 0.14 & 0.49 & 0.48 & 0.15 & 0.95 & $1,830,894.80$ & 36 & $2,704,097.84$ \\
\hline 5 & 0.44 & 0.70 & 0.00 & 0.16 & 0.27 & 0.64 & 0.70 & $1,830,894.80$ & 36 & $2,704,097.84$ \\
\hline 6 & 0.10 & 0.63 & 0.71 & 0.43 & 0.97 & 0.98 & 0.12 & $1,832,741.60$ & 36 & $2,704,097.84$ \\
\hline 7 & 0.09 & 0.15 & 0.55 & 0.42 & 0.37 & 0.42 & 0.31 & $1,961,275.87$ & 36 & $4,556,064.96$ \\
\hline 8 & 0.21 & 0.83 & 0.95 & 0.35 & 0.75 & 0.31 & 0.18 & $1,832,741.60$ & 36 & $2,704,097.84$ \\
\hline 9 & 0.46 & 0.45 & 0.99 & 0.55 & 0.80 & 0.05 & 0.74 & $1,832,741.60$ & 36 & $2,704,097.84$ \\
\hline 10 & 0.83 & 0.01 & 0.85 & 0.72 & 0.64 & 0.89 & 0.80 & $1,945,751.89$ & 36 & $3,857,983.11$ \\
\hline 11 & 0.53 & 0.76 & 0.56 & 0.91 & 0.78 & 0.98 & 1.00 & $1,363,662.60$ & 22 & $3,313,032.61$ \\
\hline 12 & 0.80 & 0.86 & 0.98 & 0.96 & 0.80 & 0.70 & 0.83 & $1,363,662.60$ & 22 & $3,313,032.61$ \\
\hline 13 & 0.02 & 0.67 & 0.28 & 0.35 & 0.08 & 0.09 & 0.44 & $1,961,275.87$ & 36 & $4,556,064.96$ \\
\hline 14 & 0.10 & 0.15 & 0.40 & 0.15 & 0.40 & 0.05 & 0.10 & $2,026,281.78$ & 36 & $4,466,841.63$ \\
\hline 15 & 0.05 & 0.10 & 0.35 & 0.20 & 0.50 & 0.02 & 0.02 & $2,026,281.78$ & 36 & $4,466,841.63$ \\
\hline 16 & 0.76 & 0.01 & 0.29 & 0.12 & 0.80 & 0.41 & 0.75 & $1,832,741.60$ & 36 & $2,704,097.84$ \\
\hline 17 & 0.51 & 0.67 & 0.22 & 0.33 & 0.79 & 0.27 & 0.97 & $1,945,751.89$ & 36 & $3,857,983.11$ \\
\hline 18 & 0.23 & 0.27 & 0.02 & 0.63 & 0.07 & 0.63 & 0.01 & $1,961,275.87$ & 36 & $4,556,064.96$ \\
\hline 19 & 0 & 0 & 0 & 0 & 0 & 0 & 0 & $2,026,281.78$ & 36 & $4,466,841.63$ \\
\hline 20 & 1 & 1 & 1 & 1 & 1 & 1 & 1 & $1,363,662.60$ & 22 & $3,313,032.61$ \\
\hline
\end{tabular}


Same three steps were also applied to Case Study 2 to see the effectiveness of the proposed model. First, the proposed SD model was simulated by using different probabilities of project objectives. The same probabilities that were formed randomly for Case Study 1 were used in Case Study 2. For instance, the probabilities of Trial 14 was input to the model, and simulated for Case Study 2. The results gave the exact resource combination as in Case Study 1 that is shown in Table 10, i.e., CM (M3, E1, S2). Additionally, Case Study 2 was simulated for the best-case scenario (where all probabilities are 0 out of 1 ) and the worst-case scenario (where all probabilities are 1 out of 1). The CM combinations obtained for the best-case and worst-case scenarios were the same as the combinations of Case Study 1 . The similarity of the CM selected results under the same probability inputs, and when simulating for two different case studies shows the consistency of the results, as well as the effectiveness of the proposed SD model. It should also be noted that, the original construction methods used in delivering Case Study 1 and Case Study 2 were different. Although there was a difference in the resources of the friction course activity, the original set did not create any difference in their results. As the inputs for changing project conditions defined the most feasible construction method, same construction methods were selected under similar scenarios. The influence of changing project conditions was reflected through various scenarios and the selected CM was the one that overcomes all other methods including the original one. In both case studies, the selected CM performed better than the original one under the influence of changing project conditions. 
The model was further evaluated by using three types of tests of system dynamics models as described in literature (Sterman, 2000). The tests are: (1) structural similarity to the actual system; (2) reasonable behavior over a wide range of input values; and (3) behavior similarity to actual system behaviors. Basing the model on previously validated project models and the literature improved the model's structural similarity to the actual system. In literature, the models had the rework cycle and feedback loops for controlling purposes. In the structure of the proposed model, the rework cycle was generated to accumulate the progress of $\mathrm{CM}$ selection, while the feedback loop starting from Suitability of the CM Selected worked as the controlling mechanism for simulation. By these units, the structural similarity of the proposed model to the actual system was achieved. When simulated, the model behavior remained reasonable across changes in individual probability values, as well as with extreme input values. The best-case and worst-case scenarios worked as the extreme points. For the extreme points, the $\mathrm{CM}$ selected for the project made sense for the users. For example, HIP mix was selected under the worst-case scenario, as it is the best performing material in terms of time and it shows considerable success in terms of project cost and EI. On the other hand, the model's behavior for typical conditions was consistent in selecting the most feasible construction method. For example, for Trial 14, both case studies output the same resource combinations because of simulating with the same probability values. The changes in probabilities and relative importance weights of project conditions were successfully reflected to the CM selection and TCEI calculation in the model. Under the influence of project conditions, the model resulted in better resource utilization plans in achieving environmentally conscious construction. This emphasized that the multi-agents 
make decisions and take actions according to the project conditions in their surrounding, and the project conditions have an effect on the flow of construction processes. Considering the results of these tests, the proposed SD model was assessed to be effective in simulating multi-agent decisions and project processes.

For the second step, the time, cost and GHG emission results of the proposed SD model were further analyzed for the multi-objective optimization. The random probabilities in Table 12 were used to generate the random population of solutions. The number of different inputs of probabilities formed the array of all conditions of the project. By this way, each chromosome was made of seven conditions of the project. The random probability inputs for each of the conditions were used to define their associated CMs. Then, TCEI values were calculated for the chromosomes of the random population, as solutions were associated with their duration, cost and GHG. Equation 8, Equation 9, and Equation 10 were used to calculate the normalized values of time, cost and GHG emissions. The normalized values are shown in Table 13. 
Table 13 Normalized Values for Time, Cost and GHG

\begin{tabular}{|r|r|r|r|}
\hline \multicolumn{1}{|l|}{ Trial \# } & \multicolumn{1}{l|}{ Normal C } & \multicolumn{1}{l|}{ Normal T } & Normal GHG \\
\hline 1 & 0.88 & 1.00 & 0.62 \\
\hline 2 & 0.88 & 1.00 & 0.62 \\
\hline 3 & 0.96 & 1.00 & 0.77 \\
\hline 4 & 0.71 & 1.00 & 0.00 \\
\hline 5 & 0.71 & 1.00 & 0.00 \\
\hline 6 & 0.71 & 1.00 & 0.00 \\
\hline 7 & 0.90 & 1.00 & 1.00 \\
\hline 8 & 0.71 & 1.00 & 0.00 \\
\hline 9 & 0.71 & 1.00 & 0.00 \\
\hline 10 & 0.88 & 1.00 & 0.62 \\
\hline 11 & 0.00 & 0.00 & 0.33 \\
\hline 12 & 0.00 & 0.00 & 0.33 \\
\hline 13 & 0.90 & 1.00 & 1.00 \\
\hline 14 & 1.00 & 1.00 & 0.95 \\
\hline 15 & 1.00 & 1.00 & 0.95 \\
\hline 16 & 0.71 & 1.00 & 0.00 \\
\hline 17 & 0.88 & 1.00 & 0.62 \\
\hline 18 & 0.90 & 1.00 & 1.00 \\
\hline 19 & 1.00 & 1.00 & 0.95 \\
\hline 20 & 0.00 & 0.00 & 0.33 \\
\hline
\end{tabular}

The normalized values were used in accordance with minimizing the time, cost and GHG objectives. The subspace of TCEI was created for all possible existing solutions. As an example, the TCEI of five solutions drown on the new space. The 2-D figures of Cost vs EI, Cost vs Time are shown in Figure 20. The numbers in the figures refer to the trial numbers. As some of the trials ended up having minimum cost (e.g., Trial 4), minimum EI and minimum time (e.g., Trial 11) values, the results of these trials are drown on the axis, where the normalized value is zero. 


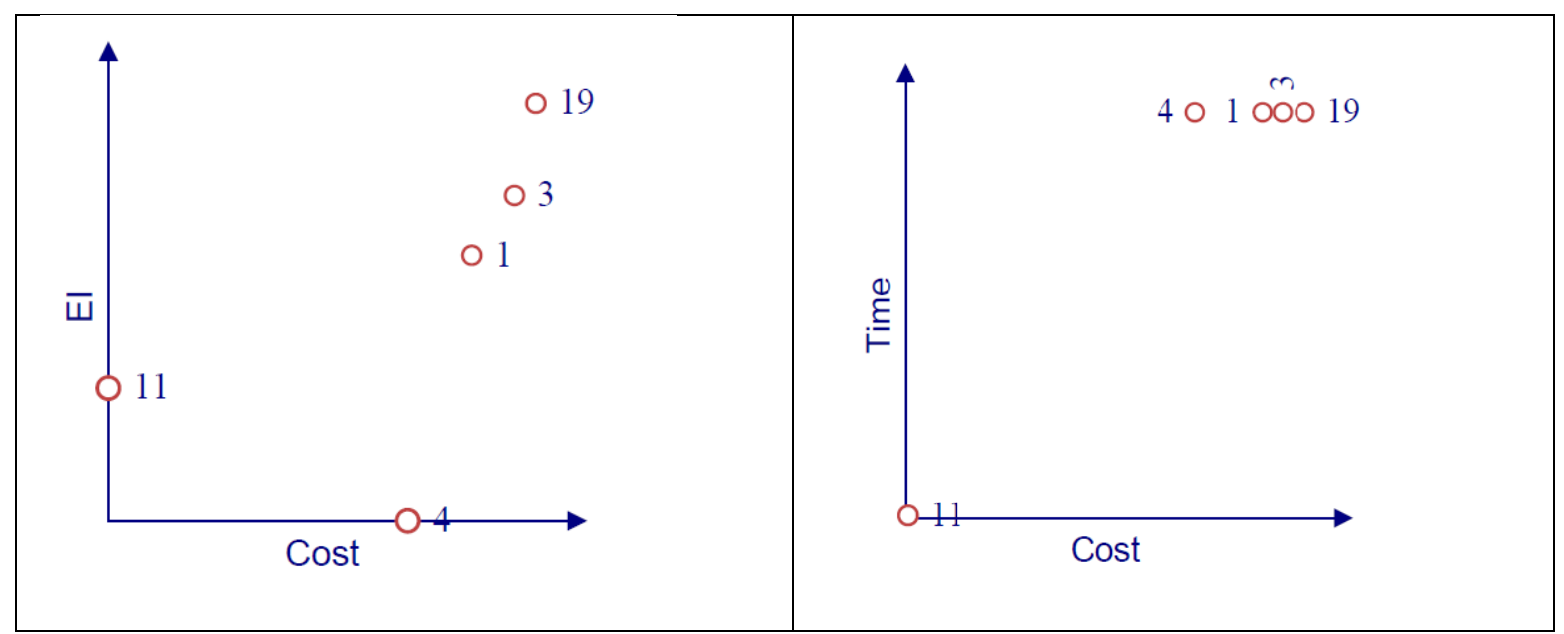

Figure 20 2-D Figures of Cost vs EI, Cost vs Time

The normalization was performed to locate TCEI on the Euclidean space, as well as to maintain consistency in the fitness function. As mentioned before, the fitness function is the representation of the distance of a solution, $\mathrm{S}_{\mathrm{m}}$ given as $\left(\mathrm{T}_{\mathrm{m}}, \mathrm{C}_{\mathrm{m}}, \mathrm{EI}_{\mathrm{m}}\right)$, to the origin of the $3 \mathrm{D}$ space associated with three objectives, time, cost and environmental impact. The fitness function, which was given in Equation 11, was used to calculate distance to the origin and evaluate the performance of each solution. Table 14 shows the fitness function values together with the normalized TCEI for the case study. As the origin has $(0,0,0)$ values for TCEI, the solution or solutions with the lowest fitness function have the least distance to the origin. In this case, Trials 11, 12, and 20 have the lowest fitness function value as 0.33 . The solutions that have the lowest fitness function were used to determine their associated CM, which was the same resource combination for all three solutions. 
Table 14 Fitness Function Values and Normalized TCEI

\begin{tabular}{|r|r|r|r|r|}
\hline \multicolumn{1}{|l|}{ Trial \# } & \multicolumn{1}{|l|}{ Normal C } & \multicolumn{1}{l|}{ Normal T } & Normal GHG & Fitness \\
\hline 1 & 0.88 & 1.00 & 0.62 & 1.47 \\
\hline 2 & 0.88 & 1.00 & 0.62 & 1.47 \\
\hline 3 & 0.96 & 1.00 & 0.77 & 1.58 \\
\hline 4 & 0.71 & 1.00 & 0.00 & 1.22 \\
\hline 5 & 0.71 & 1.00 & 0.00 & 1.22 \\
\hline 6 & 0.71 & 1.00 & 0.00 & 1.23 \\
\hline 7 & 0.90 & 1.00 & 1.00 & 1.68 \\
\hline 8 & 0.71 & 1.00 & 0.00 & 1.23 \\
\hline 9 & 0.71 & 1.00 & 0.00 & 1.23 \\
\hline 10 & 0.88 & 1.00 & 0.62 & 1.47 \\
\hline 11 & 0.00 & 0.00 & 0.33 & 0.33 \\
\hline 12 & 0.00 & 0.00 & 0.33 & 0.33 \\
\hline 13 & 0.90 & 1.00 & 1.00 & 1.68 \\
\hline 14 & 1.00 & 1.00 & 0.95 & 1.70 \\
\hline 15 & 1.00 & 1.00 & 0.95 & 1.70 \\
\hline 16 & 0.71 & 1.00 & 0.00 & 1.23 \\
\hline 17 & 0.88 & 1.00 & 0.62 & 1.47 \\
\hline 18 & 0.90 & 1.00 & 1.00 & 1.68 \\
\hline 19 & 1.00 & 1.00 & 0.95 & 1.70 \\
\hline 20 & 0.00 & 0.00 & 0.33 & 0.33 \\
\hline
\end{tabular}

Although the probabilities of conditions can take a wide range of values, the nature of the highway construction projects limits the number of available construction methods. Consequently, the TCEI values calculated based on construction methods are bounded between certain values. As the population of solutions is limited, the results of optimization have been obtained without requiring the generation of further populations as in common genetic algorithm procedure. The full genetic algorithm procedure was not needed to optimize with a limited population. The procedure was given to emphasize that the framework can be applied to projects other than highway construction. However, with a random population of 20 solutions, different probability ranges were covered, and the 
results converged to the optimum minimum points of TCEI with the initial population because of the nature of highway projects.

The results of the multi-objective selection showed that Trials 11, 12, and 20 have the lowest fitness function. All results had the same construction method and demonstrated that using HIP mix with biodiesel equipment was the most feasible resource combination under the randomly generated probabilities. As mentioned before, HIP mix is the best performing material under extreme conditions. The original project utilized Superpave as the asphalt type. However, HIP technology has been evaluated effective in saving about $50 \%$ cost over the conventional milling and resurfacing, and eliminated $90 \%$ of the emissions resulting from pavement milling and resurfacing process. Additionally, HIP showed reduced downtime of pavements being restored in recent projects (EPA, 2011). Thus, the optimal solution not only was practical and reliable, but also resulted in better resource utilization plans in achieving environmentally conscious construction. This can also be interpreted as the simulated results gave real case solutions under the influence of changing project conditions. When the probabilities of project conditions were changed, the system selected the most feasible resources based on the probability values. Different resources or construction methods were selected by the framework for each set of probabilities. Selecting different construction methods resulted in various time, cost and environmental impact values depending on the probabilities input to the system. Thus, the results showed that the change in project conditions had a significant impact on the TCEI optimal solutions. 
For the third step, the results of the framework were handled to find out the relationship of TCEI related to the change in the project conditions, as well as the contractor's decision on CM selection. In this case, all twenty data points were used because they represent the actual construction methods used by FDOT. Simple linear correlation, also referred to as Pearson's correlation, was used to determine the extent of relationship between the three project objectives. Pearson's correlation compares two variables at once, and the value of correlation gives if the variables are proportional. If they are proportional, that means they are linearly related. The value of correlation or correlation coefficient gets values between -1.00 and 1.00 , where they represent negative and positive correlation respectively. Pearson's correlation coefficient is calculated by using three different sums of squares (SS). As there are three variables (time, cost, and EI) in this study, there are three sets of SS calculation in pairs (time \& cost, time \& EI, and cost \& EI). As an example, the Pearson's correlation coefficient calculation for time \& cost will be explained in detail.

The first step was to calculate the SS of time and cost separately. Then, the sum of cross products SS time-cost was computed by using both variables. The SS formulas for variables and the cross product are shown in Equation 16, Equation 17, and Equation 18. These equations were further used to find the correlation coefficient (r), which is shown in Equation 19. By following the same steps and using similar equations, the correlation coefficient was calculated for time \& EI and cost \& EI. The SS values and correlation coefficients of TCEI are shown in Table 15 and Table 16. 


$$
\begin{gathered}
S S_{T T}=\sum_{i=1}^{i=n}\left(T_{i}-\bar{T}\right)^{2} \\
S S_{C C}=\sum_{i=1}^{i=n}\left(C_{i}-\bar{C}\right)^{2} \\
S S_{T C}=\sum_{i=1}^{i=n}\left(T_{i}-\bar{T}\right)\left(C_{i}-\bar{C}\right) \\
r=\frac{S S_{T C}}{\sqrt{\left(S S_{T T}\right)\left(S S_{C C}\right)}}
\end{gathered}
$$

\begin{tabular}{|c|c|c|}
\hline & Values & TCEI Pair \\
\hline$S S_{C C}$ & $8.99 \mathrm{E}+11$ & \multirow{3}{*}{ Time \& Cost } \\
\hline$S S_{T T}$ & 499.80 & \\
\hline$S S_{T C}$ & $2.01 \mathrm{E}+07$ & \\
\hline$S S_{C C}$ & $8.99 \mathrm{E}+11$ & \multirow{3}{*}{ Cost \& EI } \\
\hline$S S_{E I E I}$ & $1.06 \mathrm{E}+13$ & \\
\hline$S S_{C E I}$ & $1.48 \mathrm{E}+12$ & \\
\hline$S S_{T T}$ & 499.80 & \multirow{3}{*}{ Time \& EI } \\
\hline$S S_{E I E I}$ & $1.06 \mathrm{E}+13$ & \\
\hline$S S_{T E I}$ & $1.37 \mathrm{E}+07$ & \\
\hline
\end{tabular}

Table 15 SS Values of TCEI Pairs

Table 16 Correlation Coefficients of TCEI

\begin{tabular}{|l|r|r|r|}
\hline & C & T & EI \\
\hline $\mathbf{C}$ & 1 & & \\
\hline T & 0.9466 & 1 & \\
\hline EI & 0.4789 & 0.1887 & 1 \\
\hline
\end{tabular}

The value of the correlation coefficient defines two properties of the correlation: (1) The sign of $r$ gives if the correlation is negative or positive; (2) The magnitude of $r$ gives the 
strength of correlation. Between time $\&$ cost, $r=0.9466$ suggests a strong positive correlation. When the correlation coefficient is between 0.3 and 0.7 as in the case of cost \& EI, it is interpreted as a moderate positive correlation. Between time \& EI, the correlation coefficient is below 0.3 , which suggests a weak positive correlation.

While the correlation coefficient (r) represents the linear relationship between two variables, the coefficient of determination $\left(\mathrm{r}^{2}\right)$ represents the proportion of common variation in the two variables. For example, the coefficient of determination of 0.90 between time \& cost suggests that $90 \%$ of the variability in the cost of the project is explained by its duration. It can be observed from the data set that when there is a decrease in the project cost, there is usually a decrease in the project duration. This situation is consistent with $90 \%$ of common variation between time \& cost. The reason for $90 \%$ being different from generally accepted time-cost tradeoff lies beneath the construction methods. The new technology such as HIP mix causes a decrease in both time $\&$ cost, so that they have a common variation. Additionally, switching from diesel to biodiesel not only affects GHG, but also shows the same kind of behavior for time \& cost. This situation of having the same increase or decrease, time $\&$ cost shows consistency in their pattern. The results of Case Study-1 and Case Study-2 are shown in $\underline{\text { Appendix } G}$ and Appendix $H$ to view the common variation of time \& cost in real data.

The coefficient of determination of 0.23 between GHG \& cost suggests that $23 \%$ of the variability in the cost of the project is explained by its GHG. The common variation between GHG \& cost is low, as the GHG data does not always increase when cost 
increases. The common variation between time \& GHG is even lower. The coefficient of determination of 0.04 between time \& GHG suggests that only $4 \%$ of the variability in the GHG of the project is explained by its duration. The very low variability can be explained by the data set, as the data of time \& GHG does not show the same pattern of behavior. The duration of project based on different construction methods can have the same value, while having the same GHG value is only limited to certain construction methods. As GHG \& cost and time \& GHG do not have significant correlations, the relationships between them are case-by-case. For each case, the variability between each pair can change. Therefore, whether or not there is a certain relationship between these objectives cannot be set.

The correlation coefficient ( $\mathrm{r}$ ) and the coefficient of determination $\left(\mathrm{r}^{2}\right)$ help contractors to visualize the impact of their decisions on the relationship of TCEI. When the probabilities of project conditions are different from the ones given in Table 12, the CM selected by the contractor, as well as the TCEI interdependency can be different from the ones in the current set. This statement implies that the simulation of different resource utilization plans demonstrates contractors how significantly their decisions affect the relationship of TCEI. By this way, the contractors not only become aware of the influence of their decisions on the project objectives, but also have the chance to change their decisions about construction processes and resources accordingly. 
To sum up, the proposed framework yielded statistically significant results in simulating project conditions and optimizing TCEI. The findings of the study are able to assist contractors to visualize the impact of their decision on the relationship of TCEI. 


\section{Conclusions}

\subsection{Summary and Results}

The construction industry has considerable impact on resource consumption and environmental impact. Although, environmentally conscious construction has been widely studied, exiting literature is still in need of a multi-objective perspective. A construction project can have multiple objectives in addition to time and cost, such as quality and safety. The new paradigm of integrating environmental impacts with time and cost objectives of construction projects has been presented in this research.

Construction projects are complex systems that include decision-making of construction professionals and multi-objective operations. Project parties' ability to fulfill multiple project objectives is limited by various project conditions in the complex construction system. The changing project conditions further affect the relationship among project objectives. This impact is still unknown by construction professionals. It is vital to study this impact to achieve environmentally conscious construction. In this study, an analytical framework was developed to analyze the impact of changing project conditions on the relationship of TCEI. The aim of the framework is to assist the planning of construction operations by considering project performance including environmental impact. This study includes environmental impact in terms of green house gas (GHG) emissions.

The decision-making model was created by using multi-agents and IF-THEN rules that characterize agents' decisions in the system. The contractor and owner agents are modeled so as to reflect the influence of various agents in the construction project. The 
contractor and owner agents had their own decision-making mechanisms and communication paths with each other to come up with common resource utilization plans. The project conditions were used as input to the decision-making mechanism. The conditions that affected the decision-making of agents were defined based on previous studies about highway construction, as well as change causes and change effects. They were represented by their relative importance weights and probabilities. The relative importance weights among project conditions were analyzed by using ANP. ANP utilized professional judgments via interviews and assigned weights to project conditions. The ANP analysis was performed in the software SuperDecisions. The probabilities were used with the relative importance weights to form a score table for each $\mathrm{CM}$ indicator (material selection, equipment selection, and stabilizing additive selection). The ranges in the score tables were used to select the most feasible CM based on the project conditions. The most feasible or selected CM was entered to the project system.

The project system was generated including resources and processes related to the project, as well as TCEI calculation. When the construction method was selected in the decision-making system, time, cost and EI (GHG in the limits of this study) was calculated in the project system. This simulation was performed for each different set of $\mathrm{CM}$ input from the decision-making system. The integration of both systems were sustained by CM selection, while the proposed model was simulated in the SD software Vensim. For each different set of probability inputs, decision-making model resulted in various CMs, and consequently project model resulted in different TCEI values. The TCEI calculated under the influence of project conditions were further compared to the 
target time, cost and GHG entered by the user. The gap between project TCEI and target TCEI were calculated to find the suitability of the CM selected, and the suitability of the $\mathrm{CM}$ selected was further feedback to the SD system through the rework cycle. The feedback maintained the flow of the SD system, until the desired suitability of the CM selected was achieved by the model.

The outcomes of the proposed SD model were used to perform multi-objective optimization. The aim was to find the TCEI optimal solution and look for the relationship between TCEI. The objective function was defined to search for optimal/near optimal tradeoffs among minimizing project duration, project cost, and project GHG. An Euclidian space was defined having the variables T, C and EI. A population of solutions was generated randomly, and the normalized TCEI values were calculated. Then, the one or ones having the minimum objective function, i.e., being closer to the origin of a new subspace, was selected to be in the optimal solution set. An application example was analyzed to observe the relationship between TCEI.

In the first step of application, the proposed framework was simulated with a wide range of probabilities including extreme values. When simulated, the model's behavior for typical and extreme conditions was consistent in selecting the most feasible construction method. Basing the model on previously validated project models and the literature improved the model's structural similarity to the actual system. The changes in probabilities and relative importance weights of project conditions were successfully reflected to the $\mathrm{CM}$ selection and TCEI calculation in the model. Under the influence of 
project conditions, the model resulted in better resource utilization plans in achieving environmentally conscious construction. This emphasized that the multi-agents make decisions and take actions according to the project conditions in their surrounding, and the project conditions have an effect on the flow of construction processes. Considering the results of these tests, the proposed SD model was assessed to be effective in simulating multi-agent decisions and project processes.

In the second step, multi-objective optimization was performed with the objective function that tried to minimize project duration, project cost and project GHG. The results showed that using HIP mix with biodiesel equipment was the most feasible resource combination under the randomly generated probabilities, i.e., it was the optimal solution considering time, cost and GHG emissions. The optimal solution was practical and reliable, as HIP mix presented considerable performance in time, cost and GHG objectives of construction projects. Considering the results, the proposed framework yielded statistically significant results in simulating project conditions and optimizing TCEI.

In the third step, Pearson's correlation was used to determine the extent of relationship between the three project objectives. The correlation coefficient suggested positive correlation between the three objectives. However, the strength of correlation between objectives was different. Time and cost had strong correlation, while cost and GHG had moderate correlation. The least correlation was found between time and GHG, which was a weak correlation. The findings implied how significantly the change in project 
conditions and decision-making process affect the relationship of TCEI. By using the proposed framework, it is possible for construction contractors to be aware of the influence of their decisions on the project objectives. They also have the chance to change their decisions about construction processes and resources accordingly.

To sum up, the proposed methodology combined multi-agent systems, multi-objective optimization, analytical network process, and system dynamics tools to study the relationships of TCEI and support decision-making under the influence of project conditions. Life cycle assessment (LCA) was applied to the evaluation of environmental impact in terms of GHG. The proposed framework was designed based on published literature and revised by data from highway construction professionals and projects. The mixed method approach was used for the collection and analysis of qualitative and quantitative data. Qualitative data was collected in the form of structured interviews. The

data collected from interviews were used to perform ANP analysis and define decisionmaking rules for multi-agents. Quantitative data were collected in terms of highway resurfacing projects from the Florida Department of Transportation (FDOT).

\subsection{Discussions and Limitations}

The proposed framework has shown some strength, weakness, and limitations by using the case studies. There is limited literature discussing the integration of environmental impact into the traditional project objectives, such as time and cost. This is mainly because including environmental performance as one of the criterion for project performance evaluation is an active research subject, and this study has contributed to the 
improvement of this subject. The environmental impacts were limited to GHG emissions and calculated with the help of life cycle assessment. LCA provided a quantitative basis for GHG, so that this objective had a potential to be compared with time and cost. Such a capability is critical to find out the optimal solutions in terms of TCEI objectives of a construction project.

The proposed framework is to be used in the planning stage of a construction project where the final project duration, cost and GHG emissions are not available to the contractors. During this stage there are different conditions affecting the decision of contractor for selecting the most feasible construction method. Neither the simulation of changing project objectives nor the evaluation of construction method alternatives can be done by the intuition of the decision maker. The proposed framework offers a more comprehensive approach to examine different alternatives of each construction method for each activity. The equations that made up the framework, as well as the system dynamics platform are capable of handling the construction method selection under the influence of project conditions.

One of the major challenges of the study is related to data availability. The challenges apply to both the quantitative and qualitative data collection and processing. In terms of the quantitative data, time, cost and environmental impact data are needed for all alternatives, besides the one that is implemented. The one that is implemented or the actual construction method can be directly used to calculate time and cost. The unit costs and quantities of resources, as well as schedules are available for the projects. For other 
alternatives except the actual one, time and cost can be estimated by using conventional methods. On the other hand, the environmental impact data for actual construction operation are difficult to acquire, because they are not measured currently. The contracts usually include fuel consumption information. This information must be combined with the life cycle assessment results of materials in the project. The environmental impacts for both materials and equipments can be estimated by using existing life cycle inventory data. Currently, life cycle inventory data cannot address the uniqueness of each project. Thus, environmental impact data derived by using life cycle inventory are not truly project specific, and really, they are estimates. Additionally, there is not such a commercial software to perform LCA considering both materials and equipments of the highway projects. In such a situation, using estimates for all types of data may be more appropriate than using a mix of real data and estimates because of data comparability issues. In addition, during the planning stage most of the data are estimated.

In terms of qualitative data, the interview questions was very detailed and to the point to reflect the decision-making patterns. In order to have precise results from the ANP analysis, the interview needed to be conducted with professionals, who have certain knowledge about construction method selection and different resource types. It was a challenge to reach professionals with the pavement design knowledge. In addition to its specificity, the ANP interview included a large number of pair wise comparisons, which makes the interview longer. The interviews were performed as face-to-face or via audio conference to help the interviewee understand the procedure and questions better. This approach improved decreasing the duration required for the interview. 
Another challenge related to data is their accuracy. The same published sources were used to estimate time, cost and GHG, so that the alternatives were comparable to each other. As estimated values are used for the planning purposes, the quality of data analyzed in this study is appropriate to utilize such data in comparing alternatives and conducting multi-objective optimization. However, it must be noted that environmental impact category in this study is limited to only GHG emissions. GHG emissions were selected as the EI category considering the major impact of construction operations on GHG and the availability of quantitative data for the analysis. When other impact categories are considered, the results of this research may change.

Finally, as the case studies and data were collected from highway construction projects, the activities were repetitive, i.e., they only had finish-to-start relationship. Although the framework addresses technical constraints (such as the constraints between resources), it is limited in reflecting different types of relationships among activities. This situation was not a problem for highway construction, as the schedules had one type of relationship. However, incorporating scheduling software can potentially enhance the applicability of the framework proposed in this research.

\subsection{Conclusions and Future Studies}

An analytical framework has been developed to analyze the decision-making mechanisms of construction agents, as well as their impact on the relationship of TCEI. The data from highway construction professionals and projects were used to simulate the proposed 
system dynamics model, test the proposed framework, and perform multi-objective optimization on the results. It is concluded that the proposed SD model can effectively simulate project conditions and multi-agent decisions. The causal link between decisionmaking and project systems was set through construction method selection, and the simulated construction methods/resource utilization plans performed better in achieving environmentally conscious construction. By this way, the findings of the study can assist contractors to select the most feasible construction method and resource combination.

The proposed framework yielded statistically significant results in simulating project conditions and optimizing TCEI. The relationship among time, cost and environmental impact was analyzed with the help of Pearson's correlation. The proposed procedure defined correlations among time, cost and environmental impact (TCEI), which can demonstrate contractors how significantly their decisions affect the relationship of TCEI.

This dissertation contributes to existing literature by demonstrating the possibility of combining decision-making, resource utilization, and LCA in a multi-objective optimization procedure. The potential for searching the most feasible construction method under the influence of changing project conditions is promising. The methods that are used to set the link between changing project conditions and the relationship of TCEI are significant to reflect the multi-objectivity and behavior of complex construction projects. Through the case studies, it has been found that existing life cycle assessment of construction processes is limited by the availability of life cycle inventory data, which cannot address the uniqueness of each project. In spite of this limitation, the proposed procedure was able to define correlations among time, cost and environmental impact. 
For future studies, it is critical to develop methods for acquiring reliable environmental data particular to each construction project. Other suggestions to improve the framework include interacting scheduling software into the proposed model, so that complex project relationships (i.e., relationships other than finish-to-start) can be handled. Another suggestion is to add new parameters and relationships among project conditions. For example, contract clauses or negotiation mechanisms can be added between agents. This process can enhance the decision-making mechanisms of agents, as they are directly affected by changing project conditions.

Additionally, the multi-objective optimization procedure in this study could be conducted without using certain algorithms. In the case study, a full procedure of genetic algorithm was not applied. The main reason for that is the limited number of construction methods associated with activities in the highway construction projects. Consequently, even though there are an unlimited number of combinations for project conditions, there are only 20 combinations of time, cost and environmental impact data. The optimal solutions can be quickly identified without going through a full procedure. This limitation is only due to the case. The analytical procedure should be further tested by including building construction cases, in which there typically exist a large number of activities, so that evolutionary algorithms, such as genetic algorithms, can be applied.

It is also a good idea to improve the proposed framework by studying other environmental impact parameters in addition to GHG emissions. Although this 
suggestion would make data process and analysis of the framework much more complex, it can change the results obtained for the relationship between time, cost and environmental impact. Such a framework can also be practiced by using different case studies.

Finally, the proposed framework includes multiple topics and their corresponding software for the simulation. A user-friendly platform can be proposed to enhance the usability and practicality of the analytical procedure. By this way, the users will be able to learn the process easily and fill in the input cells to simulate the construction projects. This process will both save time and take attention of the users to adopt the framework. 


\section{References}

Abdel-Hamid, T. K. (1984). The dynamics of software development project management: An integrative systems dynamics perspective. Ph.D. thesis . Cambridge, MA: Massachusetts Institute of Technology.

Abdel-Hamid, T. K. (1988). Understanding the '90\% Syndrome' in Software Project Management: A Simulation-Based Case Study. Journal of Systems and Software , 8, 319330.

Abdel-Hamid, T., \& Madnick, S. (1991). Software Project Dynamics, An Integrated Approach. Englewood Cliffs, NJ: Prentice-Hall.

Afhsar, A., Kaveh, A., \& Shoghli, O. (2007). Multi-objective optimization of time-costquality using multi-colony ant algorithm. Asian Journal of Civil Engineering , 8 (2), 113 124.

Al-Momani, A. H. (2000). Construction delay: a quantitative analysis. International Journal of Project Management , 18 (1), 51-59.

Anumba, C. J., Ren, Z., Thorpe, A., Ugwu, O. O., \& Newnham, L. (2003). Negotiation within a multi-agent system for the collaborative design of light industrial buildings. Advances in Engineering Software , 34, 389-401.

Arain, F. M., \& Pheng, L. S. (2005). The potential effects of variation orders on institutional building projects. Facilities , 23 (11), 496-510.

Arun, C., \& Rao, B. N. (2007). Knowledge based Decision Support Tool for Duration and Cost Overrun Analysis of Highway Construction Projects. Journal of the Institution of Engineers , 88 (8), 27-33.

Assaf, S. A., \& Al-Hejji, S. (2006). Causes of delay in large construction projects. International Journal of Project Management , 24, 349-357.

Azaron, A., Katagiri, H., \& Sakawa, M. (2007). Time-cost trade-off via optimal control theory in Markov PERT networks. Annals of Operations Research , 150, 47-64.

Bahia, H. U. (1993). Bibliographies for physical properties of asphalt cement, SHRP-A626. Washington, DC.: National Research Council.

Bellifemine, F., Caire, G., Poggi, A., \& Rimassa, G. (2008). JADE: A software framework for developing multi-agent applications. Lessons learned. Information and Software Technology , 50, 10-21.

Bengtsson, M. (2001). Weighting in practice: implications for the use of life-cycle assessment in decision making. Journal of Industrial Ecology , 4 (4), 47-60. 
Bilec, M., Ries, R., \& Matthews, H. S. (2007). Sustainable development and green design - who is leading the green initiative? Journal of Professional Issues in Engineering Education and Practice , 133 (4), 265-269.

Bilec, M., Ries, R., Matthews, H. S., \& Sharrard, A. L. (2006). Example of a hybrid life cycle assessment of construction processes. Journal Infrastructure Systems , 12, 207-215.

Bishop, I. D., Stock, C., \& Williams, K. J. (2008). Using virtual environments and agent models in multi-criteria decision-making. Land Use Policy, 26, 87-94.

Boje, D. M., \& Murnighan, J. K. (1982). Group Confidence Pressures in Iterative Decisions. Management Science , 28, 1187-1196.

Bourdeau, L. (1999). Sustainable development and the future of construction: a comparison of vision from various countries. Journal of Building Research and Information , 27 (6), 354-366.

Bousquet, F., \& Le Page, C. (2004). Multi-agent simulations and ecosystem management: a review. Ecological Modelling , 176, 313-372.

Bradshaw, J. M. (1997). Software Agents. AAAI Press, MIT Press.

Browning, T. R., Fricke, E., \& Negele, H. (2006). Key Concepts in Modeling Product Development Processes. Systems Engineering , 9 (2), 104-128.

Brustoloni, J. (1991). Autonomous Agents: Characterisation and Requirements. Carnegie Mellon University, Pittsburgh, PA.

Burns, S. A., Liu, L., \& Feng, C. (1996). The LP/IP hybrid method for construction timecost trade-off analysis. Construction Management and Economics , 14, 265-276.

CCE. (2005). Road Rehabilitation Energy Reduction Guide for Canadian Road Builders. Canadian Construction Association . Ontario: Natural Resources Canada.

Chan, D. W., \& Kumaraswamy, M. M. (1996). An evaluation of construction time performance in the building industry. Building and Environment , 31 (6), 569-578.

Chappat, M., \& Bilal, J. (2003). The Environmental Road of the Future: Life Cycle Analysis, Energy Consumption and Greenhouse Gas Emissions. Colas Group.

Chen, Z., Heng, L., \& Wong, C. T. (2005). EnvironalPlanning: Analytic Network Process Model for Environmentally Conscious Construction Planning. Journal of Construction Engineering and Management, 131 (1), 92-101.

Chen, Z., Li, H., \& Wong, C. T. (2000). Environmental management of urban construction projects in China. Journal of Construction Engineering and Management, $126,320-324$. 
Chen, Z., Li, H., Kong, S. C., \& Xu, Q. (2005). A knowledge-driven management approach to environmental-conscious construction. Construction Innovation , 5, 27-39.

Cheng, E. W., \& Li, H. (2005). Analytic Network Process Applied to Project Selection. Journal of Construction Engineering and Management , 131 (4), 459-466.

Cheng, E. W., \& Li, H. (2001). Information Priority-Setting for Better Resource Allocation Using Analytic Hierarchy Process (AHP). Information Management \& Computer Security, 9 (2), 61-70.

Cheng, E. W., \& Li, H. (2006). Job Performance Evaluation for Construction Companies: An Analytic Network Process Approach. Journal of Construction Engineering and Management, 132 (8), 827-835.

Cheng, S., Chan, C. W., \& Huang, G. (2002). Using multiple criteria decision analysis for supporting decisions of solid waste management. Journal of Environmental Science \& Health , A37 (6), 975-990.

Chowdhury, A., \& Button, J. W. (2008). A Review of Warm Mix Asphalt. Texas A\&M University System, Texas Transportation Institute, College Station, TX.

Clymer, J. R. (2000). Optimizing production work flow using OpEMCSS. Proceedings of the Winter Simulation Conference, 10-13 December. Orlando, FL.

Clymer, J. R. (1999). Simulation-based engineering of complex adaptive systems. Proceedings of the Winter Simulation Conference, 5-8 December. Phoenix, AZ.

Cole, R. (1999). Building environmental assessment methods. Building Research and Information , 27 (4/5), 230-246.

Cole, R. (1998). Emerging trends in building environmental assessment. Building Research and Information, 26 (1), 3-16.

Cooper, K. G. (1980). Naval ship production: A claim settled and a framework built. Interfaces , 10 (6), 20-36.

Cooper, K. G. (1993). The change cycle: Benchmarks for the project manager. Project Management Journal , 24 (1), 17-22.

Curran, M. A. (1996). Environmental Life-Cycle Assessment. NY: McGraw-Hill.

Cysewski, J. B. (1995). 3M International Environmental Management System. Total Quality and Environment Management , 5 (2), 25-34.

Dayananda, D., Irons, R., Harrison, S., Herbohn, J., \& Rowland, P. (2002). Capital Budgeting: Financial Appraisal of Investment Projects (First Edition ed.). Cambridge, UK: Cambridge University Press. 
Dijkstra, J., \& Timmermans, H. (2002). Towards a multi-agent model for visualizing simulated user behavior to support the assessment of design performance. Automation in Construction , 11, 135-145.

Dorchies, P. T. (2008). The Environmental Road of the Future: Analysis of Energy Consumption and Greenhouse Gas Emissions. The 2008 Annual Conference of the Transportation Association of Canada. Toronto, Ontario.

Doyle, J. K., \& Ford, D. N. (1998). Mental Models Concepts for System Dynamics Research. System Dynamics Review , 14 (1), 3-29.

Doyle, J. K., Ford, D. N., Radzicki, M. J., \& Trees, M. J. (2001). Mental Models of Dynamic Systems. UNESCO Encyclopedia of Life Support Systems . UK: EOLSS Publications.

El-Rayes, K., \& Kandil, A. (2005). Time-cost-quality trade off analysis for highway construction. Journal of Construction Engineering and Management , 131 (4), 477-486.

El-Rayes, K., \& Moselhi, O. (2001). Impact of rainfall on the productivity of highway construction. Journal of Construction Engineering and Management, 127 (2), 125-131.

EPA. (2011). Evaluation of the 100\% Recyclability of Superpave Hot Mix Asphalt. Retrieved June 06, 2011, from Extramural Research: http://cfpub.epa.gov/ncer_abstracts/INDEX.cfm/fuseaction/display.abstractDetail/abstract /9497/report/0

EPA. (1993). Life Cycle Assessment: Inventory Guidelines and Principles, EPA/600/R92/245. U.S. Environmental Protection Agency, Office of Research, Washington, D.C.

EPA. (2009). Potential for Reducing Greenhouse Gas Emissions in the Construction Sector. U.S. Environmental Protection Agency, Washington, D.C.

EPA. (2009). Potential for Reducing Greenhouse Gas Emissions in the Construction Sector. U.S. Environmental Protection Agency, Washington, DC.

EPA. (2008). The Emission and Generation Resource Integrated Database. Washington, D.C.: U.S. Environmental Protection Agency.

EPA. (2003). User's guide to MOBILE 6.1 and MOBILE 6.2: mobiles source emission factor model. Washington, D.C.: U.S. Environmental Protection Agency.

Erffmeyer, R. C., \& Lane, I. M. (1984). Quality and acceptance of an evaluative task: the effects of four group decision-making formats. Group and Organization Studies , 9 (4), 509-529.

Feng, C., Liu, L., \& Burns, S. (2000). Stochastic construction time-cost trade-off analysis. Journal of Computing in Civil Engineering , 14 (2), 117-126. 
Feng, C., Liu, L., \& Burns, S. (1997). Using genetic algorithms to solve construction time-cost trade-off problems. Journal of Computing in Civil Engineering , 11 (3), 184189.

Ferber, J. (1999). Multi-Agent System, An Introduction to Distributed Artificial Intelligence. Addison-Wesley, Pearson Education Limited.

Fischer, G. (1981). When oracles fail - A comparison of four procedures for aggregating subjective probability forecasts. Organizational Behavior and Human Performance , 28, 96-110.

Fondahl, J. W. (1961). A Non-Computer Approach to the Critical Path Method for the Construction Industry. The Construction Institute, Department of Civil Engineering. Stanford, CA: Stanford University.

Ford, D. N. (2002). Achieving multiple project objectives through contingency management. Journal of Construction Engineering and Management , 128 (1), 30-39.

Ford, D. N. (1995). The dynamics of project management: An investigation of the impacts of project process and coordination on performance. Doctoral thesis . Cambridge, MA: Massachusetts Institute of Technology.

Ford, D. N., \& Mahieu, L. A. (1998). Operationalising the Resource-Based View of the Firm. International System Dynamics Conference. Quebec.

Ford, D. N., \& Sterman, J. D. (1998). Dynamic modeling of product development processes. System Dynamics Review , 14 (1), 31-68.

Ford, D. N., \& Sterman, J. D. (2003b). Overcoming the 90\% syndrome: Iteration management in concurrent development projects. Concurrent Engineering: Research and Applications , 111 (3), 177-186.

Ford, D. N., \& Sterman, J. D. (2003a). The liar's club: Concealing rework in concurrent development. Concurrent Engineering: Research and Applications , 111 (3), 211-219.

Ford, D. N., Anderson, S. D., de Las Casas, R., Gokmen, N., \& Kuennen, S. T. (2004). Managing Constructibility Reviews to Reduce Highway Project Durations. Journal of Construction Engineering and Management , 130 (1), 33-42.

Ford, D. N., Lyneis, J. M., \& Taylor, T. R. (2007). Project Controls to Minimize Cost and Schedule Overruns: A Model, Research Agenda, and Initial Results. The 2007 International Conference of the System Dynamics Society and 50th Anniversay Celebration, July 29 - August 2. Boston, MA.

Forrester, J. (1971). Counterintuitive behavior of social systems (Vol. In Collected Papers of J. W. Forrester). Cambridge, MA: Wright-Allen Press, Inc. 
Forrester, J. (1961). Industrial Dynamics. Cambridge, MA: Productivity Press.

Forrester, J. (1994). Policies, decisions, and information sources for modeling, In Morecroft, J. D. W., and Sterman, J. D. (Eds.), Modeling for Learning Organizations. Portland, OR: Productivity Press.

Frey, D., Stockheim, T., Woelk, P., \& Zimmermann, P. (2003). Integrated multi-agentbased supply chain management. Proceedings of the Twelfth IEEE International Workshops on Enabling Technologies: Infrastructure for Collaborative Enterprises, 9-11 June. Johannes Kepler University of Linz, Austria.

Frimpong, Y., Oluwoye, J., \& Crawford, L. (2003). Causes of delay and cost overruns in construction of groundwater projects in a developing countries; Ghana as a case study. International Journal of Project Management , 21 (5), 321-326.

Fujii, H., \& Tanimoto, J. (2004). Integration of building simulation and agent simulation for exploration to environmentally symbiotic architecture. Building and Environment , $39,885-893$.

Gangolells, M., Casals, M., Gasso, S., Forcada, N., Roca, X., \& Fuertes, A. (2009). A methodology for predicting the severity of environmental impacts related to the construction process of residential buildings. Building and Environment, 44 (3), 558571.

Garcia, J. M. (2006). Theory and practical exercises of system dynamics. Barcelona, Spain: Universitat Politecnica De Catalunya.

Graham, A. K. (2000). Beyond PM 101:lessons for managing large development programs. Project Management Journal, PMI, 31 (4), 7-18.

Gupta, A., Whitman, L., \& Agarwal, R. K. (2001). Supply chain agent decision aid system (SCADAS). Proceedings of the 2001 Winter Simulation Conference, (pp. 553559). Arlington, VA.

Hackman, J., \& Morris, C. (1975). Group tasks, group interaction process, and group performance effectiveness: A review and proposed integration. (L. Berkowitz, Ed.) New York, NY: Academic Press.

Hajjar, D., \& AbouRizk, S. (1992). Simphony: an environment for building special purpose construction simulation tools. Proceedings of the Winter Simulation Conference, 5-8 December. Phoenix, AZ.

Hallowell, M. R., \& Gambatese, J. A. (2010). Qualitative Research: Application of the Delphi Method to CEM Research. Journal of Construction Engineering and Management , 136 (1), 99-107. 
Halpin, D. W. (1977). CYCLONE: Method for Modeling of Job Site Processes. Journal of the Construction Division, 103 (3), 489-499.

Halpin, D. W., \& Riggs, L. S. (1992). Planning and Analysis of Construction Operations. New York, NY: Wiley Inter Science.

Hanna, A. S., Russell, J. S., \& Vandenberg, P. (1999). The impact of change orders on mechanical construction labour efficiency. Construction Management and Economics , 17 (6), 721-730.

Hassan, M. M. (2009). Life-Cycle Assessment of Warm-Mix Asphalt: An Environmental and Economic Perspective. The 88th Transportation Research Board Annual Meeting. Washington, DC.

Henderickson, C., \& Au, T. (1989). Project Management for Construction. Englewood Cliffs, NJ: Prentice-Hall, Inc.

Hendrickson, C., \& Horvath, A. (2000). Resource use and environmental emissions of U.S. construction sectors. Journal of Construction Engineering and Management , 126 (1), 38-44.

Huddleston, J. (2008). Sustainable Pavement Management Practices. Northwest Pavement Management Association 2008 Fall Conference. Vancouver, WA.

IPCC. (2007). Climate Change 2007: Mitigation. Contribution of Working Group III to the Fourth Assessment Report of the Intergovernmental Panel on Climate Change. [Metz, B., O.R. Davidson, P.R. Bosch, R. Dve, L.A. Myer (eds)]. Cambridge, U.K. and New York, NY, U.S.A.: Cambridge University Press.

Jennings, N., Sycara, K., \& Woodridge, M. (1999). A roadmap of agent research and development. Autonomous Agents and Multi-Agent Systems , 1 (1), 7-38.

Jiang, A., \& Zhu, Y. (2010). A multi-stage approach to time-cost trade-off analysis using mathematical programming. International Journal of Construction Management .

Joglekar, N., \& Ford, D. N. (2005). Product development resource allocation with foresight. European Journal of Operational Research , 160 (1), 72-87.

Kandil, A., \& El-Rayes, K. (2006). MACROS: Multiobjective automated construction resource optimization system. Journal of Management in Engineering , 22 (3), 126-134.

Kandil, A., El-Rayes, K., \& El-Anwar, O. (2010). Optimization research: enhancing the robustness of large-scale multiobjective optimization in construction. Journal of Construction Engineering and Management, 136 (1), 17-25. 
Keoleian, G. A., Blanchard, S., \& Reppe, P. (2001). Life-cycle energy, costs, and strategies for improving a single-family house. Journal of Industrial Ecology , 4 (2), 135156.

Kim, K., \& Paulson, B. C. (2003). An agent-based compensatory negotiation methodology to facilitate distributed coordination of project schedual changes. Journal of Computing in Civil Engineering , 17 (1), 10-18.

Kua, H. W., \& Lee, S. E. (2002). Demonstration intelligent building-a methodology for the promotion of total sustainability in the built environment. Building and Environment, $37,231-240$.

Kuang, Y., \& Xiong, Y. (2007). Construction time-cost trade-off analysis using ant colony optimization algorithm. The International Conference on Management Science and Engineering. Chengdu, China.

Larsen, D. A. (2003). Demonstration and Evaluation of SUPERPAVE Technologies, Final Evaluation Report for CT Route 2, Report No: 2219-F-02-7. Connecticut Department of Transportation, Bureau of Engineering and Highway Operations Research and Materials, Rocky Hill, CT.

Lee, S., Pena-Mora, F., \& Park, M. (2005). "Quality and change management model for large scale concurrent design and construction projects. Journal of Construction Engineering and Management, 131 (8), 890-902.

Lee, S., Pena-Mora, F., \& Park, M. (2006). Reliability and stability buffering approach: Focusing on the issues of errors and changes in concurrent design and construction projects. Journal of Construction Engineering and Management , 131 (5), 452-464.

Lee, Z. W., Ford, D. N., \& Joglekar, N. (2007). Effects of Resource Allocation Policies for Reducing Project Durations: A Systems Modelling Approach. Systems Research and Behavioral Science, 24, 551-556.

Leu, S., Chen, A., \& Yang, C. (2001). A GA-based fuzzy optimal model for construction time-cost trade-off. International Journal of Project Management , 19, 47-55.

Li, J., Sheng, Z., \& Liu, H. (2010). Multi-agent simulation for the dominant players' behavior in supply chains. Simulation Modelling Practice and Theory, 18, 850-859.

Li, X., Zhu, Y., \& Zhang, Z. (2010). An LCA-based environmental impact assessment model for construction processes. Building and Environment , 45 (3), 766-775.

Lippiatt, B. C. (1999). Selecting cost-effective green building products: BEES approach. Journal of Construction Engineering and Management, 125 (6), 448-455.

Logical Decisions. (2007). Logical Decisions, Decision Support Software, User's Manual. Fairfax, VA: Logical Decisions. 
Love, P., Mandal, P., \& Li, H. (1999). Determining the causal structure of rework influences in construction. Construction Management and Economics , 17 (4), 505-517.

Lyneis, J. M., \& Ford, D. N. (2007). System dynamics applied to project management: a survey, assessment, and directions for future research. System Dynamics Review , 23, 157-189.

Lyneis, J. M., Cooper, K. G., \& Els, S. A. (2001). Strategic management of complex projects: a case study using system dynamics. System Dynamics Review , 17, 237-260.

Maes, P. (1995). Artificial life meets entertainment: life like autonomous agents. Communications of the ACM, Special Issue on New Horizons of Commercial and Industrial AI , 38 (11), 108-114.

Martinez, J., \& Ioannou, P. (1999). General-purpose systems for effective construction simulation. Journal of Construction Engineering and Management , 125 (4), 265-276.

Marzouk, M., \& Moselhi, O. (2004). Multiobjective optimization of earthmoving operations. Journal of Construction Engineering and Management , 130 (1), 105-113.

Marzouk, M., Madany, M., Abou-Zied, A., \& El-Said, M. (2008). Handling construction pollutions using multi-objective optimization. Construction Management and Economics , 26, 1113-1125.

Meade, L. M., \& Presley, A. (2002). R and D Project Selection Using the Analytic Network Process. IEEE Transaction on Engineering Management , 49 (1), 59-66.

Moselhi, O. (1993). Schedule compression using the direct stiffness method. Canadian Journal of Civil Engineering, Ottawa , 20 (1), 65-72.

Mouzon, G., \&Yildirim, M. B. (2008). A Framework To Minimize Total Energy Consumption And Total Tardiness On A Single Machine. International Journal of Sustainable Engineering, 1 (2), 105-116.

Muench, S. T., \& Anderson, J. L. (2009). Greenroads: A sustainability performance metric for roadway design and construction. University of Washington, Transportation Northwest Regional Center X (TransNow), Seattle, WA .

Mukherjee, A., \& Rojas, E. M. (2003). Reasoning About Actions and Events in Situational Simulations. Proceedings of the 2003 Winter Simulation Conference, (pp. 1552-1560). New Orleans, LA.

Mukherjee, A., Rojas, E. M., \& Winn, W. D. (2004). Implementing a General Purpose Framework Using Multi-Agents for Construction Management Education. Proceedings of the 2004 Winter Simulation Conference, (pp. 1244-1251). Washington, DC. 
Mukherjee, A., Winn, W., \& Rojas, E. (2005). Interactive Situational Simulations in Construction Management. The First Conference on the Future of the AEC Industry. Las Vegas, NV: The Building Futures Council.

NREL. (2004). U.S. LCI Database Project: User Guide. Golden, CO: The National Renewable Energy Laboratory.

Nwana, H. S. (1996). Software agents: an overview. The Knowledge Engineering Review , $11(3), 205-244$.

Ofori, G. (1992). The environment: the fourth construction project objective? Construction Management and Economics , 10 (5), 369-395.

Ogunlana, S., Li, H., \& Sukhera, F. (2003). System dynamics approach to exploring performance enhancement in a construction organization. Journal of Construction Engineering and Management, 129 (5), 528-536.

Omicini, A., \& Zambonelli, F. (1999). Coordination for Internet application development. International Journal of Autonomous Agents and Multi-Agent Systems , 2 (3), 251-269.

Osyczka, A. (2002). Evolutionary Algorithms for Single and Multicriteria Design Optimization. Physica, NY.

Ozcan, G., \& Zhu, Y. (2009). Life-Cycle Assessment of a Zero-Net Energy House. The Proceedings of the International Conference of Construction and Real Estate Management (ICCREM), the Chinese Construction Industry Press. Beijing, China.

Ozorhon, B., Dikmen, I., \& Birgonul, M. T. (2007). Using Analytic Network Process to Predict the Performance of International Construction Joint Ventures. Journal of Management in Engineering , 23 (3), 156-163.

Park, M., \& Pena-Mora, F. (2003). Dynamic change management for construction: Introducing the change cycle into model-based project management. System Dynamics Review, 19 (3), 213-242.

Park, M., Nepal, M., \& Dulaimi, M. (2004). Dynamic modeling for construction innovation. Journal of Management in Engineering , 20 (4), 170-177.

Partovi, F. Y. (2006). An Analytic Model for Locating Facilities Strategically. Omega, 34, 41-55.

Pena-Mora, F., \& Li, M. (2001). "Dynamic planning and control methodology for design/build fast-track construction projects. Journal of Construction Engineering and Management , 127 (1), 1-17. 
Pena-Mora, F., \& Park, M. (2001). Dynamic planning for fast-tracking building construction projects. Journal of Construction Engineering and Management , 127 (6), 445-456.

Polydoropoulou, A., \& Roumboutsos, A. (2009). Evaluating the impact of decision making during construction on transport project outcome. Evaluation and Program Planning , 32, 369-380.

Prager, W. (1963). A structured method of computing project cost polygons. Management Science , 9 (3), 394-404.

Pulselli, R. M., Simoncini, M., \& Marchettini, N. (2009). Energy and emergy based costbenefit evaluation of building envelopes relative to geographical location and climate. Building and Environment , 44, 920-928.

Rakas, J., Teodorovic, D., \& Kim, T. (2004). Multi-objective modeling for determining location of undesirable facilities. Transportation Research , D 9, 125-138.

Ren, Z., \& Anumba, C. J. (2002). Learning in multi-agent systems: a case study of construction claims negotiation. Advanced Engineering Informatics , 16, 265-275.

Ren, Z., \& Anumba, C. J. (2004). Multi-agent systems in construction-state of the art and prospects. Automation in Construction , 13, 421-434.

Ren, Z., Anumba, C. J., \& Ugwu, O. O. (2003). The development of a multi-agent system for construction claims negotiation. Advances in Engineering Software , 34, 683-696.

Repenning, N. P., \& Sterman, J. D. (2001). Nobody Ever Gets Credit for Fixing Problems that Never Happened: Creating and Sustaining Process Improvement. California Management Review , 43 (4), 64-88.

Richardson, G. P., \& Pugh, A. L. (1981). Introduction to System Dynamics Modeling with Dynamo. Cambridge, MA: MIT Press.

Roberts, F., Mohammad, M., \& Wang, L. (2002). History of hot mix asphalt mixture design in the USA. Journal of Materials Civil Engineering , 14 (4), 279-293.

Rodrigues, A. G. (2001). Managing and modelling project risk dynamics: a system dynamics-based framework. The Fourth European Project Management Conference: PMI Europe 2001, 6-7 June. London.

Rodrigues, A. G. (1994). The role of system dynamics in project management: A comparative analysis with traditional methods. International System Dynamics Conference. Lincoln, MA. 
Rodrigues, A., \& Bowers, J. (1996). System dynamics in project management: a comparative analysis with traditional methods. System Dynamics Review , 12 (1), 121139.

Rodrigues, A., \& Williams, T. M. (1997). "System dynamics in project management: assessing the impacts of client behavior on project performance. Journal of Operational Research , 49, 2-15.

Rohrbaugh, J. (1979). Improving the Quality of Group Judgment: Social Judgment Analysis and the Delphi Technique. Organizational Behavior and Human Performance, 24, 73-92.

Rojas, E. M., \& Mukherjee, A. (2003). Modeling the Construction Management Process to Support Situational Simulations. Journal of Computing in Civil Engineering , 17 (4), $273-280$.

Rojas, E. M., \& Mukherjee, A. (2006). Multi-Agent Framework for General-Purpose Situational Simulations in the Construction Management Domain. Journal of Computing in Civil Engineering , 20 (3), 165-176.

Russell, M., Uhlmeyer, J. S., DeVol, J., \& Johnson, C. (2010). Evaluation of Hot InPlace Recycle. Washington State Department of Transportation, Materials Laboratory, MS-47365, Olympia, WA.

Russell, S., \& Norvig, P. (2002). Artificial intelligence: A modern approach (2nd ed.). Upper Saddle River, NJ: Prentice-Hall.

Saaty, R. W. (2003). Decision Making in Complex Environments. Pittsburgh, PA: Creative Decisions Foundation.

Saaty, T. L. (1996). Decision making with dependence and feedback: The analytic network process. Pittsburgh: RWS Publ.

Saaty, T. L. (2001). Decision-Making with the AHP: Why Is the Principal Eigenvector Necessary. In K. Dellman (Ed.), ISAHP Proceedings, 2-4 August 2001, (pp. 383-396). Bern, Switzerland.

Saaty, T. L. (2004). Fundamentals of the Analytical Network Process-Dependence and Feedback in Decision-Making with a Single Network. Journal of Systems Science and Systems Engineering , 13 (2), 129-157.

Saaty, T. L. (1994). How to Make A Decision: The Analytic Hierarchy Process. Interfaces , 24 (6), 19-43.

Saaty, T. L. (1980). The Analytic Hierarchy Process. New York, NY: McGraw-Hill. 
Saaty, T. L. (2005). Theory and Applications of the Analytic Network Process: Decision Making with Benefits, Opportunities, Costs, and Risks. Pittsburgh, PA: RWS Publications.

Saaty, T. L., \& Vargas, L. G. (2006). Decision Making with the Analytical Network Process: Economic, Polytical, Socail and Technological Applications with Benefits, Opportunities, Costs and Risks. New York, NY: Springer Science+ Business Media, LLC.

Sartori, I., \& Hestnes, A. G. (2007). Energy use in the life cycle of conventional and lowenergy buildings: A review article. Energy and Buildings , 39, 249-257.

Selih, J. (2007). Environmental management systems and construction SMES: a case study for Slovenia. Journal of Civil Engineering and Management , 13 (3), 217-226.

Sharrard, A. L., Matthews, H. S., \& Roth, M. (2007). Environmental implications of construction site energy use and electricity generation. Journal of Construction Engineering and Management , 133 (11), 846-854.

Shen, L. Y., Lu, W. S., Yao, H., \& Wu, D. H. (2005a). A computer-based scoring method for measuring the environmental performance of construction activities. Automation in Construction, 14, 297-309.

Shen, L. Y., Wu, Y. Z., Chan, E. H., \& Hao, J. L. (2005b). Application of system dynamics for assessment of sustainable performance of construction projects. Journal of Zhejiang University SCIENCE, 6A (4), 339-349.

Sholar, G. A., Page, G. C., Musselman, J. A., \& Moseley, H. L. (2004). Resurfacing of SR-471 Using the Hot-In-Place Recycling Process. FL State Materials Office.

Simon, H. (1996). The Sciences of the Artificial. Cambridge, MA: MIT Press.

Smith, D., Cypher, A., \& Spohrer, J. (1994). Kidsim: programming agents without a programming language. Communications of the ACM , 37 (7), 54-67.

Sniezek, J. A. (1990). A comparison of techniques for judgmental forecasting by groups with common information. Group and Organization Studies , 15 (1), 5-19.

Soibelman, L., \& Pena-Mora, F. (2000). Distributed multi-reasoning mechanism to support conceptual structural design. Journal of Structural Engineering , 126 (6), 733 742.

Sterman, J. (2000). Business dynamics: Systems thinking and modeling for a complex world. New York, NY: Irwin McGraw-Hill.

Sterman, J. (1992). System dynamics modeling for project management. Sloan School of Management. Cambridge, MA: Massachusets Institute of Technology (MIT). 
Sun, M., \& Meng, X. (2009). Taxonomy for change causes and effects in construction projects. International Journal of Project Management , 27, 560-572.

Tah, J. H. (2005). Towards an agent-based construction supply network modelling and simulation platform. Automation in Construction, 14, 353-359.

Tah, J. H. (2006). Towards an agent-based construction supply network modelling and simulation platform. Automation in Construction, 14, 353-359.

Tang, Y., \& Ogunlana, S. (2003). Modeling the dynamic performance of a construction organization. Construction Management and Economics , 21 (2), 127-136.

Taylor, T. R., \& Ford, D. N. (2008). Managing Tipping Point Dynamics in Complex Construction Projects. Journal of Construction Engineering and Management , 134 (6), 421-431.

Taylor, T. R., \& Ford, D. N. (2006). Tipping point dynamics in development projects. System Dynamics Review , 22 (1), 51-71.

Terrel, R. L., \& Hicks, R. G. (2008). Viability of Hot In-Place Recycling as a Pavement Preservation Strategy. California Pavement Preservation Center, CP2 Center, Chico, CA.

Thabrew, L., Wiek, A., \& Ries, R. (2009). Environmental decision making in multistakeholder contexts: applicability of life cycle thinking in development planning and implementation. Journal of Cleaner Production , 17, 67-76.

Tuzkaya, G., Onut, S., Tuzkaya, U. R., \& Gulsun, G. (2008). An Analytic Network Process Approach for Locating Undesirable Facilities: An Example from Istanbul, Turkey. Journal of Environmental Management , 88, 970-983.

U.S.-DOE. (2007). Lifetime Cycle Inventory of Biodiesel and Petroleum Diesel for Use on an Urban Transit Bus, MAy 1998. (U.S. Dept. of Energy) Retrieved February 11, 2011, from Kansas Energy Chart Book, Chapter 5:

http://kec.kansas.gov/chart_book/Chapter5/03_LifeCycleGHGEmissions.pdf

Udeaja, C., \& Tah, J. (2001). Agent-based material supply chain integration in construction. In C. E. C.J. Anumba, Perspectives on Innovation in Architecture Engineering and Construction, CICE (pp. 377-388). Loughborough University.

Ugwu, O. O., Anumba, C. J., \& Thorpe, A. (2005). Ontological foundations for agent support in constructability assessment of steel structures-a case study. Automation in Construction , 14, 99-114.

UNEP-SBCI. (2009). Buildings and Climate Change: Summary for Decision Makers. Paris, France: United Nations Environment Programme. 
USGBC. (2008). A National Green Building Research Agenda. (the U.S. Green Building Council (USGBC) Research Committee) Retrieved December 16, 2010, from http://www.usgbc.org/ShowFile.aspx?DocumentID=3402

Vensim. (2007). Vensim-User's Guide Version 5.0. Ventana ${ }^{\circledR}$ Simulation Environment. Harvard, MA: Ventana Systems, Inc.

Williams, T. M. (2000). Safety regulation changes during projects: the use of system dynamics to quantify the effects of change. International Journal of Project Management , $18(1), 23-31$.

Williams, T. (2002). Modelling Complex Projects. Chichester, UK: Wiley.

Wooldridge, M., \& Jennings, N. R. (1995). Intelligent agents: theory and practice. Knowledge Engineering Review , 10 (2), 115-152.

Wu, C., Hsieh, T., Lu, S., \& Cheng, W. (2004). Grey relation analysis of causes for change orders in highway construction. Construction Management and Economics , 22 (5), 509-520.

Wu, W., Simpson, A. R., \& Maier, H. R. (2010). Accounting for Greenhouse Gas Emissions in Multiobjective Genetic Algorithm Optimization of Water Distribution Systems. Journal of Water Resource Planning and Management , 136 (2), 146-155.

Xing, S., Xu, Z., \& Jun, G. (2008). Inventory analysis of LCA on steel and concrete construction office buildings. Energy and Buildings , 40, 1188-1193.

Xue, X., Li, X., Shen, Q., \& Wang, Y. (2005). An agent-based framework for supply chain coordination in construction. Automation in Construction, 14, 413-430.

Yao, H., Shen, L. Y., \& Yam, C. M. (2007). A fuzzy-analysis-based method for measuring contractor's environmental performance. Management of Environmental Quality: An International Journal , 18 (4), 442-458.

Yurdakul, M. (2003). Measuring Long-Term Performance of a Manufacturing Firm Using the Analytic Network Process (ANP) Approach. International Journal of Production Research , 41 (11), 2501-2529.

Zayed, T. M., \& Halpin, D. W. (2000). Simulation as a tool for resource management. Proceedings of the Winter Simulation Conference, 10-13 December. Orlando, FL.

Zeeger, C. V., \& Rizenbergs, R. L. (1979). Priority programming for highway reconstruction. Washington, DC: Transportation Research Record 698, Transportation Research Board.

Zhang, C., Hammad, A., \& Bahnassi, H. (2009). Collaborative multi-agent systems for construction equipment based on real-time field data capturing. Journal of Information 
Technology in Construction (ITcon), Special Issue Next Generation Construction IT:

Technology Foresight, Future Studies, Roadmapping, and Scenario Planning , 14, 204228.

Zheng, D. X., Ng, S. T., \& Kumaraswamy, M. M. (2004). Applying a genetic algorithmbased multiobjective approach for time-cost optimization. Journal of Construction Engineering and Management, 130 (2), 168-176. 
APPENDICES 
Appendix A: Vensim CM Selection Model and the Decision-Making Functions 


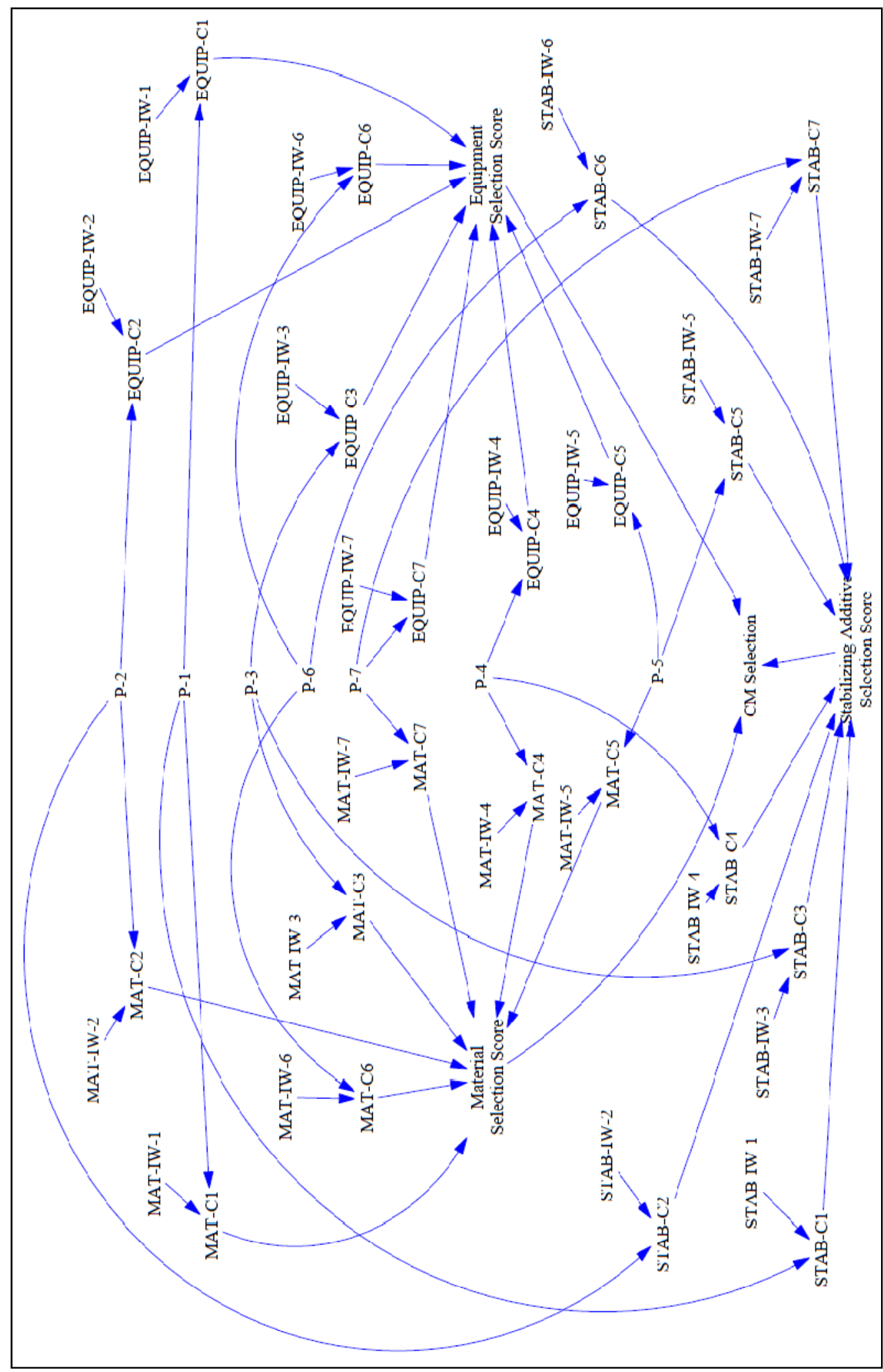

Vensim CM Selection Model 


\section{Vensim Decision-Making Functions}

(01) $\mathrm{CM}$ Selection = A FUNCTION OF( Equipment Selection Score, Material Selection Score, Stabilizing Additive Selection Score)

Units: **undefined**

"EQUIP-C1"= "EQUIP-IW-1"*"P-1"

Units: nondimensional

(03) "EQUIP-C2"= "EQUIP-IW-2"*"P-2"

Units: nondimensional

(04) "EQUIP-C3"= "EQUIP-IW-3"*"P-3"

Units: nondimensional

(05)

"EQUIP-C4"= "EQUIP-IW-4"*"P-4"

Units: nondimensional

(06)

"EQUIP-C5"= "EQUIP-IW-5"*"P-5"

Units: nondimensional

(07) EQUIP-C6"= "EQUIP-IW-6"*"P-6"

Units: nondimensional 
(08)

"EQUIP-C7"= "EQUIP-IW-7"*"P-7"

Units: nondimensional

(09) "EQUIP-IW-1" = constant

Units: nondimensional

(10) "EQUIP-IW-2" = constant

Units: nondimensional

(11) "EQUIP-IW-3" = constant

Units: nondimensional

(12) "EQUIP-IW-4" = constant

Units: nondimensional

(13) "EQUIP-IW-5" = constant

Units: nondimensional

(14) "EQUIP-IW-6" = constant

Units: nondimensional

(15) "EQUIP-IW-7" = constant

Units: nondimensional 
(16) Equipment Selection Score= "EQUIP-C1"+"EQUIP-C2"+"EQUIP-

C3"+"EQUIP-C4"+"EQUIP-C5"+"EQUIP-C6"+"EQUIP-C7"

Units: nondimensional $[0,100]$

(17) "MAT-C1"="MAT-IW-1"*"P-1"

Units: nondimensional

(18) "MAT-C2"="MAT-IW-2"*"P-2"

Units: nondimensional

(19) "MAT-C3"="MAT-IW-3"**"P-3"

Units: nondimensional

(20)

"MAT-C4"="MAT-IW-4"*"P-4"

Units: nondimensional

(21)

"MAT-C5"="MAT-IW-5"*"P-5"

Units: nondimensional

(22) "MAT-C6"="MAT-IW-6"*"P-6"

Units: nondimensional 
(23)

"MAT-C7"="MAT-IW-7"*"P-7"

Units: nondimensional

(24)

"MAT-IW-1" = constant

Units: nondimensional

(25) "MAT-IW-2" = constant

Units: nondimensional

(26) "MAT-IW-3" = constant

Units: nondimensional

(27) "MAT-IW-4"= constant

Units: nondimensional

(28) "MAT-IW-5" = constant

Units: nondimensional

(29) "MAT-IW-6" = constant

Units: nondimensional

(30) "MAT-IW-7" = constant

Units: nondimensional 
(31) Material Selection Score="MAT-C1"+"MAT-C2"+"MAT-C3"+"MATC4"+"MAT-C5"+"MAT-C6"+"MAT-C7"

Units: nondimensional $[0,100,20]$

(32) $\quad \mathrm{P}-1 "=$ constant

Units: Dimensionless [0,1]

(33) $\quad$ P-2"= constant

Units: Dimensionless $[0,1]$

(34) $\quad \mathrm{P}-3 "=$ constant

Units: Dimensionless $[0,1]$

(35) $\quad$ P-4"= constant

Units: Dimensionless $[0,1]$

(36) $\quad \mathrm{P}-5 "=$ constant

Units: Dimensionless $[0,1]$

(37) $\quad \mathrm{P}-6 "=$ constant

Units: Dimensionless [0,1] 
(38)

"P-7"= constant

Units: Dimensionless $[0,1]$

(39)

"STAB-C1"="STAB-IW-1"*"P-1"

Units: nondimensional

(40) "STAB-C2"="STAB-IW-2"*"P-2"

Units: nondimensional

(41)

"STAB-C3"="STAB-IW-3"*"P-3"

Units: nondimensional

"STAB-C4"="STAB-IW-4"*"P-4"

Units: nondimensional

(43) "STAB-C5"="STAB-IW-5"*"P-5"

Units: nondimensional

(44) "STAB-C6"="STAB-IW-6"*"P-6"

Units: nondimensional

"STAB-C7"="STAB-IW-7"*"P-7"

Units: nondimensional 
"STAB-IW-1" = constant

Units: nondimensional

(47) "STAB-IW-2" = constant

Units: nondimensional

(48)

"STAB-IW-3" = constant

Units: nondimensional

(49)

"STAB-IW-4" = constant

Units: nondimensional

(50) "STAB-IW-5" = constant

Units: nondimensional

(51) "STAB-IW-6" = constant

Units: nondimensional

(52) "STAB-IW-7" = constant

Units: nondimensional 
(53) Stabilizing Additive Selection Score="STAB-C1"+"STAB-C2"+"STABC3"+"STAB-C4"+"STAB-C5"+"STAB-C6"+"STAB-C7"

Units: nondimensional $[0,100]$ 
Appendix B: Vensim Project Model 


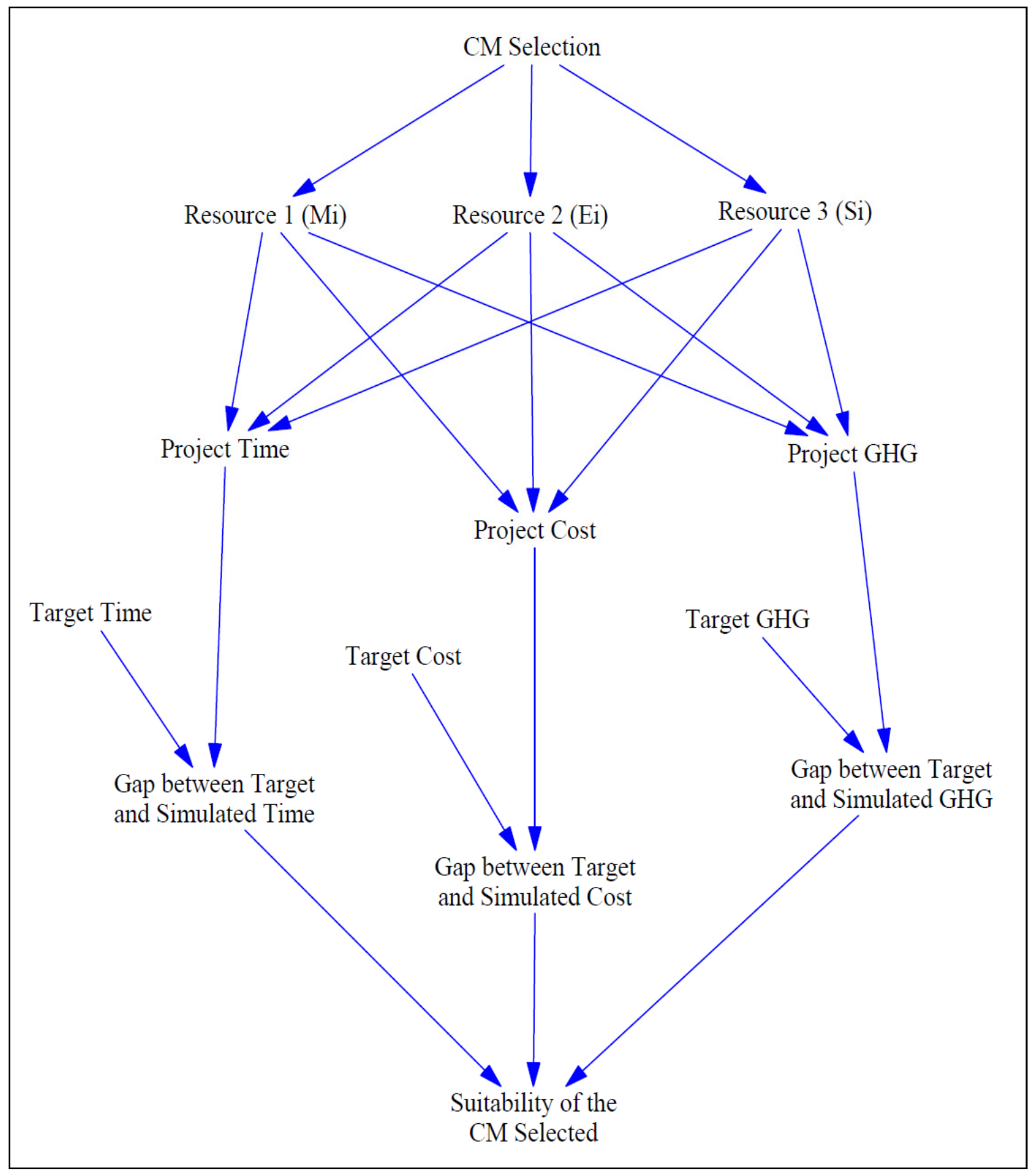

Vensim Project Model 
Appendix C: Vensim Proposed Model Functions 


\section{Vensim Proposed Model Functions}

(01) Cumulative Real Progress of CM Change= INTEG (Progress Rate-Discover CMs Needing Changes, 10)

Units: days

(02) Discover CMs Needing Changes $=$ IF THEN ELSE(Initiate CM Rate $>0,0,1$ ) Units: Dimensionless

(03) "EQUIP-C1"= "EQUIP-IW-1"*"P-1"

Units: nondimensional

(04) "EQUIP-C2"= "EQUIP-IW-2"*"P-2"

Units: nondimensional

(05)

"EQUIP-C3"= "EQUIP-IW-3"*"P-3"

Units: nondimensional

(06)

"EQUIP-C4"= "EQUIP-IW-4"*"P-4"

Units: nondimensional

(07) "EQUIP-C5"= "EQUIP-IW-5"*"P-5"

Units: nondimensional 
(08)

"EQUIP-C6"= "EQUIP-IW-6"*"P-6"

Units: nondimensional

(09) "EQUIP-C7"= "EQUIP-IW-7"*"P-7"

Units: nondimensional

(10) "EQUIP-IW-1"= 0.22169

Units: nondimensional

(11) "EQUIP-IW-2"= 0.16524

Units: nondimensional

(12) "EQUIP-IW-3"= 0.04685

Units: nondimensional

(13) "EQUIP-IW-4"= 0.23607

Units: nondimensional

(14) "EQUIP-IW-5"= 0.26938

Units: nondimensional

(15) "EQUIP-IW-6"= 0.03753

Units: nondimensional 
(16)

"EQUIP-IW-7"= 0.2323

Units: nondimensional

(17) Equipment Selection Score= "EQUIP-C1"+"EQUIP-C2"+"EQUIP-

C3"+"EQUIP-C4"+"EQUIP-C5"+"EQUIP-C6"+"EQUIP-C7"

Units: nondimensional $[0,100]$

(18) FINAL TIME $=40$

Units: Day

The final time for the simulation.

(19) Gap between Target and Simulated Cost $=($ Project Cost-Target Cost $) /$ Target Cost Units: Dimensionless

(20) Gap between Target and Simulated GHG= (Project GHG-Target GHG)/Target

GHG

Units: Dimensionless

(21) Gap between Target and Simulated Time $=($ Project Time-Target Time $) /$ Target Time

Units: Dimensionless 
(22) INITIAL TIME $=0$

Units: Day

The initial time for the simulation.

(23) Initial Value $=$ IF THEN ELSE(Original CM To Be Changed $<0,1,0$ )

Units: Dimensionless

(24) Initiate CM Rate $=$ IF THEN ELSE( Suitability of the CM Selected $<=0.35$, Initial Value, 0 )

Units: Dimensionless

(25) "MAT-C1"= "MAT-IW-1"*"P-1"

Units: nondimensional

(26)

"MAT-C2"= "MAT-IW-2"*"P-2"

Units: nondimensional

(27)

"MAT-C3"= "MAT-IW-3"*"P-3"

Units: nondimensional

(28) "MAT-C4"= "MAT-IW-4"*"P-4"

Units: nondimensional 
"MAT-C5"= "MAT-IW-5"*"P-5"

Units: nondimensional

(30)

"MAT-C6"= "MAT-IW-6"*"P-6"

Units: nondimensional

(31)

"MAT-C7"= "MAT-IW-7"*"P-7"

Units: nondimensional

(32) "MAT-IW-1"= 0.22169

Units: nondimensional

(33) "MAT-IW-2"= 0.16524

Units: nondimensional

(34) "MAT-IW-3" $=0.04685$

Units: nondimensional

(35) "MAT-IW-4" $=0.23607$

Units: nondimensional

(36) "MAT-IW-5" $=0.26938$

Units: nondimensional 
"MAT-IW-6"= 0.03753

Units: nondimensional

(38) $\quad$ "MAT-IW-7"= 0.02323

Units: nondimensional

(39) Material Selection Score= "MAT-C1"+"MAT-C2"+"MAT-C3"+"MATC4"+"MAT-C5"+"MAT-C6"+"MAT-C7"

Units: nondimensional $[0,100,20]$

(40) Original CM To Be Changed= INTEG ( Discover CMs Needing Changes-

Progress Rate, 20)

Units: days

(41) $\quad \mathrm{P}-1 "=$ constant

Units: Dimensionless [0,1]

(42) $\quad$ P-2"= constant

Units: Dimensionless $[0,1]$

(43) $\quad$ P-3"= constant

Units: Dimensionless [0,1] 
(44)

"P-4"= constant

Units: Dimensionless [0,1]

(45)

"P-5"= constant

Units: Dimensionless $[0,1]$

(46)

"P-6"= constant

Units: Dimensionless $[0,1]$

(47)

"P-7"= constant

Units: Dimensionless $[0,1]$

(48) Progress Rate $=$ IF THEN ELSE(Initiate CM Rate=1, Initiate CM Rate , 0 ) Units: Dimensionless

(49) Project Cost= IF THEN ELSE(("Resource 1 (Mi)"=1) :AND: ("Resource 2 $(\mathrm{Ei})=1)$ :AND: ("Resource 3 (Si)"=1), 1.95943e+006 , IF THEN ELSE(("Resource 1 $(\mathrm{Mi}) "=1)$ :AND: ("Resource 2 (Ei)"=2) :AND: ("Resource 3 (Si)"=1), 1.9962e+006 , IF THEN ELSE(("Resource 1 (Mi)" =2) :AND: ("Resource 2 (Ei)"=1) :AND: ("Resource 3 (Si)"=1), 1.79412e+006, IF THEN ELSE(("Resource 1 (Mi)"=2) :AND: ("Resource 2 (Ei)"=2) :AND: ("Resource 3 (Si)"=1), 1.83089e+006 , IF THEN ELSE(("Resource 1 (Mi)"=3) :AND: ("Resource 2 (Ei)"=1) :AND: ("Resource 3 
$(\mathrm{Si}) "=1), 2.02443 \mathrm{e}+006$, IF THEN ELSE(("Resource 1 (Mi)"=4) :AND: ("Resource 2 $(\mathrm{Ei}) "=1)$ :AND: ("Resource 3 (Si)"=1), 1.94575e+006 , IF THEN ELSE(("Resource 1 (Mi)"=5) :AND: ("Resource 2 (Ei)"=3) :AND: ("Resource 3 (Si)"=1), 1.35694e+006 , IF THEN ELSE(("Resource 1 (Mi)"=5) :AND: ("Resource 2 (Ei)"=4) :AND: ("Resource 3 $(\mathrm{Si}) "=1), 1.36366 \mathrm{e}+006$, IF THEN ELSE(("Resource 1 (Mi)" =1) :AND: ("Resource 2 (Ei)"=1) :AND: ("Resource 3 (Si)"=2), 1.96128e+006 , IF THEN ELSE(("Resource 1 (Mi)"=1) :AND: ("Resource 2 (Ei)"=2) :AND: ("Resource 3 $(\mathrm{Si}) "=2), 1.99805 \mathrm{e}+006$, IF THEN ELSE(("Resource 1 (Mi)"=2) :AND: ("Resource 2 (Ei)"=1) :AND: ("Resource 3 (Si)"=2), 1.79597e+006, IF THEN ELSE(("Resource 1 (Mi)"=2) :AND: ("Resource 2 (Ei)"=2) :AND: ("Resource 3 (Si)"=2), 1.83274e+006 , IF THEN ELSE(("Resource 1 (Mi)"=3) :AND: ("Resource 2 (Ei)"=1) :AND: ("Resource 3 $(\mathrm{Si}) "=2), 2.02628 \mathrm{e}+006$, IF THEN ELSE(("Resource 1 (Mi)"=4) :AND: ("Resource 2 $($ Ei)"=1) :AND: ("Resource 3 (Si)"=2), 1.9476e+006, IF THEN ELSE(("Resource 1 $(\mathrm{Mi}) "$ =5) :AND: ("Resource 2 (Ei)"=3) :AND: ("Resource 3 (Si)"=2), 1.35878e+006, IF THEN ELSE(("Resource 1 (Mi)"=5) :AND: ("Resource 2 (Ei)"=4) :AND: ("Resource (Si)"=2), (.3655(e+006, 0 ) ) ) ) ) ) ) ) ) ) ) ) ) ) ) )

Units: dollars

(50) Project GHG=IF THEN ELSE(("Resource 1 (Mi)"=1) :AND: ("Resource 2 $(\mathrm{Ei})=1)$ :AND: ("Resource 3 (Si)"=1), 4.57119e+006 , IF THEN ELSE(("Resource 1 $(\mathrm{Mi}) "=1)$ :AND: ("Resource 2 (Ei)"=2) :AND: ("Resource 3 (Si)"=1), 4.13052e+006 , IF THEN ELSE(("Resource 1 (Mi)" =2) :AND: ("Resource 2 (Ei)"=1) :AND: ("Resource 3 (Si)"=1), 3.14477e+006, IF THEN ELSE(("Resource 1 (Mi)"=2) :AND: 
("Resource 2 (Ei)"=2) :AND: ("Resource 3 (Si)"=1), 2.7041e+006 , IF THEN ELSE(("Resource 1 (Mi)"=3) :AND: ("Resource 2 (Ei)"=1) :AND: ("Resource 3 $(\mathrm{Si}) "=1), 4.48197 \mathrm{e}+006$, IF THEN ELSE(("Resource 1 (Mi)"=4) :AND: ("Resource 2 (Ei)"=1) :AND: ("Resource 3 (Si)"=1), 3.85798e+006 , IF THEN ELSE(("Resource 1 $(\mathrm{Mi}) "=5)$ :AND: ("Resource 2 (Ei)"=3) :AND: ("Resource 3 (Si)"=1), 3.34252e+006 , IF THEN ELSE(("Resource 1 (Mi)"=5) :AND: ("Resource 2 (Ei)"=4) :AND: ("Resource 3 $(\mathrm{Si}) "=1), 3.31303 \mathrm{e}+006$, IF THEN ELSE(("Resource 1 (Mi)" =1) :AND: ("Resource 2 (Ei)"=1) :AND: ("Resource 3 (Si)"=2), 4.55606e+006 , IF THEN ELSE(("Resource 1 (Mi)"=1) :AND: ("Resource 2 (Ei)"=2) :AND: ("Resource 3 (Si)"=2), 4.13052e+006, IF THEN ELSE(("Resource 1 (Mi)"=2) :AND: ("Resource 2 (Ei)"=1) :AND: ("Resource 3 (Si)"=2), 3.12964e+006 , IF THEN ELSE(("Resource 1 (Mi)"=2) :AND: ("Resource 2 (Ei)"=2) :AND: ("Resource 3 (Si)"=2), 2.7041e+006, IF THEN ELSE(("Resource 1 (Mi)"=3) :AND: ("Resource 2 (Ei)"=1) :AND: ("Resource 3 (Si)"=2), 4.46684e+006, IF THEN ELSE(("Resource 1 (Mi)"=4) :AND: ("Resource 2 $(\mathrm{Ei}) "=1)$ :AND: ("Resource 3 (Si)"=2), 3.84285e+006 , IF THEN ELSE(("Resource 1 $(\mathrm{Mi}) "$ =5) :AND: ("Resource 2 (Ei)"=3) :AND: ("Resource 3 (Si)"=2), 3.32739e+006, IF THEN ELSE(("Resource 1 (Mi)"=5) :AND: ("Resource 2 (Ei)"=4) :AND: ("Resource $3(\mathrm{Si}$ "=2), 3.2979e+006, 0 ) ) ) ) ) ) ) ) ) ) ) ) ) ) ) )

Units: $\mathrm{kg} \mathrm{CO} 2$ eq

(51) Project Time=IF THEN ELSE(("Resource 1 (Mi)"=1) :AND: ("Resource 2 $(\mathrm{Ei}) "=1)$ :AND: ("Resource 3 (Si)"=1), 36 , IF THEN ELSE(("Resource 1 (Mi)"=1) :AND: ("Resource 2 (Ei)"=2) :AND: ("Resource 3 (Si)"=1), 36 , IF THEN 
ELSE(("Resource 1 (Mi)"=2) :AND: ("Resource 2 (Ei)"=1) :AND: ("Resource 3 (Si)"=1), 36 , IF THEN ELSE(("Resource 1 (Mi)"=2) :AND: $\quad$ ("Resource 2 $($ Ei)"=2) :AND: ("Resource 3 (Si)"=1), 36 , IF THEN ELSE(("Resource 1 (Mi)"=3) :AND: ("Resource 2 (Ei)"=1) :AND: ("Resource 3 (Si)"=1), 36 , IF THEN ELSE (("Resource 1 (Mi)"=4) :AND: ("Resource 2 (Ei)"=1) :AND: ("Resource 3 (Si)"=1), 36 , IF THEN ELSE(("Resource 1 (Mi)"=5) :AND: ("Resource 2 (Ei)"=3) :AND: ("Resource $3(\mathrm{Si}) "=1), 22$, IF THEN ELSE(("Resource 1 (Mi)"=5) :AND: ("Resource 2 (Ei)"=4) :AND: ("Resource 3 (Si)"=1), 22 , IF THEN ELSE(("Resource 1 (Mi)"=1) :AND: ("Resource 2 (Ei)"=1) :AND: ("Resource 3 (Si)"=2), 36, IF THEN ELSE(("Resource 1 $(\mathrm{Mi}) "=1)$ :AND: ("Resource 2 (Ei)"=2) :AND: ("Resource 3 (Si)"=2), 36 , IF THEN ELSE(("Resource 1 (Mi)"=2) :AND: ("Resource 2 (Ei)"=1) :AND: ("Resource 3 $(\mathrm{Si}) "=2), 36$, IF THEN ELSE(("Resource 1 (Mi)"=2) :AND: ("Resource 2 (Ei)"=2) :AND: ("Resource 3 (Si)"=2), 36 , IF THEN ELSE(("Resource 1 (Mi)"=3) :AND: ("Resource 2 (Ei)"=1) :AND: ("Resource 3 (Si)"=2), 36, IF THEN ELSE(("Resource 1 $(\mathrm{Mi}) "=4)$ :AND: $\quad(" R e s o u r c e ~ 2(\mathrm{Ei}) "=1)$ :AND: ("Resource $3(\mathrm{Si}) "=2), 36$, IF THEN ELSE(("Resource 1 (Mi)"=5) :AND: ("Resource 2 (Ei)"=3) :AND: ("Resource 3 (Si)"=2), 22 , IF THEN ELSE (("Resource 1 (Mi)"=5) :AND: ("Resource 2 (Ei)"=4) :AND: ("Resource $3(\mathrm{Si})^{\prime}=2$ ), 22, 0 ) ) ) ) ) ) ) ) ) ) ) ) ) ) ) ) ) Units: days

(52) "Resource 1 (Mi)"=IF THEN ELSE( (Cumulative Real Progress of CM Change>0) :AND: (Material Selection Score<20), 3 , IF THEN ELSE( (Cumulative Real Progress of CM Change $>0)$ :AND: $(20<=$ Material Selection Score) :AND: (Material 
Selection Score<40), 1, IF THEN ELSE( (Cumulative Real Progress of CM Change >0) :AND: $(40<=$ Material Selection Score) :AND: (Material Selection Score $<60), 2$, IF THEN ELSE( (Cumulative Real Progress of CM Change $>0)$ :AND: $(60<=$ Material Selection Score) :AND: (Material Selection Score<80) , 4 , IF THEN ELSE( (Cumulative Real Progress of CM Change $>0)$ :AND: $(80<=$ Material Selection Score) :AND: (Material Selection Score $<=100), 5,0$ ) ) ) ) )

Units: nondimensional

"Resource 2 (Ei)"=IF THEN ELSE(("Resource 1 (Mi)"=1) :AND: (Equipment Selection Score<50), 1, IF THEN ELSE(("Resource 1 (Mi)"=1) :AND: (Equipment Selection Score $>=50), 2$, IF THEN ELSE(("Resource 1 (Mi)"=2) :AND: (Equipment Selection Score<50), 1, IF THEN ELSE(("Resource 1 (Mi)"=2) :AND: (Equipment Selection Score $>=50$ ), 2 , IF THEN ELSE("Resource 1 (Mi)"=3, 1 , IF THEN ELSE("Resource 1 (Mi)"=4, 1 , IF THEN ELSE(("Resource 1 (Mi)"=5) :AND: (Equipment Selection Score<50), 3, IF THEN ELSE(("Resource 1 (Mi)"=5) :AND: (Equipment Selection Score $>=50), 4,0$ ) ) ) ) ) ) ) )

Units: nondimensional "Resource 3 (Si)"=IF THEN ELSE(Stabilizing Additive Selection Score<50, 2 , 1

Units: nondimensional 
(55)

SAVEPER $=$ TIME STEP

Units: Day [0,?]

The frequency with which output is stored.

(56)

"STAB-C1"="STAB-IW-1"*"P-1"

Units: nondimensional

(57)

"STAB-C2"="STAB-IW-2"*"P-2"

Units: nondimensional

"STAB-C3"="STAB-IW-3"*"P-3"

Units: nondimensional

(59) $\quad$ "STAB-C4"= "STAB-IW-4"*"P-4"

Units: nondimensional

(60) $\quad$ STAB-C5"="STAB-IW-5"*"P-5"

Units: nondimensional

(61) "STAB-C6"="STAB-IW-6"*"P-6"

Units: nondimensional 
(62)

"STAB-C7"="STAB-IW-7"*"P-7"

Units: nondimensional

(63) "STAB-IW-1"=0.22169

Units: nondimensional

(64) "STAB-IW-2" $=0.16524$

Units: nondimensional

(65) "STAB-IW-3" $=0.04685$

Units: nondimensional

(66) "STAB-IW-4"=0.23607

Units: nondimensional

(67) "STAB-IW-5" $=0.26938$

Units: nondimensional

(68) "STAB-IW-6" $=0.03753$

Units: nondimensional

(69) "STAB-IW-7"=0.02323

Units: nondimensional 
(70) Stabilizing Additive Selection Score="STAB-C1"+"STAB-C2"+"STABC3"+"STAB-C4"+"STAB-C5"+"STAB-C6"+"STAB-C7"

Units: nondimensional $[0,100]$

(71) Suitability of the CM Selected $=(0.33354 *$ Gap between Target and Simulated Time $)+(0.55534 *$ Gap between Target and Simulated Cost $)+(0.11112 *$ Gap between Target and Simulated GHG)

Units: Dimensionless

(72) Target $\operatorname{Cos} \mathrm{t}=1.3 \mathrm{e}+006$

Units: dollars

(73) Target $\mathrm{GHG}=2.7 \mathrm{e}+006$

Units: $\mathrm{kg} \mathrm{CO} 2$ eq

(74) Target Time $=20$

Units: days

(75) TIME STEP $=1$

Units: Day [0,?]

The time step for the simulation. 
Appendix D: Pavement Design Survey 


\section{FIU Pavement Design Survey}

The questions 1-7 \& 9 are designed for performing pair wise comparison between row and column components. The input needs to be in 1-9 scale where:

\begin{tabular}{|l|l|l|}
\hline $\begin{array}{l}\text { Intensity of } \\
\text { importance }\end{array}$ & Definition & Explanation \\
\hline 1 & Equal importance & $\begin{array}{l}\text { Two activities (row and column components) } \\
\text { contribute equally to the objective }\end{array}$ \\
\hline 3 & $\begin{array}{l}\text { Moderate } \\
\text { importance }\end{array}$ & $\begin{array}{l}\text { Experience and judgment slightly favor one (row } \\
\text { component) over another (column component) }\end{array}$ \\
\hline 5 & $\begin{array}{l}\text { Strong } \\
\text { importance }\end{array}$ & $\begin{array}{l}\text { Experience and judgment strongly favor one } \\
\text { (row component) over another (column } \\
\text { component) }\end{array}$ \\
\hline 7 & $\begin{array}{l}\text { Very strong } \\
\text { importance }\end{array}$ & $\begin{array}{l}\text { An activity (row component) is strongly favored } \\
\text { over another (column component) and its } \\
\text { dominance is demonstrated in practice }\end{array}$ \\
\hline 9 & $\begin{array}{l}\text { Extreme } \\
\text { importance }\end{array}$ & $\begin{array}{l}\text { The evidence favoring one activity over another } \\
\text { is of the highest possible order of affirmation, } \\
\text { i.e. overwhelming dominance of an activity (row } \\
\text { component) is over another (column component) }\end{array}$ \\
\hline $2,4,6,8$ & $\begin{array}{l}\text { Intermediate } \\
\text { values }\end{array}$ & $\begin{array}{l}\text { sed represent compromise between the } \\
\text { priorities listed above }\end{array}$ \\
\hline
\end{tabular}

1) What is the relative importance weight of favorability of project conditions \& resource performance with respect to construction method (CM) selection? [1-9 scale] E.g., Favorability of project conditions is moderately more important than resource performance with respect to $\mathrm{CM}$ selection.

\begin{tabular}{|l|l|l|}
\hline CM Selection & $\begin{array}{l}\text { Favorability of Project } \\
\text { Conditions }\end{array}$ & Resource Performance \\
\hline $\begin{array}{l}\text { Favorability of Project } \\
\text { Conditions }\end{array}$ & 1 & \\
\hline Resource Performance & & 1 \\
\hline
\end{tabular}


2) What is the relative importance weight of project conditions with respect to favorability of project conditions? [1-9 scale]

\begin{tabular}{|c|c|c|c|c|c|c|c|}
\hline $\begin{array}{l}\text { Favorability } \\
\text { of Project } \\
\text { Conditions }\end{array}$ & $\begin{array}{l}\text { C1: } \\
\text { Adverse } \\
\text { financial } \\
\text { issues of } \\
\text { owner }\end{array}$ & $\begin{array}{l}\text { C2: } \\
\text { Adverse } \\
\text { market } \\
\text { condition } \\
\text { s } \\
\text { (affectin } \\
\text { g owner) }\end{array}$ & $\begin{array}{l}\text { C3: } \\
\text { Change } \\
\text { in design }\end{array}$ & $\begin{array}{l}\text { C4: } \\
\text { Unavaila } \\
\text { bility of } \\
\text { resources }\end{array}$ & $\begin{array}{l}\text { C5: } \\
\text { Delay in } \\
\text { resource } \\
\text { delivery }\end{array}$ & $\begin{array}{l}\text { C6: } \\
\text { Increase } \\
\text { in unit } \\
\text { cost of } \\
\text { resources }\end{array}$ & $\begin{array}{l}\text { C7: } \\
\text { Unexpect } \\
\text { ed } \\
\text { condition } \\
\mathrm{s}\end{array}$ \\
\hline $\begin{array}{l}\text { C1: Adverse } \\
\text { financial } \\
\text { issues of } \\
\text { owner }\end{array}$ & 1 & & & & & & \\
\hline $\begin{array}{l}\text { C2: Adverse } \\
\text { market } \\
\text { conditions } \\
\text { (affecting } \\
\text { owner) }\end{array}$ & & 1 & & & & & \\
\hline $\begin{array}{l}\text { C3: Change } \\
\text { in design }\end{array}$ & & & 1 & & & & \\
\hline $\begin{array}{l}\text { C4: } \\
\text { Unavailabilit } \\
y \quad \text { of } \\
\text { resources }\end{array}$ & & & & 1 & & & \\
\hline $\begin{array}{l}\text { C5: Delay in } \\
\text { resource } \\
\text { delivery }\end{array}$ & & & & & 1 & & \\
\hline $\begin{array}{l}\text { C6: Increase } \\
\text { in unit cost } \\
\text { of resources }\end{array}$ & & & & & & 1 & \\
\hline $\begin{array}{l}\text { C7: } \\
\text { Unexpected } \\
\text { conditions }\end{array}$ & & & & & & & 1 \\
\hline
\end{tabular}


3) What is the relative importance weight of $\mathrm{CM}$ indicators with respect to resource performance? [1-9 scale]

\begin{tabular}{|l|l|l|l|}
\hline Resource & Material Selection & Equipment Selection & Stabilizing Additive \\
\hline Material Selection & 1 & & Selection \\
\hline Equipment Selection & & 1 & \\
\hline Stabilizing Additive & & & 1 \\
Selection & & & \\
\hline
\end{tabular}

4) What is the relative importance weight of $\mathrm{C} 1$ : Adverse financial issues of owner \& C2: Adverse market conditions (affecting owner) with respect to C3: Change in design? [1-9 scale] E.g., C1 is moderately important than C2 wrt C3.

\begin{tabular}{|l|l|l|}
\hline C3: Change in design & $\begin{array}{l}\text { C1: Adverse financial issues } \\
\text { of owner }\end{array}$ & $\begin{array}{l}\text { C2: Adverse market } \\
\text { conditions (affecting owner) }\end{array}$ \\
\hline $\begin{array}{l}\text { C1: Adverse financial issues } \\
\text { of owner }\end{array}$ & 1 & 1 \\
\hline $\begin{array}{l}\text { C2: Adverse market } \\
\text { conditions (affecting owner) }\end{array}$ & & \\
\hline
\end{tabular}


5) What is the relative importance weight of project conditions with respect to material selection? [1-9 scale]

\begin{tabular}{|c|c|c|c|c|c|c|c|}
\hline $\begin{array}{l}\text { Material } \\
\text { Selection }\end{array}$ & $\begin{array}{l}\text { C1: } \\
\text { Adverse } \\
\text { financial } \\
\text { issues of } \\
\text { owner }\end{array}$ & $\begin{array}{l}\mathrm{C} 2: \\
\text { Adverse } \\
\text { market } \\
\text { condition } \\
\text { s } \\
\text { (affectin } \\
\text { g owner) }\end{array}$ & $\begin{array}{l}\text { C3: } \\
\text { Change } \\
\text { in design }\end{array}$ & $\begin{array}{l}\text { C4: } \\
\text { Unavaila } \\
\text { bility of } \\
\text { resources }\end{array}$ & $\begin{array}{l}\text { C5: } \\
\text { Delay in } \\
\text { resource } \\
\text { delivery }\end{array}$ & $\begin{array}{l}\text { C6: } \\
\text { Increase } \\
\text { in unit } \\
\text { cost of } \\
\text { resources }\end{array}$ & $\begin{array}{l}\text { C7: } \\
\text { Unexpect } \\
\text { ed } \\
\text { condition } \\
\text { s }\end{array}$ \\
\hline $\begin{array}{l}\text { C1: Adverse } \\
\text { financial } \\
\text { issues of } \\
\text { owner }\end{array}$ & 1 & & & & & & \\
\hline $\begin{array}{l}\text { C2: Adverse } \\
\text { market } \\
\text { conditions } \\
\text { (affecting } \\
\text { owner) }\end{array}$ & & 1 & & & & & \\
\hline $\begin{array}{l}\text { C3: Change } \\
\text { in design }\end{array}$ & & & 1 & & & & \\
\hline $\begin{array}{l}\text { C4: } \\
\text { Unavailabilit } \\
\text { y of } \\
\text { resources }\end{array}$ & & & & 1 & & & \\
\hline $\begin{array}{l}\text { C5: Delay in } \\
\text { resource } \\
\text { delivery }\end{array}$ & & & & & 1 & & \\
\hline $\begin{array}{l}\text { C6: Increase } \\
\text { in unit cost } \\
\text { of resources }\end{array}$ & & & & & & 1 & \\
\hline $\begin{array}{l}\text { C7: } \\
\text { Unexpected } \\
\text { conditions }\end{array}$ & & & & & & & 1 \\
\hline
\end{tabular}


6) What is the relative importance weight of project conditions with respect to equipment selection? [1-9 scale]

\begin{tabular}{|c|c|c|c|c|c|c|c|}
\hline $\begin{array}{l}\text { Equipment } \\
\text { Selection }\end{array}$ & $\begin{array}{l}\text { C1: } \\
\text { Adverse } \\
\text { financial } \\
\text { issues of } \\
\text { owner }\end{array}$ & $\begin{array}{l}\mathrm{C} 2: \\
\text { Adverse } \\
\text { market } \\
\text { condition } \\
\text { s } \\
\text { (affectin } \\
\text { g owner) }\end{array}$ & $\begin{array}{l}\text { C3: } \\
\text { Change } \\
\text { in design }\end{array}$ & $\begin{array}{l}\text { C4: } \\
\text { Unavaila } \\
\text { bility of } \\
\text { resources }\end{array}$ & $\begin{array}{l}\text { C5: } \\
\text { Delay in } \\
\text { resource } \\
\text { delivery }\end{array}$ & $\begin{array}{l}\text { C6: } \\
\text { Increase } \\
\text { in unit } \\
\text { cost of } \\
\text { resources }\end{array}$ & $\begin{array}{l}\text { C7: } \\
\text { Unexpect } \\
\text { ed } \\
\text { condition } \\
\text { s }\end{array}$ \\
\hline $\begin{array}{l}\text { C1: Adverse } \\
\text { financial } \\
\text { issues of } \\
\text { owner }\end{array}$ & 1 & & & & & & \\
\hline $\begin{array}{l}\text { C2: Adverse } \\
\text { market } \\
\text { conditions } \\
\text { (affecting } \\
\text { owner) }\end{array}$ & & 1 & & & & & \\
\hline $\begin{array}{l}\text { C3: Change } \\
\text { in design }\end{array}$ & & & 1 & & & & \\
\hline $\begin{array}{l}\text { C4: } \\
\text { Unavailabilit } \\
\text { y of } \\
\text { resources }\end{array}$ & & & & 1 & & & \\
\hline $\begin{array}{l}\text { C5: Delay in } \\
\text { resource } \\
\text { delivery }\end{array}$ & & & & & 1 & & \\
\hline $\begin{array}{l}\text { C6: Increase } \\
\text { in unit cost } \\
\text { of resources }\end{array}$ & & & & & & 1 & \\
\hline $\begin{array}{l}\text { C7: } \\
\text { Unexpected } \\
\text { conditions }\end{array}$ & & & & & & & 1 \\
\hline
\end{tabular}


7) What is the relative importance weight of project conditions with respect to stabilizing additive selection? [1-9 scale]

\begin{tabular}{|c|c|c|c|c|c|c|c|}
\hline $\begin{array}{l}\text { Stabilizing } \\
\text { Additive } \\
\text { Selection }\end{array}$ & $\begin{array}{l}\text { C1: } \\
\text { Adverse } \\
\text { financial } \\
\text { issues of } \\
\text { owner }\end{array}$ & $\begin{array}{l}\mathrm{C} 2: \\
\text { Adverse } \\
\text { market } \\
\text { condition } \\
\text { s } \\
\text { (affectin } \\
\text { g owner) }\end{array}$ & $\begin{array}{l}\text { C3: } \\
\text { Change } \\
\text { in design }\end{array}$ & $\begin{array}{l}\text { C4: } \\
\text { Unavaila } \\
\text { bility of } \\
\text { resources }\end{array}$ & $\begin{array}{l}\text { C5: } \\
\text { Delay in } \\
\text { resource } \\
\text { delivery }\end{array}$ & $\begin{array}{l}\text { C6: } \\
\text { Increase } \\
\text { in unit } \\
\text { cost of } \\
\text { resources }\end{array}$ & $\begin{array}{l}\text { C7: } \\
\text { Unexpect } \\
\text { ed } \\
\text { condition } \\
\text { s }\end{array}$ \\
\hline $\begin{array}{l}\text { C1: Adverse } \\
\text { financial } \\
\text { issues of } \\
\text { owner }\end{array}$ & 1 & & & & & & \\
\hline $\begin{array}{l}\text { C2: Adverse } \\
\text { market } \\
\text { conditions } \\
\text { (affecting } \\
\text { owner) }\end{array}$ & & 1 & & & & & \\
\hline $\begin{array}{l}\text { C3: Change } \\
\text { in design }\end{array}$ & & & 1 & & & & \\
\hline $\begin{array}{l}\text { C4: } \\
\text { Unavailabilit } \\
\text { y of } \\
\text { resources }\end{array}$ & & & & 1 & & & \\
\hline $\begin{array}{l}\text { C5: Delay in } \\
\text { resource } \\
\text { delivery }\end{array}$ & & & & & 1 & & \\
\hline $\begin{array}{l}\text { C6: Increase } \\
\text { in unit cost } \\
\text { of resources }\end{array}$ & & & & & & 1 & \\
\hline $\begin{array}{l}\text { C7: } \\
\text { Unexpected } \\
\text { conditions }\end{array}$ & & & & & & & 1 \\
\hline
\end{tabular}


8) What is the probability of occurrence for each condition in percentages?

\begin{tabular}{|l|l|}
\hline Conditions & Probability (\%) \\
\hline C1: Adverse financial issues of owner & \\
\hline C2: Adverse market conditions (affecting owner) & \\
\hline C3: Change in design & \\
\hline C4: Unavailability of resources & \\
\hline C5: Delay in resource delivery & \\
\hline C6: Increase in unit cost of resources & \\
\hline C7: Unexpected conditions & \\
\hline
\end{tabular}

9) The project success is measured in terms of time, cost and environmental impact (TCEI) in this study. What is the relative importance weight of TCEI with respect to project success? [1-9 scale]

\begin{tabular}{|l|l|l|l|}
\hline Project Success & T & C (Life cycle cost) & EI \\
\hline T & 1 & & \\
\hline C & & 1 & \\
\hline EI & & & 1 \\
\hline
\end{tabular}


10) Rate the performance of the material types with respect to decreasing time, cost and environmental impact (TCEI). [0-100]

\begin{tabular}{|l|l|l|l|}
\hline Material Types & Time & Cost & Environmental \\
& & & \\
\hline M1: Virgin HMA & & & \\
\hline M2: Recycled HMA & & & \\
\hline M3: Virgin WMA & & & \\
\hline M4: Superpave & & & \\
\hline M5: HIP Mix & & & \\
\hline
\end{tabular}

11) Rate the impact of material types with respect to increasing the maintenance cost of highway projects. [1-5] scale where 1: very low, 2: low, 3: medium, 4: high, 5: very high.

\begin{tabular}{|l|l|}
\hline Material Types & Maintenance Cost \\
\hline M1: Virgin HMA & \\
\hline M2: Recycled HMA & \\
\hline M3: Virgin WMA & \\
\hline M4: Superpave & \\
\hline M5: HIP Mix & \\
\hline
\end{tabular}


Appendix E: ANP Pair Wise Comparison Matrices 


\begin{tabular}{|l|l|l|}
\hline CM Selection & $\begin{array}{l}\text { Favorability of Project } \\
\text { Conditions }\end{array}$ & Resource Performance \\
\hline $\begin{array}{l}\text { Favorability of Project } \\
\text { Conditions }\end{array}$ & 1 & $1 / 3$ \\
\hline Resource Performance & 3 & 1 \\
\hline
\end{tabular}

(1) Relative importance weight of favorability of project conditions \& resource performance with respect to $\mathrm{CM}$ selection

\begin{tabular}{|c|c|c|c|c|c|c|c|}
\hline $\begin{array}{l}\text { Favorability of Project } \\
\text { Conditions }\end{array}$ & $\begin{array}{l}\text { C1: Adverse } \\
\text { financial issues } \\
\text { of owner }\end{array}$ & \begin{tabular}{l|} 
C2: Adverse \\
market \\
conditions \\
(affecting \\
owner) \\
\end{tabular} & $\begin{array}{l}\text { C3: Change in } \\
\text { design }\end{array}$ & \begin{tabular}{|l|} 
C4: \\
Unavailability of \\
resources
\end{tabular} & $\begin{array}{l}\text { C5: Delay } \\
\text { resource } \\
\text { delivery }\end{array}$ & in $\left|\begin{array}{lll}\text { C6: Increase in } \\
\text { unit } & \text { cost } & \text { of } \\
\text { resources }\end{array}\right|$ & $\begin{array}{l}\text { C7: } \\
\text { Unexpected } \\
\text { conditions }\end{array}$ \\
\hline $\begin{array}{l}\text { C1: Adverse financial issues } \\
\text { of owner }\end{array}$ & 1 & 7 & 7 & 7 & 3 & 1 & 7 \\
\hline $\begin{array}{lcc}\text { C2: } & \text { Adverse } & \text { market } \\
\text { conditions (affecting } & \text { owner) }\end{array}$ & $1 / 7$ & 1 & 7 & 7 & 3 & 1 & 7 \\
\hline \begin{tabular}{|l|} 
C3: Change in design \\
\end{tabular} & $1 / 7$ & $1 / 7$ & 1 & $1 / 5$ & $1 / 7$ & 1 & 5 \\
\hline $\begin{array}{ll}\text { C4: } & \text { Unavailability } \\
\text { resources }\end{array}$ & $1 / 7$ & $1 / 7$ & 5 & 1 & 1 & 5 & 7 \\
\hline C5: Delay in resource delivery & $1 / 3$ & $1 / 3$ & 7 & 1 & 1 & 5 & 6 \\
\hline $\begin{array}{l}\text { C6: Increase in unit cost of } \\
\text { resources }\end{array}$ & 1 & 1 & 1 & $1 / 5$ & $1 / 5$ & 1 & 2 \\
\hline C7: Unexpected conditions & $1 / 7$ & $1 / 7$ & $1 / 5$ & $1 / 7$ & $1 / 6$ & $1 / 2$ & 1 \\
\hline
\end{tabular}

(2) Relative importance weight of project conditions with respect to favorability of project conditions 


\begin{tabular}{|c|c|c|c|}
\hline \begin{tabular}{|l|} 
Resource \\
Performance
\end{tabular} & Material Selection & Equipment Selection & Stabilizing Additive Selection \\
\hline Material Selection & 1 & 1 & 1 \\
\hline Equipment Selection & 1 & 1 & $1 / 3$ \\
\hline $\begin{array}{l}\text { Stabilizing Additive } \\
\text { Selection }\end{array}$ & & 3 & 1 \\
\hline
\end{tabular}

(3) Relative importance weight of CM indicators with respect to resource performance

\begin{tabular}{|l|l|l|}
\hline C3: Change in design & $\begin{array}{l}\text { C1: Adverse financial } \\
\text { issues of owner }\end{array}$ & $\begin{array}{l}\text { C2: Adverse market } \\
\text { conditions (affecting } \\
\text { owner) }\end{array}$ \\
\hline $\begin{array}{l}\text { C1: Adverse financia } \\
\text { issues of owner }\end{array}$ & 1 & 5 \\
\hline $\begin{array}{l}\text { C2: Adverser market } \\
\text { conditions } \\
\text { owner) }\end{array}$ & $1 / 5$ & 1 \\
\hline
\end{tabular}

(4) Relative importance weight of C1: Adverse financial issues of owner \& C2: Adverse market conditions (affecting owner) with respect to $\mathrm{C} 3$ : Change in design 


\begin{tabular}{|c|c|c|c|c|c|c|c|}
\hline Material Selection & $\begin{array}{l}\mathrm{C} 1: \text { Adverse } \\
\text { financial issues } \\
\text { of owner }\end{array}$ & \begin{tabular}{|l|} 
C2: Adverse \\
market \\
conditions \\
(affecting \\
owner)
\end{tabular} & $\begin{array}{l}\text { C3: Change in } \\
\text { design }\end{array}$ & $\begin{array}{l}\text { C4: } \\
\text { Unavailability of } \\
\text { resources }\end{array}$ & $\begin{array}{l}\text { C5: Delay in } \\
\text { resource } \\
\text { delivery }\end{array}$ & $\begin{array}{l}\text { C6: Increase in } \\
\text { unit cost of } \\
\text { resources }\end{array}$ & $\begin{array}{l}\text { C7: } \\
\text { Unexpected } \\
\text { conditions }\end{array}$ \\
\hline \begin{tabular}{|l|l|} 
C1: Adverse financial \\
issues of owner
\end{tabular} & 1 & 1 & 5 & $1 / 5$ & $1 / 5$ & 5 & 5 \\
\hline$\left|\begin{array}{lll}\text { C2: } & \text { Adverse } & \text { market } \\
\text { conditions (affecting } & \text { owner) }\end{array}\right|$ & 1 & 1 & 5 & \begin{tabular}{|l|l} 
& $1 / 7$
\end{tabular} & \begin{tabular}{|l|}
$1 / 6$ \\
\end{tabular} & 5 & 6 \\
\hline C3: Change in design & $1 / 5$ & $1 / 5$ & 1 & $1 / 7$ & $1 / 7$ & 5 & 5 \\
\hline $\begin{array}{ll}\text { C4: Unavailability of } \\
\text { resources }\end{array}$ & 5 & 7 & 7 & 1 & 1 & 6 & 7 \\
\hline $\begin{array}{l}\text { C5: Delay in resource } \\
\text { delivery }\end{array}$ & 5 & 6 & 7 & 1 & 1 & 6 & 7 \\
\hline $\begin{array}{l}\text { C6: Increase in unit cost of } \\
\text { resources }\end{array}$ & $1 / 5$ & $1 / 5$ & $1 / 5$ & $1 / 6$ & $1 / 6$ & 1 & 1 \\
\hline C7: Unexpected conditions & $1 / 5$ & $1 / 6$ & $1 / 5$ & $1 / 7$ & $1 / 7$ & 1 & 1 \\
\hline
\end{tabular}

(5) Relative importance weight of project conditions with respect to material selection 


\begin{tabular}{|c|c|c|c|c|c|c|c|}
\hline Equipment Selection & $\begin{array}{l}\text { C1: Adverse } \\
\text { financial issues } \\
\text { of owner }\end{array}$ & $\begin{array}{l}\text { C2: Adverse } \\
\text { market } \\
\text { conditions } \\
\text { (affecting } \\
\text { owner) }\end{array}$ & $\begin{array}{l}\text { C3: Change in } \\
\text { design }\end{array}$ & \begin{tabular}{|l|} 
C4: \\
Unavailability of \\
resources
\end{tabular} & $\begin{array}{l}\text { C5: Delay } \\
\text { resource } \\
\text { delivery }\end{array}$ & $\begin{array}{lll}\text { C6: Increase in } \\
\text { unit } & \text { cost } & \text { of } \\
\text { resources }\end{array}$ & \begin{tabular}{l|l} 
in & C7: \\
Unexpected \\
conditions
\end{tabular} \\
\hline $\begin{array}{l}\text { C1: Adverse financial issues } \\
\text { of owner }\end{array}$ & 1 & 1 & 5 & $1 / 5$ & $1 / 5$ & 5 & 5 \\
\hline 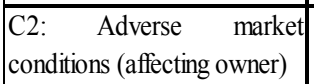 & 1 & 1 & 5 & $1 / 7$ & $1 / 6$ & 5 & 6 \\
\hline C3: Change in design & $1 / 5$ & $1 / 5$ & 1 & $1 / 7$ & $1 / 7$ & 5 & 5 \\
\hline $\begin{array}{|ll|}\text { C4: } & \text { Unavailability } \\
\text { resources } & \text { of } \\
\end{array}$ & 5 & 7 & 7 & 1 & 1 & 6 & 7 \\
\hline $\begin{array}{l}\text { C5: Delay in resource } \\
\text { delivery }\end{array}$ & 5 & 6 & 7 & 1 & 1 & 6 & 7 \\
\hline $\begin{array}{l}\text { C6: Increase in unit cost of } \\
\text { resources }\end{array}$ & $1 / 5$ & $1 / 5$ & $1 / 5$ & $1 / 6$ & $1 / 6$ & 1 & 1 \\
\hline C7: Unexpected conditions & $1 / 5$ & $1 / 6$ & $1 / 5$ & $1 / 7$ & $1 / 7$ & $\frac{1}{1}$ & 1 \\
\hline
\end{tabular}

(6) Relative importance weight of project conditions with respect to equipment selection 


\begin{tabular}{|c|c|c|c|c|c|c|c|}
\hline Stabilizing Additive Selection & $\begin{array}{l}\text { C1: Adverse } \\
\text { financial issues } \\
\text { of owner }\end{array}$ & \begin{tabular}{|l|} 
C2: Adverse \\
market \\
conditions \\
(affecting \\
owner)
\end{tabular} & $\begin{array}{l}\text { C3: Change in } \\
\text { design }\end{array}$ & $\begin{array}{l}\text { C4: } \\
\text { Unavailability of } \\
\text { resources }\end{array}$ & $\begin{array}{l}\text { C5: Delay il } \\
\text { resource } \\
\text { delivery }\end{array}$ & $\begin{array}{l}\text { C6: Increase in } \\
\text { unit cost of } \\
\text { resources }\end{array}$ & $\begin{array}{l}\text { C7: } \\
\text { Unexpected } \\
\text { conditions }\end{array}$ \\
\hline $\begin{array}{l}\text { C1: Adverse financial issues of } \\
\text { owner }\end{array}$ & 1 & 1 & 3 & 1 & $1 / 5$ & 5 & 7 \\
\hline $\begin{array}{l}\text { C2: Adverse market conditions } \\
\text { (affecting owner) }\end{array}$ & 1 & 1 & 3 & $1 / 5$ & $1 / 4$ & 1 & 4 \\
\hline C3: Change in design & $1 / 3$ & $1 / 3$ & 1 & $1 / 5$ & $1 / 5$ & $1 / 2$ & 3 \\
\hline C4: Unavailability of resources & 1 & 5 & 5 & 1 & 1 & 5 & 7 \\
\hline C5: Delay in resource delivery & 5 & 4 & 5 & 1 & 1 & 5 & 7 \\
\hline $\begin{array}{l}\text { 66: Increase in unit cost of } \\
\text { resources }\end{array}$ & & 1 & 2 & $1 / 5$ & $1 / 5$ & 1 & 3 \\
\hline C7: Unexpected conditions & $1 / 7$ & $1 / 4$ & $1 / 3$ & $1 / 7$ & $1 / 7$ & $1 / 3$ & 1 \\
\hline
\end{tabular}

(7) Relative importance weight of project conditions with respect to stabilizing additive selection 
Appendix F: ANP Unweighted, Weighted, and Limit Supermatrices 


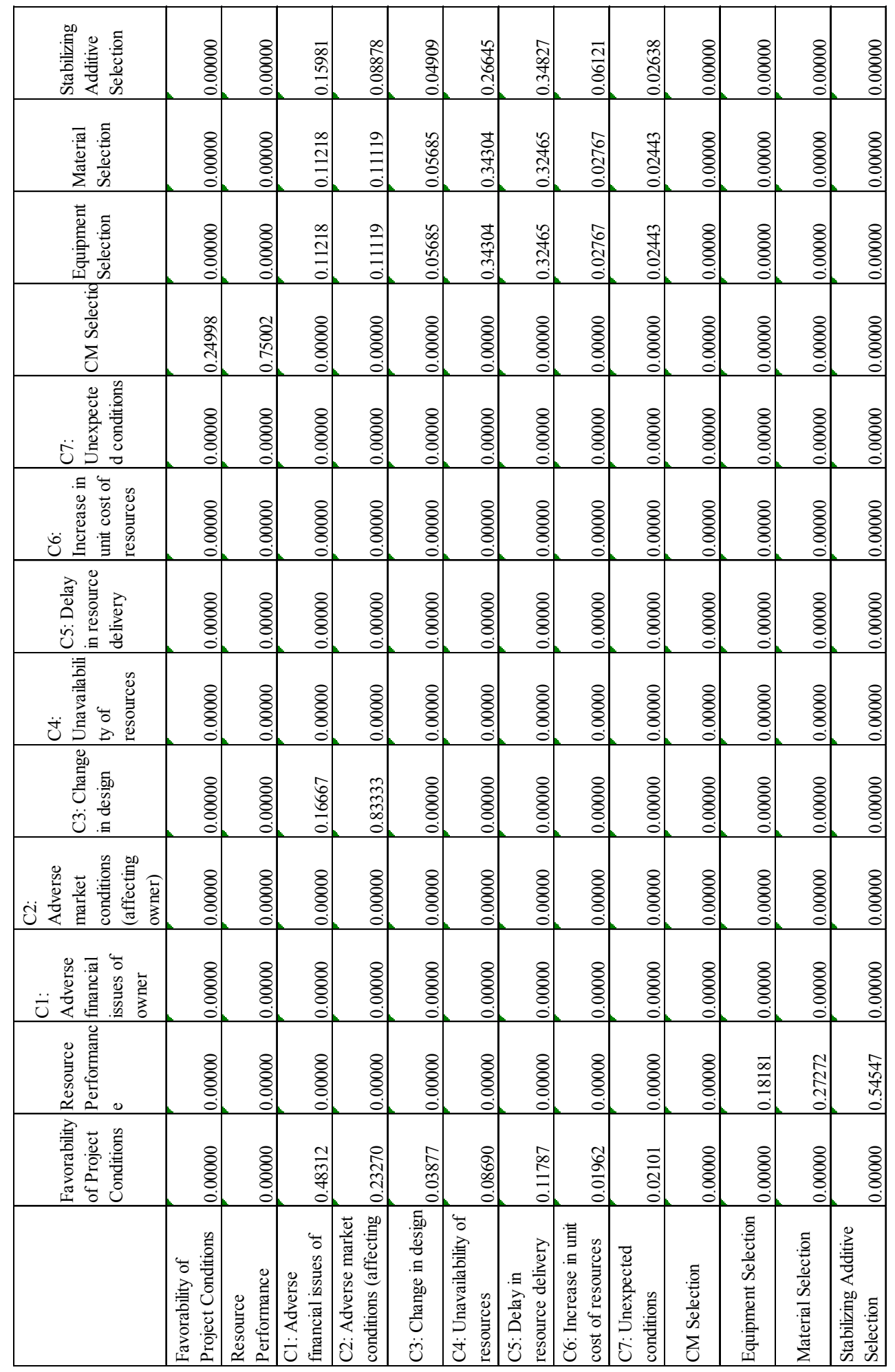

ANP Unweighted Supermatrix 


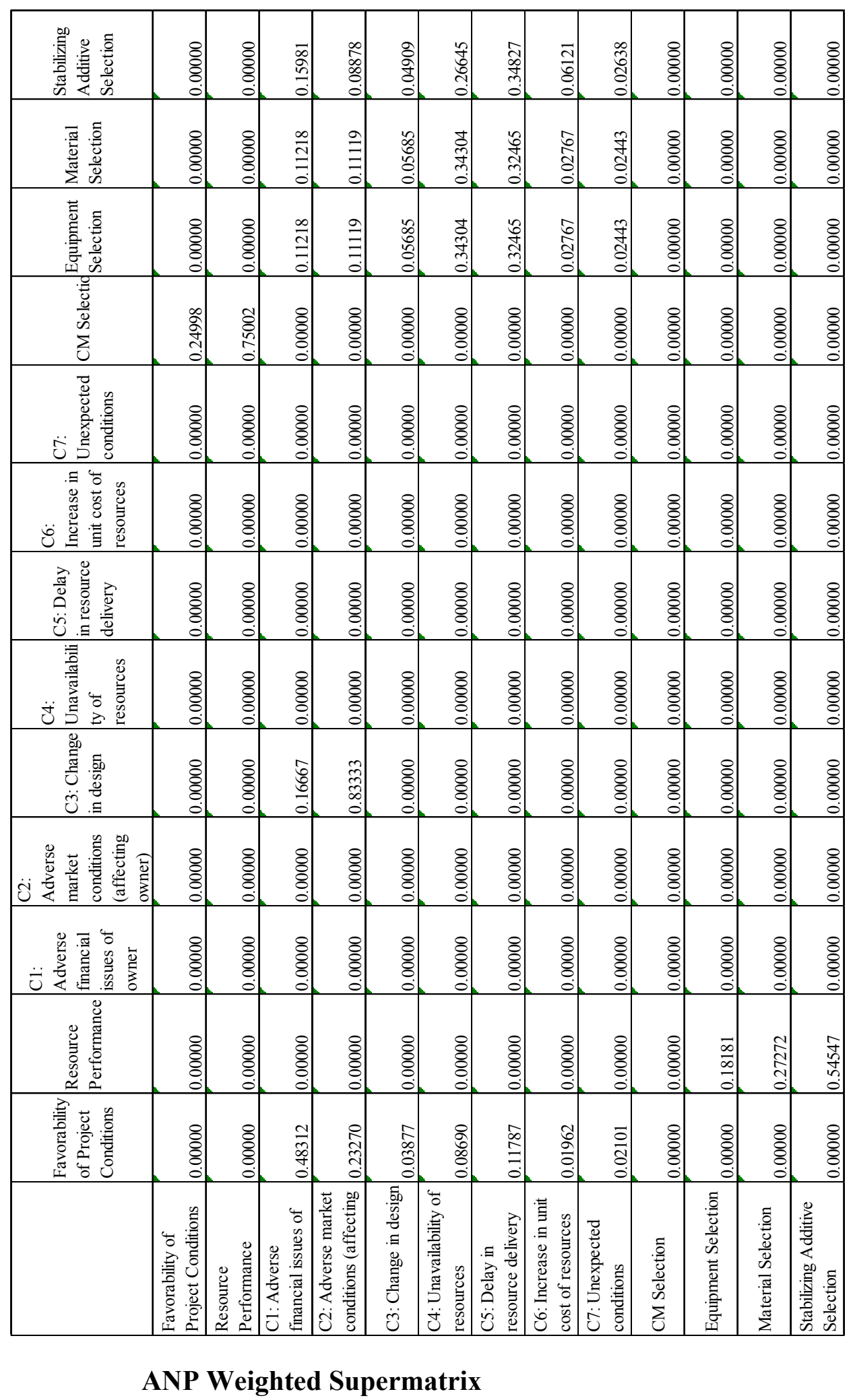




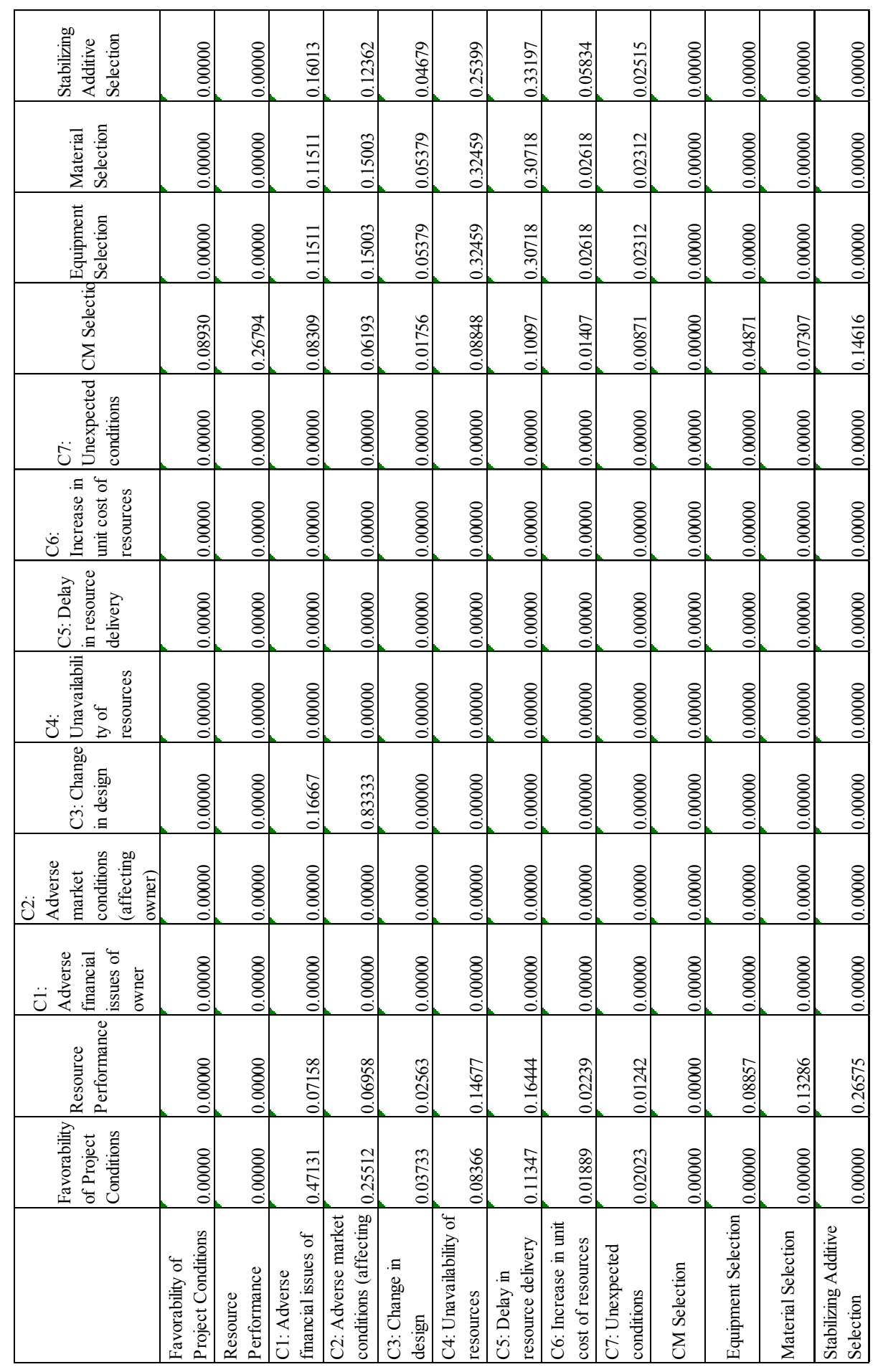

ANP Limit Supermatrix 
Appendix G: Case Study 1-Functions and Results 


\section{Case Study 1 Functions}

(01) Cumulative Real Progress of CM Change= INTEG (Progress Rate-Discover CMs Needing Changes, 10)

Units: days

(02) Discover CMs Needing Changes $=$ IF THEN ELSE(Initiate CM Rate $>0,0,1$ ) Units: Dimensionless

(03) EQUIP-C1"= "EQUIP-IW-1"*"P-1"

Units: nondimensional

(04) "EQUIP-C2"= "EQUIP-IW-2"*"P-2"

Units: nondimensional

(05) "EQUIP-C3"= "EQUIP-IW-3"*"P-3"

Units: nondimensional

(06) "EQUIP-C4"= "EQUIP-IW-4"*"P-4"

Units: nondimensional

(07) EQUIP-C5"= "EQUIP-IW-5"*"P-5"

Units: nondimensional 
(08)

"EQUIP-C6"= "EQUIP-IW-6"*"P-6"

Units: nondimensional

(09) "EQUIP-C7"= "EQUIP-IW-7"*"P-7"

Units: nondimensional

(10) "EQUIP-IW-1"= 0.22169

Units: nondimensional

(11) "EQUIP-IW-2"= 0.16524

Units: nondimensional

(12) "EQUIP-IW-3"= 0.04685

Units: nondimensional

(13) "EQUIP-IW-4"= 0.23607

Units: nondimensional

(14) "EQUIP-IW-5"= 0.26938

Units: nondimensional

(15) "EQUIP-IW-6"= 0.03753

Units: nondimensional 
(16)

"EQUIP-IW-7"= 0.2323

Units: nondimensional

(17) Equipment Selection Score= "EQUIP-C1"+"EQUIP-C2"+"EQUIP-

C3"+"EQUIP-C4"+"EQUIP-C5"+"EQUIP-C6"+"EQUIP-C7"

Units: nondimensional $[0,100]$

(18) FINAL TIME $=40$

Units: Day

The final time for the simulation.

(19) Gap between Target and Simulated Cost $=($ Project Cost-Target Cost $) /$ Target Cost Units: Dimensionless

(20) Gap between Target and Simulated GHG= (Project GHG-Target GHG)/Target

GHG

Units: Dimensionless

(21) Gap between Target and Simulated Time $=($ Project Time-Target Time $) /$ Target Time

Units: Dimensionless 
(22) INITIAL TIME $=0$

Units: Day

The initial time for the simulation.

(23) Initial Value $=$ IF THEN ELSE(Original CM To Be Changed $<0,1,0$ )

Units: Dimensionless

(24) Initiate CM Rate $=$ IF THEN ELSE( Suitability of the CM Selected $<=0.35$, Initial Value, 0 )

Units: Dimensionless

(25) "MAT-C1"= "MAT-IW-1"*"P-1"

Units: nondimensional

"MAT-C2"= "MAT-IW-2"*"P-2"

Units: nondimensional

"MAT-C3"= "MAT-IW-3"*"P-3"

Units: nondimensional

(28) "MAT-C4"= "MAT-IW-4"*"P-4"

Units: nondimensional 
"MAT-C5"= "MAT-IW-5"*"P-5"

Units: nondimensional

(30)

"MAT-C6"= "MAT-IW-6"*"P-6"

Units: nondimensional

(31)

"MAT-C7"= "MAT-IW-7"*"P-7"

Units: nondimensional

(32) "MAT-IW-1"= 0.22169

Units: nondimensional

(33) "MAT-IW-2"= 0.16524

Units: nondimensional

(34) "MAT-IW-3" $=0.04685$

Units: nondimensional

(35) "MAT-IW-4" $=0.23607$

Units: nondimensional

(36) "MAT-IW-5" $=0.26938$

Units: nondimensional 
"MAT-IW-6"= 0.03753

Units: nondimensional

(38) $\quad$ "MAT-IW-7"= 0.02323

Units: nondimensional

(39) Material Selection Score= "MAT-C1"+"MAT-C2"+"MAT-C3"+"MATC4"+"MAT-C5"+"MAT-C6"+"MAT-C7"

Units: nondimensional $[0,100,20]$

(40) Original CM To Be Changed= INTEG ( Discover CMs Needing Changes-

Progress Rate, 20)

Units: days

(41) $" \mathrm{P}-1 "=$ constant

Units: Dimensionless $[0,100]$

(42) $\quad$ P-2"= constant

Units: Dimensionless $[0,1]$

(43) $\quad$ P-3"= constant

Units: Dimensionless $[0,1]$ 
(44)

"P-4"= constant

Units: Dimensionless [0,1]

(45)

"P-5"= constant

Units: Dimensionless [0,1]

(46)

"P-6"= constant

Units: Dimensionless [0,100]

(47)

"P-7"= constant

Units: Dimensionless [0,1]

(48) Progress Rate $=$ IF THEN ELSE(Initiate CM Rate=1, Initiate CM Rate , 0 ) Units: Dimensionless

(49) Project Cost= IF THEN ELSE(("Resource 1 (Mi)"=1) :AND: ("Resource 2 (Ei)"=1) :AND: ("Resource 3 (Si)"=1), 1.95943e+006 , IF THEN ELSE(("Resource 1 (Mi)"=1) :AND: ("Resource 2 (Ei)"=2) :AND: ("Resource 3 (Si)"=1), 1.9962e+006 , IF THEN ELSE(("Resource 1 (Mi)" =2) :AND: ("Resource 2 (Ei)"=1) :AND: ("Resource 3 (Si)"=1), 1.79412e+006, IF THEN ELSE(("Resource 1 (Mi)"=2) :AND: ("Resource 2 (Ei)"=2) :AND: ("Resource 3 (Si)"=1), 1.83089e+006 , IF THEN ELSE(("Resource 1 (Mi)"=3) :AND: ("Resource 2 (Ei)"=1) :AND: ("Resource 3 
$(\mathrm{Si}) "=1), 2.02443 \mathrm{e}+006$, IF THEN ELSE(("Resource 1 (Mi)"=4) :AND: ("Resource 2 $(\mathrm{Ei}) "=1)$ :AND: ("Resource 3 (Si)"=1), 1.94575e+006 , IF THEN ELSE(("Resource 1 (Mi)"=5) :AND: ("Resource 2 (Ei)"=3) :AND: ("Resource 3 (Si)"=1), 1.35694e+006 , IF THEN ELSE(("Resource 1 (Mi)"=5) :AND: ("Resource 2 (Ei)"=4) :AND: ("Resource 3 $(\mathrm{Si}) "=1), 1.36366 \mathrm{e}+006$, IF THEN ELSE(("Resource 1 (Mi)" =1) :AND: ("Resource 2 (Ei)"=1) :AND: ("Resource 3 (Si)"=2), 1.96128e+006 , IF THEN ELSE(("Resource 1 (Mi)"=1) :AND: ("Resource 2 (Ei)"=2) :AND: ("Resource 3 $(\mathrm{Si}) "=2), 1.99805 \mathrm{e}+006$, IF THEN ELSE(("Resource 1 (Mi)"=2) :AND: ("Resource 2 (Ei)"=1) :AND: ("Resource 3 (Si)"=2), 1.79597e+006, IF THEN ELSE(("Resource 1 (Mi)"=2) :AND: ("Resource 2 (Ei)"=2) :AND: ("Resource 3 (Si)"=2), 1.83274e+006 , IF THEN ELSE(("Resource 1 (Mi)"=3) :AND: ("Resource 2 (Ei)"=1) :AND: ("Resource 3 $(\mathrm{Si}) "=2), 2.02628 \mathrm{e}+006$, IF THEN ELSE(("Resource 1 (Mi)"=4) :AND: ("Resource 2 $($ Ei)"=1) :AND: ("Resource 3 (Si)"=2), 1.9476e+006, IF THEN ELSE(("Resource 1 $(\mathrm{Mi}) "$ =5) :AND: ("Resource 2 (Ei)"=3) :AND: ("Resource 3 (Si)"=2), 1.35878e+006, IF THEN ELSE(("Resource 1 (Mi)"=5) :AND: ("Resource 2 (Ei)"=4) :AND: ("Resource (Si)"=2), (.3655(e+006, 0 ) ) ) ) ) ) ) ) ) ) ) ) ) ) ) )

Units: dollars

(50) Project GHG=IF THEN ELSE(("Resource 1 (Mi)"=1) :AND: ("Resource 2 $(\mathrm{Ei})=1)$ :AND: ("Resource 3 (Si)"=1), 4.57119e+006 , IF THEN ELSE(("Resource 1 $(\mathrm{Mi}) "=1)$ :AND: ("Resource 2 (Ei)"=2) :AND: ("Resource 3 (Si)"=1), 4.13052e+006 , IF THEN ELSE(("Resource 1 (Mi)" =2) :AND: ("Resource 2 (Ei)"=1) :AND: ("Resource 3 (Si)"=1), 3.14477e+006, IF THEN ELSE(("Resource 1 (Mi)"=2) :AND: 
("Resource 2 (Ei)"=2) :AND: ("Resource 3 (Si)"=1), 2.7041e+006 , IF THEN ELSE(("Resource 1 (Mi)"=3) :AND: ("Resource 2 (Ei)"=1) :AND: ("Resource 3 $(\mathrm{Si}) "=1), 4.48197 \mathrm{e}+006$, IF THEN ELSE(("Resource 1 (Mi)"=4) :AND: ("Resource 2 (Ei)"=1) :AND: ("Resource 3 (Si)"=1), 3.85798e+006 , IF THEN ELSE(("Resource 1 $(\mathrm{Mi}) "=5)$ :AND: ("Resource 2 (Ei)"=3) :AND: ("Resource 3 (Si)"=1), 3.34252e+006 , IF THEN ELSE(("Resource 1 (Mi)"=5) :AND: ("Resource 2 (Ei)"=4) :AND: ("Resource 3 $(\mathrm{Si}) "=1), 3.31303 \mathrm{e}+006$, IF THEN ELSE(("Resource 1 (Mi)" =1) :AND: ("Resource 2 (Ei)"=1) :AND: ("Resource 3 (Si)"=2), 4.55606e+006 , IF THEN ELSE(("Resource 1 (Mi)"=1) :AND: ("Resource 2 (Ei)"=2) :AND: ("Resource 3 (Si)"=2), 4.13052e+006, IF THEN ELSE(("Resource 1 (Mi)"=2) :AND: ("Resource 2 (Ei)"=1) :AND: ("Resource 3 (Si)"=2), 3.12964e+006 , IF THEN ELSE(("Resource 1 (Mi)"=2) :AND: ("Resource 2 (Ei)"=2) :AND: ("Resource 3 (Si)"=2), 2.7041e+006, IF THEN ELSE(("Resource 1 (Mi)"=3) :AND: ("Resource 2 (Ei)"=1) :AND: ("Resource 3 (Si)"=2), 4.46684e+006, IF THEN ELSE(("Resource 1 (Mi)"=4) :AND: ("Resource 2 $(E i) "=1)$ :AND: ("Resource 3 (Si)"=2), 3.84285e+006, IF THEN ELSE(("Resource 1 $(\mathrm{Mi}) "$ =5) :AND: ("Resource 2 (Ei)"=3) :AND: ("Resource 3 (Si)"=2), 3.32739e+006, IF THEN ELSE(("Resource 1 (Mi)"=5) :AND: ("Resource 2 (Ei)"=4) :AND: ("Resource $3(\mathrm{Si}$ "=2), 3.2979e+006, 0 ) ) ) ) ) ) ) ) ) ) ) ) ) ) ) )

Units: $\mathrm{kg} \mathrm{CO} 2$ eq

(51) Project Time=IF THEN ELSE(("Resource 1 (Mi)"=1) :AND: ("Resource 2 (Ei)"=1) :AND: ("Resource 3 (Si)"=1), 36 , IF THEN ELSE(("Resource 1 (Mi)"=1) :AND: ("Resource 2 (Ei)"=2) :AND: ("Resource 3 (Si)"=1), 36 , IF THEN 
ELSE(("Resource 1 (Mi)"=2) :AND: ("Resource 2 (Ei)"=1) :AND: ("Resource 3 (Si)"=1), 36 , IF THEN ELSE(("Resource 1 (Mi)"=2) :AND: $\quad$ ("Resource 2 $($ Ei)"=2) :AND: ("Resource 3 (Si)"=1), 36 , IF THEN ELSE(("Resource 1 (Mi)"=3) :AND: ("Resource 2 (Ei)"=1) :AND: ("Resource 3 (Si)"=1), 36 , IF THEN ELSE (("Resource 1 (Mi)"=4) :AND: ("Resource 2 (Ei)"=1) :AND: ("Resource 3 (Si)"=1), 36 , IF THEN ELSE(("Resource 1 (Mi)"=5) :AND: ("Resource 2 (Ei)"=3) :AND: ("Resource 3 (Si)"=1), 22 , IF THEN ELSE(("Resource 1 (Mi)"=5) :AND: ("Resource 2 (Ei)"=4) :AND: ("Resource 3 (Si)"=1), 22 , IF THEN ELSE(("Resource 1 (Mi)"=1) :AND: ("Resource 2 (Ei)"=1) :AND: ("Resource 3 (Si)"=2), 36, IF THEN ELSE(("Resource 1 $(\mathrm{Mi}) "=1)$ :AND: ("Resource 2 (Ei)"=2) :AND: ("Resource 3 (Si)"=2), 36 , IF THEN ELSE(("Resource 1 (Mi)"=2) :AND: ("Resource 2 (Ei)"=1) :AND: ("Resource 3 $(\mathrm{Si}) "=2), 36$, IF THEN ELSE(("Resource 1 (Mi)"=2) :AND: ("Resource 2 (Ei)"=2) :AND: ("Resource 3 (Si)"=2), 36 , IF THEN ELSE(("Resource 1 (Mi)"=3) :AND: ("Resource 2 (Ei)"=1) :AND: ("Resource 3 (Si)"=2), 36, IF THEN ELSE(("Resource 1 $(\mathrm{Mi}) "=4)$ :AND: $\quad(" R e s o u r c e ~ 2(\mathrm{Ei}) "=1)$ :AND: ("Resource $3(\mathrm{Si}) "=2), 36$, IF THEN ELSE(("Resource 1 (Mi)"=5) :AND: ("Resource 2 (Ei)"=3) :AND: ("Resource 3 (Si)"=2), 22 , IF THEN ELSE (("Resource 1 (Mi)"=5) :AND: ("Resource 2 (Ei)"=4) :AND: ("Resource $3(\mathrm{Si})^{\prime}=2$ ), 22, 0 ) ) ) ) ) ) ) ) ) ) ) ) ) ) ) ) ) Units: days

(52) "Resource 1 (Mi)"=IF THEN ELSE( (Cumulative Real Progress of CM Change>0) :AND: (Material Selection Score<20), 3 , IF THEN ELSE( (Cumulative Real Progress of CM Change $>0)$ :AND: $(20<=$ Material Selection Score) :AND: (Material 
Selection Score<40), 1, IF THEN ELSE( (Cumulative Real Progress of CM Change >0) :AND: $(40<=$ Material Selection Score) :AND: (Material Selection Score $<60), 2$, IF THEN ELSE( (Cumulative Real Progress of CM Change $>0)$ :AND: $(60<=$ Material Selection Score) :AND: (Material Selection Score<80) , 4 , IF THEN ELSE( (Cumulative Real Progress of CM Change $>0)$ :AND: $(80<=$ Material Selection Score) :AND: (Material Selection Score $<=100), 5,0$ ) ) ) ) )

Units: nondimensional

"Resource 2 (Ei)"=IF THEN ELSE(("Resource 1 (Mi)"=1) :AND: (Equipment Selection Score<50), 1, IF THEN ELSE(("Resource 1 (Mi)"=1) :AND: (Equipment Selection Score $>=50), 2$, IF THEN ELSE(("Resource 1 (Mi)"=2) :AND: (Equipment Selection Score<50), 1, IF THEN ELSE(("Resource 1 (Mi)"=2) :AND: (Equipment Selection Score $>=50$ ), 2 , IF THEN ELSE("Resource 1 (Mi)"=3, 1 , IF THEN ELSE("Resource 1 (Mi)"=4, 1 , IF THEN ELSE(("Resource 1 (Mi)"=5) :AND: (Equipment Selection Score<50), 3, IF THEN ELSE(("Resource 1 (Mi)"=5) :AND: (Equipment Selection Score $>=50), 4,0$ ) ) ) ) ) ) ) )

Units: nondimensional "Resource 3 (Si)"=IF THEN ELSE(Stabilizing Additive Selection Score<50, 2 , 1

Units: nondimensional 
(55)

SAVEPER $=$ TIME STEP

Units: Day [0,?]

The frequency with which output is stored.

(56)

"STAB-C1"="STAB-IW-1"*"P-1"

Units: nondimensional

(57)

"STAB-C2"="STAB-IW-2"*"P-2"

Units: nondimensional

"STAB-C3"="STAB-IW-3"*"P-3"

Units: nondimensional

(59) "STAB-C4"= "STAB-IW-4"*"P-4"

Units: nondimensional

(60) $\quad$ STAB-C5"="STAB-IW-5"*"P-5"

Units: nondimensional

(61) "STAB-C6"="STAB-IW-6"*"P-6"

Units: nondimensional 
(62)

"STAB-C7"="STAB-IW-7"*"P-7"

Units: nondimensional

(63) "STAB-IW-1"=0.22169

Units: nondimensional

(64) "STAB-IW-2" $=0.16524$

Units: nondimensional

(65) "STAB-IW-3" $=0.04685$

Units: nondimensional

(66) "STAB-IW-4"=0.23607

Units: nondimensional

(67) "STAB-IW-5" $=0.26938$

Units: nondimensional

(68) "STAB-IW-6" $=0.03753$

Units: nondimensional

(69) "STAB-IW-7"=0.02323

Units: nondimensional 
(70) Stabilizing Additive Selection Score="STAB-C1"+"STAB-C2"+"STABC3"+"STAB-C4"+"STAB-C5"+"STAB-C6"+"STAB-C7"

Units: nondimensional $[0,100]$

(71) Suitability of the CM Selected $=(0.33354 *$ Gap between Target and Simulated Time $)+(0.55534 *$ Gap between Target and Simulated Cost $)+(0.11112 *$ Gap between Target and Simulated GHG)

Units: Dimensionless

(72) Target $\operatorname{Cos} \mathrm{t}=1.3 \mathrm{e}+006$

Units: dollars

(73) Target $\mathrm{GHG}=2.7 \mathrm{e}+006$

Units: $\mathrm{kg} \mathrm{CO} 2$ eq

(74) Target Time $=20$

Units: days

(75) TIME STEP $=1$

Units: Day [0,?]

The time step for the simulation. 


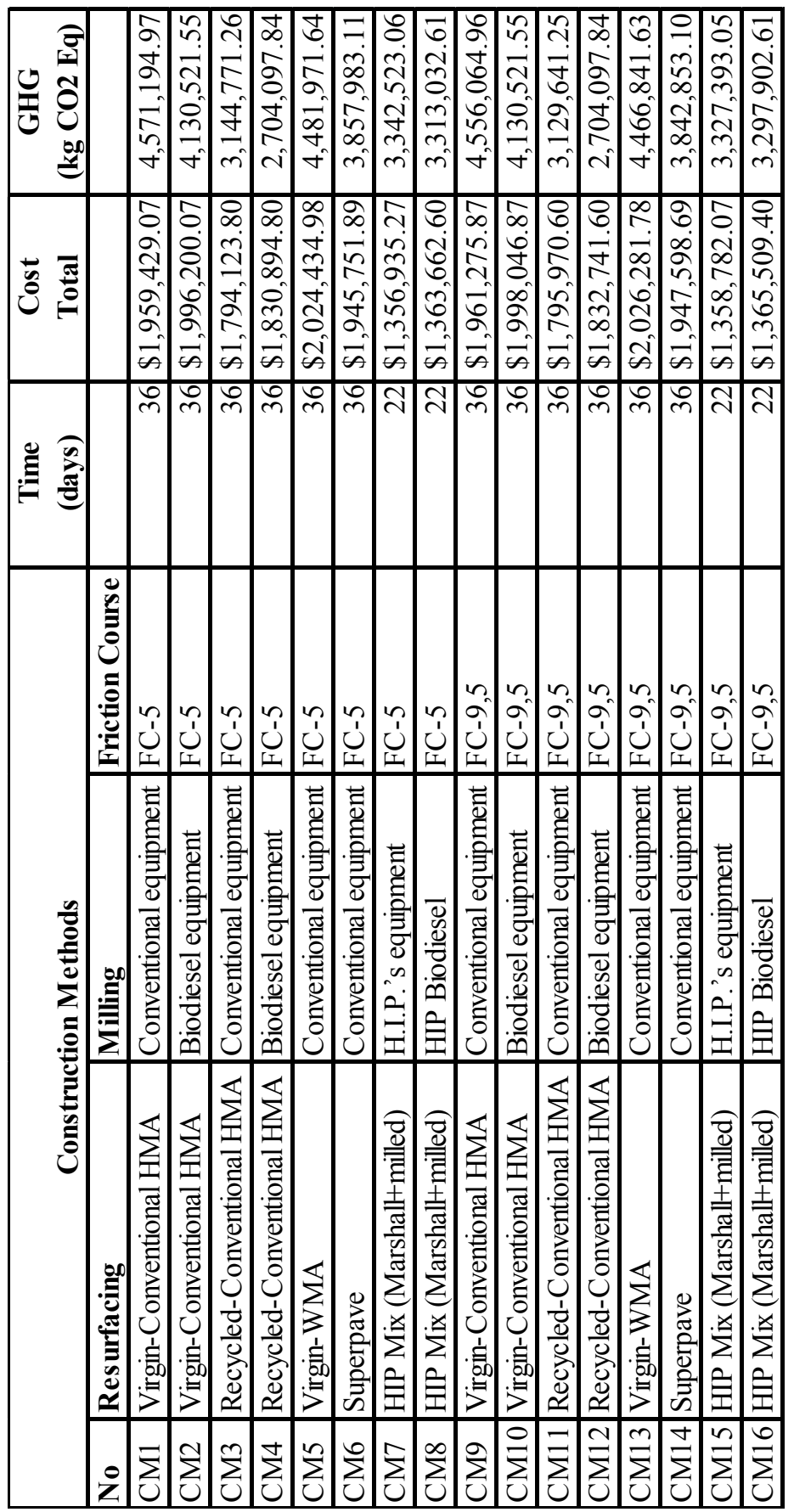

Case Study 1 Results 
Appendix H: Case Study 2-Functions and Results 


\section{Case Study 2 Functions}

(01) Cumulative Real Progress of CM Change= INTEG (Progress Rate-Discover CMs Needing Changes, 10)

Units: days

(02) Discover CMs Needing Changes $=$ IF THEN ELSE(Initiate CM Rate $>0,0,1$ ) Units: Dimensionless

(03) "EQUIP-C1"= "EQUIP-IW-1"*"P-1"

Units: nondimensional

(04) "EQUIP-C2"= "EQUIP-IW-2"*"P-2"

Units: nondimensional

(05) EQUIP-C3"= "EQUIP-IW-3"*"P-3"

Units: nondimensional

(06) EQUIP-C4"= "EQUIP-IW-4"*"P-4"

Units: nondimensional

(07) EQUIP-C5"= "EQUIP-IW-5"*"P-5"

Units: nondimensional 
(08)

"EQUIP-C6"= "EQUIP-IW-6"*"P-6"

Units: nondimensional

(09) "EQUIP-C7"= "EQUIP-IW-7"*"P-7"

Units: nondimensional

(10) "EQUIP-IW-1"= 0.22169

Units: nondimensional

(11) "EQUIP-IW-2"= 0.16524

Units: nondimensional

(12) "EQUIP-IW-3"= 0.04685

Units: nondimensional

(13) "EQUIP-IW-4"= 0.23607

Units: nondimensional

(14) "EQUIP-IW-5"= 0.26938

Units: nondimensional

(15) "EQUIP-IW-6"= 0.03753

Units: nondimensional 
(16)

"EQUIP-IW-7"= 0.2323

Units: nondimensional

(17) Equipment Selection Score= "EQUIP-C1"+"EQUIP-C2"+"EQUIP-

C3"+"EQUIP-C4"+"EQUIP-C5"+"EQUIP-C6"+"EQUIP-C7"

Units: nondimensional $[0,100]$

(18) FINAL TIME $=40$

Units: Day

The final time for the simulation.

(19) Gap between Target and Simulated Cost $=($ Project Cost-Target Cost $) /$ Target Cost Units: Dimensionless

(20) Gap between Target and Simulated GHG= (Project GHG-Target GHG)/Target

GHG

Units: Dimensionless

(21) Gap between Target and Simulated Time $=($ Project Time-Target Time $) /$ Target Time

Units: Dimensionless 
(22) INITIAL TIME $=0$

Units: Day

The initial time for the simulation.

(23) Initial Value $=$ IF THEN ELSE(Original CM To Be Changed $<0,1,0$ )

Units: Dimensionless

(24) Initiate CM Rate $=$ IF THEN ELSE( Suitability of the CM Selected $<=0.35$, Initial Value, 0 )

Units: Dimensionless

(25) "MAT-C1"= "MAT-IW-1"*"P-1"

Units: nondimensional

(26)

"MAT-C2"= "MAT-IW-2"*"P-2"

Units: nondimensional

(27)

"MAT-C3"= "MAT-IW-3"*"P-3"

Units: nondimensional

(28) "MAT-C4"= "MAT-IW-4"*"P-4"

Units: nondimensional 
"MAT-C5"= "MAT-IW-5"*"P-5"

Units: nondimensional

$(30)$

"MAT-C6"= "MAT-IW-6"*"P-6"

Units: nondimensional

(31) "MAT-C7"= "MAT-IW-7"*"P-7"

Units: nondimensional

(32) "MAT-IW-1"= 0.22169

Units: nondimensional

(33) "MAT-IW-2"= 0.16524

Units: nondimensional

(34) "MAT-IW-3"= 0.04685

Units: nondimensional

(35) $\quad$ "MAT-IW-4" $=0.23607$

Units: nondimensional

(36) "MAT-IW-5" $=0.26938$

Units: nondimensional 
"MAT-IW-6"= 0.03753

Units: nondimensional

(38) $\quad$ "MAT-IW-7"= 0.02323

Units: nondimensional

(39) Material Selection Score= "MAT-C1"+"MAT-C2"+"MAT-C3"+"MATC4"+"MAT-C5"+"MAT-C6"+"MAT-C7"

Units: nondimensional $[0,100,20]$

(40) Original CM To Be Changed= INTEG ( Discover CMs Needing Changes-

Progress Rate, 20)

Units: days

(41) $" \mathrm{P}-1 "=$ constant

Units: Dimensionless [0,1]

(42) $\quad$ P-2"= constant

Units: Dimensionless [0,1]

(43) $\quad$ P-3"= constant

Units: Dimensionless $[0,1]$ 
"P-4"= constant

Units: Dimensionless [0,1]

(45)

"P-5"= constant

Units: Dimensionless [0,1]

(46)

"P-6"= constant

Units: Dimensionless [0,1]

(47)

"P-7"= constant

Units: Dimensionless [0,1]

(48) Progress Rate $=$ IF THEN ELSE(Initiate CM Rate=1, Initiate CM Rate , 0 ) Units: Dimensionless

(49) Project Cost= IF THEN ELSE(("Resource 1 (Mi)"=1) :AND: ("Resource 2 (Ei)"=1) :AND: ("Resource 3 (Si)"=1), 1.15435e+006 , IF THEN ELSE(("Resource 1 (Mi)"=1) :AND: ("Resource 2 (Ei)"=2) :AND: ("Resource 3 (Si)"=1), 1.16638e+006 , IF THEN ELSE(("Resource 1 (Mi)"=2) :AND: ("Resource 2 (Ei)"=1) :AND: ("Resource 3 (Si)"=1), 1.02681e+006, IF THEN ELSE(("Resource 1 (Mi)"=2) :AND: ("Resource 2 (Ei)"=2) :AND: ("Resource 3 (Si)"=1), 1.03885e+006 , IF THEN ELSE(("Resource 1 (Mi)"=3) :AND: ("Resource 2 (Ei)"=1) :AND: ("Resource 3 (Si)"=1), 1.20452e+006 , IF 
THEN ELSE(("Resource 1 (Mi)"=4) :AND: ("Resource 2 (Ei)"=1) :AND: ("Resource 3 $(\mathrm{Si}) "=1), 1.14377 \mathrm{e}+006$, IF THEN ELSE(("Resource 1 (Mi)"=5) :AND: ("Resource 2 (Ei)"=3) :AND: ("Resource 3 (Si)"=1), 774203 , IF THEN ELSE(("Resource 1 (Mi)"=5) :AND: ("Resource 2 (Ei)"=4) :AND: ("Resource 3 (Si)"=1), 778342 , IF THEN ELSE(("Resource 1 (Mi)"=1) :AND: ("Resource 2 (Ei)"=1) :AND: ("Resource 3 $(\mathrm{Si}) "=2), 1.15668 \mathrm{e}+006$, IF THEN ELSE(("Resource 1 (Mi)"=1) :AND: ("Resource 2 $($ Ei)"=2) :AND: ("Resource 3 (Si)"=2), 1.16872e+006, IF THEN ELSE(("Resource 1 (Mi)"=2) :AND: ("Resource 2 (Ei)"=1) :AND: ("Resource 3 (Si)"=2), 1.02915e+006 , IF THEN ELSE(("Resource 1 (Mi)"=2) :AND: ("Resource 2 (Ei)"=2) :AND: ("Resource 3 (Si)"=2), 1.02119e+006, IF THEN ELSE(("Resource 1 (Mi)"=3) :AND: ("Resource 2 $($ Ei)"=1) :AND: ("Resource 3 (Si)"=2), 1.20686e+006 , IF THEN ELSE(("Resource 1 $(\mathrm{Mi}) "=4)$ :AND: ("Resource 2 (Ei)"=1) :AND: ("Resource 3 (Si)"=2), 1.14611e+006 , IF THEN ELSE(("Resource 1 (Mi)"=5) :AND: ("Resource 2 (Ei)"=3) :AND: ("Resource 3 (Si)"=2), 776541 , IF THEN ELSE(("Resource 1 (Mi)"=5) :AND: ("Resource 2 (Ei)"=4) :AND: ("Resource $\left.3(\mathrm{Si})^{\prime}=2\right), 780680,0$ ) ) ) ) ) ) ) ) ) ) ) ) ) ) ) )

Units: dollars

(50) Project GHG=IF THEN ELSE(("Resource 1 (Mi)"=1) :AND: ("Resource 2 $(E i) "=1)$ :AND: ("Resource 3 (Si)"=1), 2.4792e+006, IF THEN ELSE(("Resource 1 (Mi)"=1) :AND: ("Resource 2 (Ei)"=2) :AND: ("Resource 3 (Si)"=1), 2.37453e+006 , IF THEN ELSE(("Resource 1 (Mi)"=2) :AND: ("Resource 2 (Ei)"=1) :AND: ("Resource 3 $(\mathrm{Si}) "=1), 1.60159 \mathrm{e}+006$, IF THEN ELSE(("Resource 1 (Mi)"=2) :AND: ("Resource 2 (Ei)"=2) :AND: ("Resource 3 (Si)"=1), 1.49692e+006, IF THEN ELSE(("Resource 1 
(Mi)"=3) :AND: ("Resource 2 (Ei)"=1) :AND: ("Resource 3 (Si)"=1), 2.42431e+006 , IF THEN ELSE(("Resource 1 (Mi)"=4) :AND: ("Resource 2 (Ei)"=1) :AND: ("Resource 3 $(\mathrm{Si}) "=1), 2.0404 \mathrm{e}+006$, IF THEN ELSE(("Resource 1 (Mi)"=5) :AND: ("Resource 2 (Ei)"=3) :AND: ("Resource 3 (Si)"=1), 1.82262e+006 , IF THEN ELSE(("Resource 1 (Mi)"=5) :AND: ("Resource 2 (Ei)"=4) :AND: ("Resource 3 (Si)"=1), 1.80447e+006 , IF THEN ELSE(("Resource 1 (Mi)"=1) :AND: ("Resource 2 (Ei)"=1) :AND: ("Resource 3 (Si)"=2), 2.47616e+006, IF THEN ELSE(("Resource 1 (Mi)"=1) :AND: ("Resource 2 $($ Ei)"=2) :AND: ("Resource 3 (Si)"=2), 2.37453e+006, IF THEN ELSE(("Resource 1 (Mi)"=2) :AND: ("Resource 2 (Ei)"=1) :AND: ("Resource 3 (Si)"=2), 1.59855e+006 , IF THEN ELSE(("Resource 1 (Mi)"=2) :AND: ("Resource 2 (Ei)"=2) :AND: ("Resource 3 $(\mathrm{Si}) "=2), 1.49692 \mathrm{e}+006$, IF THEN ELSE(("Resource 1 (Mi)"=3) :AND: ("Resource 2 $($ Ei)"=1) :AND: ("Resource 3 (Si)"=2), 2.42127e+006 , IF THEN ELSE(("Resource 1 $(\mathrm{Mi}) "=4)$ :AND: ("Resource 2 (Ei)"=1) :AND: ("Resource 3 (Si)"=2), 2.03736e+006 , IF THEN ELSE(("Resource 1 (Mi)"=5) :AND: ("Resource 2 (Ei)"=3) :AND: ("Resource 3 $(\mathrm{Si}) "=2), 1.81958 \mathrm{e}+006$, IF THEN ELSE(("Resource 1 (Mi)"=5) :AND: ("Resource 2 (Ei)"=4) :AND: ("Resource $3(\mathrm{Si}) "=2), 1.80143 \mathrm{e}+006,0$ ) ) ) ) ) ) ) ) ) ) ) ) ) ) ) ) Units: $\mathrm{kg} \mathrm{CO} 2 \mathrm{eq}$

(51) Project Time=IF THEN ELSE(("Resource 1 (Mi)"=1) :AND: ("Resource 2 $(\mathrm{Ei})=1)$ :AND: ("Resource 3 (Si)"=1), 29 , IF THEN ELSE(("Resource 1 (Mi)"=1) :AND: ("Resource 2 (Ei)"=2) :AND: ("Resource 3 (Si)"=1), 29 , IF THEN ELSE(("Resource 1 (Mi)"=2) :AND: ("Resource 2 (Ei)"=1) :AND: ("Resource 3 $(\mathrm{Si}) "=1), 29$, IF THEN ELSE(("Resource 1 (Mi)"=2) :AND: ("Resource 2 (Ei)"=2) 
:AND: ("Resource 3 (Si)"=1), 29 , IF THEN ELSE(("Resource 1 (Mi)"=3) :AND: ("Resource 2 (Ei)"=1) :AND: ("Resource 3 (Si)"=1), 29 , IF THEN ELSE(("Resource 1 $(\mathrm{Mi}) "=4)$ :AND: ("Resource 2 (Ei)"=1) :AND: ("Resource 3 (Si)"=1), 29 , IF THEN ELSE(("Resource 1 (Mi)"=5) :AND: ("Resource 2 (Ei)"=3) :AND: ("Resource 3 $(\mathrm{Si}) "=1), 19$, IF THEN ELSE(("Resource 1 (Mi)"=5) :AND: ("Resource 2 (Ei)"=4) :AND: ("Resource 3 (Si)"=1), 19 , IF THEN ELSE(("Resource 1 (Mi)"=1) :AND: ("Resource 2 (Ei)"=1) :AND: ("Resource 3 (Si)"=2), 29 , IF THEN ELSE(("Resource 1 $(\mathrm{Mi}) "=1)$ :AND: ("Resource 2 (Ei)"=2) :AND: ("Resource 3 (Si)"=2), 29 , IF THEN ELSE(("Resource 1 (Mi)"=2) :AND: ("Resource 2 (Ei)"=1) :AND: ("Resource 3 $(\mathrm{Si}) "=2), 29$, IF THEN ELSE(("Resource 1 (Mi)"=2) :AND: ("Resource 2 (Ei)"=2) :AND: ("Resource 3 (Si)"=2), 29 , IF THEN ELSE(("Resource 1 (Mi)"=3) :AND: ("Resource 2 (Ei)"=1) :AND: ("Resource 3 (Si)"=2), 29, IF THEN ELSE(("Resource 1 $(\mathrm{Mi}) "=4)$ :AND: ("Resource 2 (Ei)"=1) :AND: ("Resource 3 (Si)"=2), 29 , IF THEN ELSE(("Resource 1 (Mi)"=5) :AND: ("Resource 2 (Ei)"=3) :AND: ("Resource 3 $(\mathrm{Si}) "=2), 19$, IF THEN ELSE(("Resource 1 (Mi)"=5) :AND: ("Resource 2 (Ei)"=4) :AND: ("Resource $\left.3(\mathrm{Si})^{\prime}=2\right), 19,0$ ) ) ) ) ) ) ) ) ) ) ) ) ) ) ) ) Units: days

(52) "Resource 1 (Mi)"=IF THEN ELSE( (Cumulative Real Progress of CM Change>0) :AND: (Material Selection Score<20), 3 , IF THEN ELSE( (Cumulative Real Progress of CM Change $>0)$ :AND: $(20<=$ Material Selection Score) :AND: (Material Selection Score $<40), 1$, IF THEN ELSE( (Cumulative Real Progress of CM Change $>0$ ) :AND: $(40<=$ Material Selection Score) :AND: (Material Selection Score $<60), 2$, IF 
THEN ELSE( (Cumulative Real Progress of CM Change $>0)$ :AND: $(60<=$ Material Selection Score) :AND: (Material Selection Score $<80)$, 4 , IF THEN ELSE( (Cumulative Real Progress of CM Change $>0)$ :AND: $(80<=$ Material Selection Score) :AND: (Material Selection Score $<=100), 5,0$ ) ) ) ) )

Units: nondimensional

"Resource 2 (Ei)"=IF THEN ELSE(("Resource 1 (Mi)"=1) :AND: (Equipment Selection Score<50), 1, IF THEN ELSE(("Resource 1 (Mi)"=1) :AND: (Equipment Selection Score $>=50), 2$, IF THEN ELSE(("Resource 1 (Mi)"=2) :AND: (Equipment Selection Score<50), 1, IF THEN ELSE(("Resource 1 (Mi)"=2) :AND: (Equipment Selection Score $>=50), 2$, IF THEN ELSE("Resource 1 (Mi)"=3, 1 , IF THEN ELSE("Resource 1 (Mi)"=4, 1 , IF THEN ELSE(("Resource 1 (Mi)"=5) :AND: (Equipment Selection Score<50), 3 , IF THEN ELSE(("Resource 1 (Mi)"=5) :AND: (Equipment Selection Score $>=50), 4,0$ ) ) ) ) ) ) ) )

Units: nondimensional

(54) "Resource 3 (Si)"=IF THEN ELSE(Stabilizing Additive Selection Score $<50,2$, 1

)

Units: nondimensional

(55) $\quad$ SAVEPER $=$ TIME STEP

Units: Day [0,?]

The frequency with which output is stored. 
"STAB-C1"="STAB-IW-1"*"P-1"

Units: nondimensional

(57)

"STAB-C2"="STAB-IW-2"*"P-2"

Units: nondimensional

(58)

"STAB-C3"="STAB-IW-3"*"P-3"

Units: nondimensional

(59)

"STAB-C4"= "STAB-IW-4"*"P-4"

Units: nondimensional

(60) "STAB-C5"="STAB-IW-5"*"P-5"

Units: nondimensional

(61) "STAB-C6"="STAB-IW-6"*"P-6"

Units: nondimensional

(62) "STAB-C7"="STAB-IW-7"*"P-7"

Units: nondimensional 
(63) "STAB-IW-1" $=0.22169$

Units: nondimensional

(64) "STAB-IW-2" $=0.16524$

Units: nondimensional

(65) "STAB-IW-3" $=0.04685$

Units: nondimensional

(66) "STAB-IW-4" $=0.23607$

Units: nondimensional

(67) "STAB-IW-5" $=0.26938$

Units: nondimensional

(68) "STAB-IW-6" $=0.03753$

Units: nondimensional

(69) "STAB-IW-7"=0.02323

Units: nondimensional 
(70) Stabilizing Additive Selection Score="STAB-C1"+"STAB-C2"+"STABC3"+"STAB-C4"+"STAB-C5"+"STAB-C6"+"STAB-C7"

Units: nondimensional $[0,100]$

(71) Suitability of the CM Selected $=(0.33354 *$ Gap between Target and Simulated Time $)+(0.55534 *$ Gap between Target and Simulated Cost $)+(0.11112 *$ Gap between Target and Simulated GHG) Units: Dimensionless

(72) Target Cost $=1.3 \mathrm{e}+006$ Units: dollars

(73) Target GHG=2.7e+006 Units: $\mathrm{kg} \mathrm{CO} 2 \mathrm{eq}$

(74) Target Time $=20$

Units: days

(75) TIME STEP $=1$

Units: Day [0,?]

The time step for the simulation. 


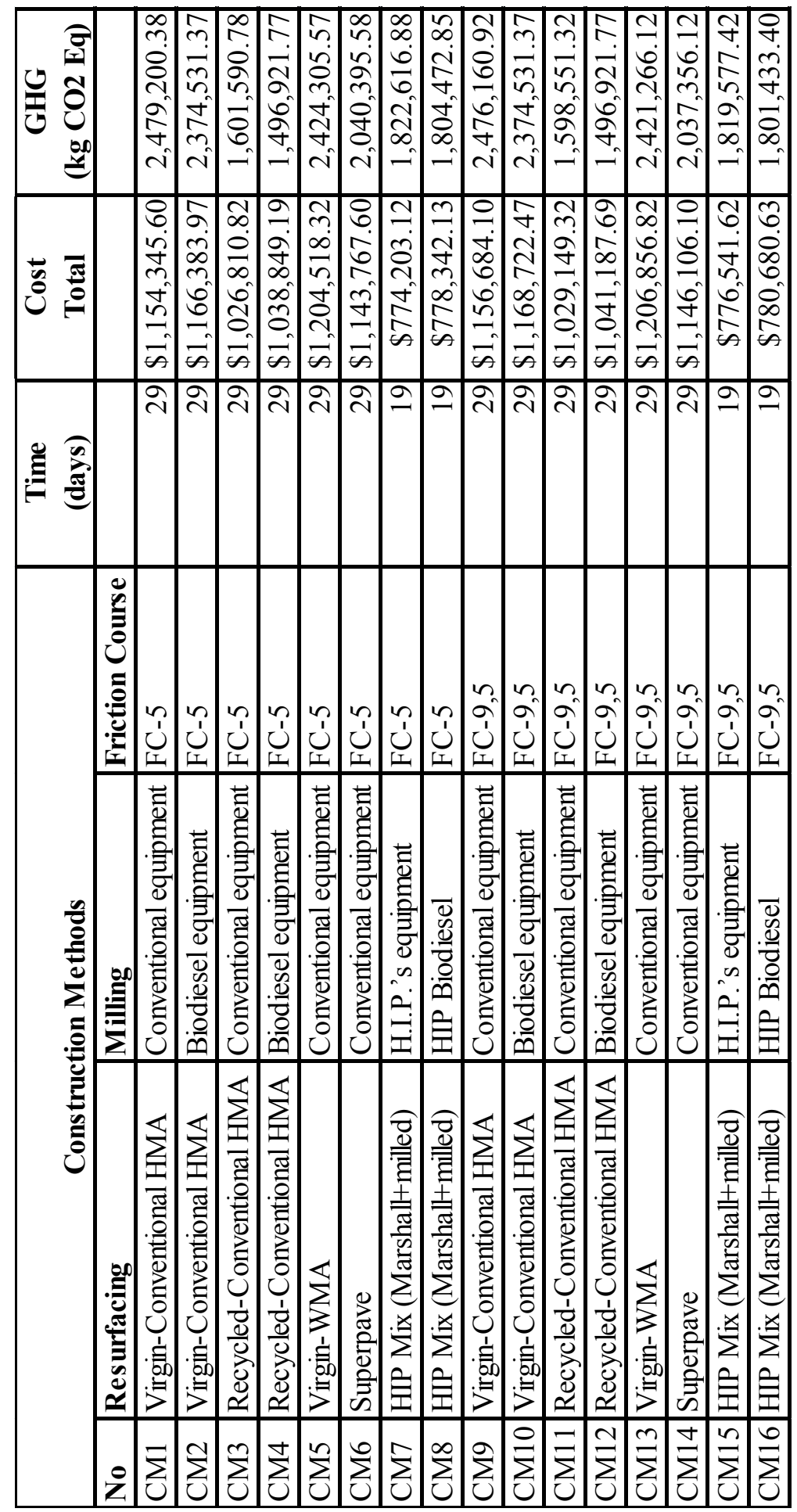

Case Study 2 Result 
VITA

\section{GULBIN OZCAN-DENIZ}

April 20, 1984

2002-2006

2006-2007

2007

2007-2008

2006-2008

2008-2011
Born, Ankara, TURKEY

B.S. in Civil Engineering Middle East Technical University (METU) Ankara TURKEY

Yuksel-Turkuaz-YDA Cons. and Trade Co. Ltd. Ankara TURKEY

Calik Energy Co. Ltd. Ankara TURKEY

Teaching and Research Assistant

Middle East Technical University (METU) Ankara TURKEY

M.S. in Civil Engineering Middle East Technical University (METU) Ankara TURKEY

Ph.D Candidate in Civil and Environmental Engineering Florida International University (FIU)

Miami, FL USA

Graduate Assistant

Construction Management Department

Florida International University (FIU)

Miami, FL USA

\section{PUBLICATIONS AND PRESENTATIONS}

Ozcan, G. (2008), A Generic Risk and Vulnerability Assessment Framework for International Construction Projects, MSc Thesis, Middle East Technical University, Ankara, Turkey.

Soibelman L., Akinci B., Ozcan G., Dikmen I., Birgonul M.T. (2008), “International Collaborative Construction Management Course: a Teaching Case Study", 5th International Conference on Innovation in Architecture, Engineering and Construction (AEC2008), June 23-25, Antalya, Turkey. 
Dikmen I., Birgonul M.T., Fidan G., Ozcan G. (2008), "A Risk and Vulnerability Ontology for Construction Projects", The 4th Scientific Conferences on Project Management \& 1st International Project Management Association (PM-04), May 2931, Chios Island, Greece.

Ozcan, G. and Zhu, Y. (2009), "Life Cycle Assessment of A Net Zero Energy House", The Proceedings of the International Conference of Construction and Real Estate Management (ICCREM), November 5-6, The Chinese Construction Industry Press, Beijing, China.

Ozcan-Deniz, G., Ceron, V., and Zhu, Y. (2011), "Time, Cost and Environmental Impact Analysis on Construction Operations", 2011 ASCE International Workshop on Computing in Civil Engineering, June 19-22, Miami, FL, USA.

Ozcan-Deniz, G. and Zhu, Y. (2011), "A Decision-Making Model for Analyzing Highway Construction Processes with Environmental Constraints", The CRIOCM 2011 International Symposium on "Advancement of Construction Management and Real Estate”, September 23-25, Chongqing Jiaotong University, Chongqing, China, Accepted for Publication.

Ozcan-Deniz, G. and Zhu, Y. (2011), “A Systems Approach to Support the Selection of Highway Construction Operations with Environmental Concerns", The Proceedings of the International Conference of Construction and Real Estate Management (ICCREM), November 18-19, Guangzhou University, Guangzhou, Guangdong, China, Under Review.

Ozcan-Deniz, G. and Zhu, Y. (2011), "Time, Cost, and Environmental Impact Analysis for Highway Construction", The Proceedings of the International Conference of Construction and Real Estate Management (ICCREM), November 1819, Guangzhou University, Guangzhou, Guangdong, China, Under Review.

Ozcan, G., Dikmen I., and Birgonul M.T. (2010), "Assessment of Risk Paths in Construction Projects", International Journal of Project Organisation and Management (IJPOM), Special Issue on "Risk Management in Projects and Enterprises", In Press.

Ozcan-Deniz, G., Ceron, V., and Zhu, Y. (2011), "Time, Cost and Environmental Impact Analysis on Construction Operation Optimization Using Genetic Algorithms", Journal of Management in Engineering, Under Review.

Ozcan-Deniz, G. (2011), “An Integrated Multi-Agent Framework for Optimizing Time, Cost and Environmental Impact of Construction Processes”, FIU Graduate Student Appreciation Week (G-SAW), 1st place award in Environmental, Energy, Earth, and Ecology at 2011 FIU Scholarly Forum, March 28-April 1, Miami, FL. 
